\title{
DISCLAIMER
}

This report was prepared as an account of work sponsored by an agency of the United States Government. Neither the United States Government nor any agency thereof, nor any of their employees, makes any warranty, express or implied, or assumes any legal liability or responsibility for the accuracy, completeness, or usefulness of any information, apparatus, product, or process disclosed, or represents that its use would not infringe privately owned rights. Reference herein to any specific commercial product, process, or service by trade name, trademark, manufacturer, or otherwise does not necessarily constitute or imply its endorsement, recommendation, or favoring by the United States Government or any agency thereof. The views and opinions of authors expressed herein do not necessarily state or reflect those of the United States Government or any agency thereof.

\section{THERMAL AND HYDRAULIC PERFORMANCE TESTS OF A SIEVE-TRAY DIRECT-CONTACT HEAT EXCHANGER VAPORIZING PURE AND MIXED-HYDROCARBON BANKINE-CYCLE WORKING FLUUIDS}

\section{Gregory L. Mines}

O. Jack Demuth

Deborah J. Wiggins

Published August 1983

EG\&G Idaho, Inc. Idaho Falls, Idaho 83415

Prepared for the

U.S. Department of Energy Idaho Operations Office 


\section{DISCLAIMER}

This report was prepared as an account of work sponsored by an agency of the United States Government. Neither the United States Government nor any agency Thereof, nor any of their employees, makes any warranty, express or implied, or assumes any legal liability or responsibility for the accuracy, completeness, or usefulness of any information, apparatus, product, or process disclosed, or represents that its use would not infringe privately owned rights. Reference herein to any specific commercial product, process, or service by trade name, trademark, manufacturer, or otherwise does not necessarily constitute or imply its endorsement, recommendation, or favoring by the United States Government or any agency thereof. The views and opinions of authors expressed herein do not necessarily state or reflect those of the United States Government or any agency thereof. 


\section{DISCLAIMER}

Portions of this document may be illegible in electronic image products. Images are produced from the best available original document. 


\section{ABSTRACT}

Experiments investigating a sieve-tray direct-contact heat exchanger were conducted as part of the Department of Energy (DOE), Division of Geothermal Energy effort in conversion technology by EG\&G Idaho, Inc. The testing was accomplished at the DOE Idaho National Engineering Laboratory (INEL) Raft River Geothermal Test Site in southeastern Idaho using the $60-\mathrm{kW}$ Mobile Heat Cycle Research Facility operating in the thermal loop mode (without a turbine). Isobutane, propane, and several hydrocarbon mixtures were heated and boiled in the direct-contact column, which is $\sim 12 \mathrm{in.}$ in diameter and $19-1 / 2 \mathrm{ft}$ high, using the energy from a $280^{\circ} \mathrm{F}$ geothermal resource.

Using pure fluids, isobutane or propane, the column operated much as intended, with 17 trays used for preheating and one or two accomplishing the boiling. For the pure fluids, individual tray efficiencies were found to be $70 \%$ or higher for preheating, and close to $100 \%$ for boiling; column pinch points were projected to be well under $1^{\circ} \mathrm{F}$ with some runs reaching values as low as $-0.02^{\circ} \mathrm{F}$. Maximum geofluid throughputs for the isobutane tests corresponded roughly to the terminal rise velocity of a 1/32 in. working fluid droplet in geofluid.

Boiling was found to occur in as many as 12 trays for the mixtures having the highest concentrations of the minor component, with overall efficiencies in the boiling section estimated on the order of 25 or $30 \%$. Preheating tray efficiencies appeared to be fairly independent of working fluid, with pinch points ranging from as low as $-0.03^{\circ} \mathrm{F}$ for a 0.95 isobutane $/ 0.05$ hexane mixture to $-2.3^{\circ} \mathrm{F}$ for a 0.85 isobutane/ 0.05 hexane mixture. Column operation was noticeably less stable for the mixtures than for the pure fluids, with maximum throughputs dropping to as low as 40 to $50 \%$ of those for the pure fluids. 


\section{SUMMARY}

As part of the conversion technology effort at the Idaho National Engineering Laboratory (INEL), a sieve-tray direct-contact heat exchanger (DCHX) was designed, built, and then tested in a binary power cycle at the INEL Raft River Geothermal Test Site. In this heat exchanger, the energy from a hot geothermal fluid (also referred to as geofluid) was transferred to a secondary working fluid that was vaporized during the heat exchange process. In the DCHX, the two fluids are in physical contact with each other (there are no physical boundaries between the fluids as heat is exchanged). These devices have been widely used in mass transfer applications; however, little experience exists in heat transfer applications.

A series of baseline thermal and hydraulic tests was conducted with an isobutane working fluid. The evaluation of these tests is a major subject of this report. The results of the baseline tests can be summarized as follows:

- The sieve-tray column is an excellent heat transfer device. Individual tray efficiencies were at or above the design value of $70 \%$ and the pinch points were determined to be well under $1^{\circ} \mathrm{F}$ (too small to be measured with installed instrumentation).

- The geofluid (continuous fluid) flow rates just before flooding corresponded to the terminal rise velocity of a $1 / 32$ in.-diameter working fluid drop, which is a typical drop size used in the design of these columns for mass transfer applications.

- The working fluid (dispersed fluid) throughput limits encountered at flooding corresponded to the predicted condition for maximum total drop surface area (or minimum average drop size, which again is a parameter commonly used in designing these sieve-tray columns for mass transfer duty.

- The data shows the more conventional spray tower has an advantage in volumetric throughput, although the advantage does not appear to be large.
- The excellent thermal performance of the column produced operational problems in that a large amount of working fluid in the column was very near its saturation temperature and could start boiling due to small flow or valve changes that reduced column pressure. Such boiling generally produced premature flooding.

After the completion of the isobutane tests, the DCHX was operated with working fluids comprised of different mixtures of hydrocarbons from the isobutane/hexane $\left(\mathrm{iC}_{4} / \mathrm{C}_{6}\right)$ and the propane/isopentane $\left(\mathrm{C}_{3} / \mathrm{iC}_{5}\right)$ families. These results can be summarized as follows:

- The thermal performance of the liquidliquid contacting preheating trays did not appear to be affected significantly by the use of mixtures.

- The thermal performance of the trays in which boiling occurred decreased when mixtures were used.

- The lower boiling tray efficiency and the higher number of theoretical : trays required for boiling resulted in a portion of the trays designed for preheating to be required for boiling duty. In an extreme case ( $85 \mathrm{iC}_{4} / 15 \mathrm{C}_{6}$ fluid) boiling was occurring in 10 of 17 preheating trays.

- The hydraulic limits of the column were reduced significantly with the use of mixtures. The throughput capacity of the column decreased as the concentration of the minor component increased. This reduced capacity is felt to be the result of boiling occurring in the preheating trays.

These series of tests conducted with the sievetray DCHX at Raft River have provided a considerable base of information on the operation of this type of column, with both pure and mixed working fluids. Overall conclusions that can be derived from these tests are as follows:

- A sieve-tray column is an excellent heat transfer device particularly for preheating duty and/or when pure fluids are used. 
- The hydraulic design of a column, par: ticularly the preheating section, can be made using the design parameters used in designing a column for mass transfer applications. In both applications, the attempt is made to minimize the mechanical entrainment of the dispersed fluid, while maximizing the surface area exposed.

- The columns need to be designed for specific applications, Overdesigning a column can produce problems as will underdesigning the column. The DCHX tested at Raft River was overdesigned (too many preheating trays) for pure fluids, and underdesigned (not enough boiling trays) for mixed fluids.
The data from these tests will be used to define the column modifications for the next phase of testing, which will examine the relationships between heat transfer, mass transfer, and column hydraulics. Those tests will attempt to maximize the thermal performance and throughputs, while minimizing the mass transfer between fluids. While the present tests have shown the sieve-tray column to be an excellent heat exchanger, the geofluid used was relatively benign. The major advantage in the use of $\mathrm{DCHX}$ columns to replace tube-and-shell configurations as heat exchange devices lies in their potential capability for accommodating the more dirty brines. It is planned that the next phase of testing will be conducted with a brine having much higher levels of dissolved solids and a higher scaling or fouling potential than exists for the geofluids at the Raft River Geothermal Site. 


\section{ACKNOWLEDGMENTS}

The successful completion of this phase of testing with the sieve-tray directcontact heat exchanger was due to the efforts of a number of individuals. Ray LaSala (DOE) and Jud Whitbeck (EG\&G) who provided program support and direction, Bert Lilburn and Roger Piscitella (EG\&G) who designed and engineered the facility modifications and heater installation, and Dan Cummings and Lance Udy (EG\&G) who provided operational support, merit special thanks from the authors. The authors would also like to acknowledge the work of Ed Wahl (The Wahl Co.). Ed designed and fabricated the DCHX column and then provided support and guidance during the preparation of test plans, design of control systems, early operation of the unit, and the initial data reduction efforts. 


\section{CONTENTS}

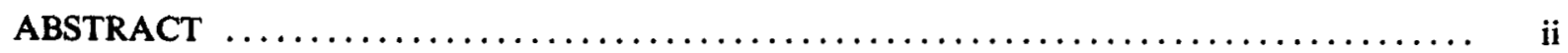

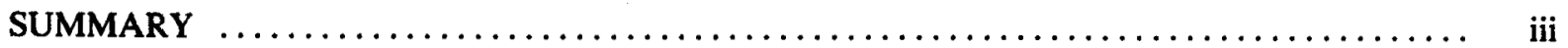

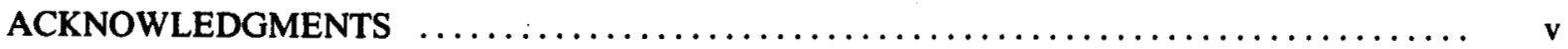

NOMENCLATURE $\ldots \ldots \ldots \ldots \ldots \ldots \ldots \ldots \ldots \ldots \ldots \ldots \ldots \ldots \ldots \ldots \ldots \ldots \ldots \ldots \ldots \ldots \ldots \ldots$, viii

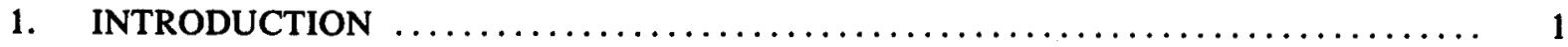

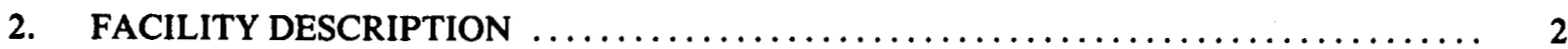

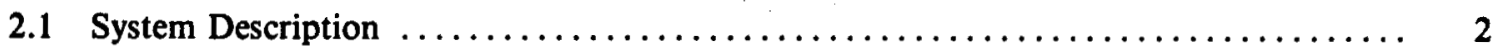

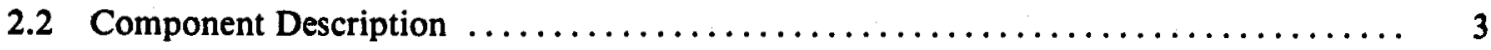

2.2.1 Direct-Contact Heat Exchanger $\ldots \ldots \ldots \ldots \ldots \ldots \ldots \ldots \ldots \ldots \ldots \ldots \ldots, \quad 3$

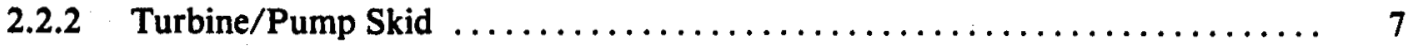

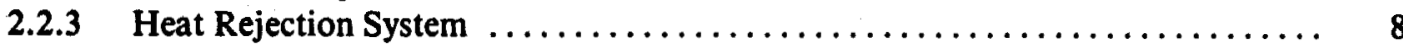

2.2.4 Geothermal Fluid Supply System $\ldots \ldots \ldots \ldots \ldots \ldots \ldots \ldots \ldots \ldots \ldots \ldots \ldots \ldots \ldots$

3. FACTORS INFLUENCING DIRECT-CONTACT HEAT EXCHANGER

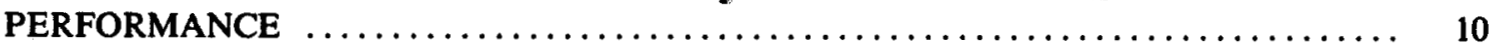

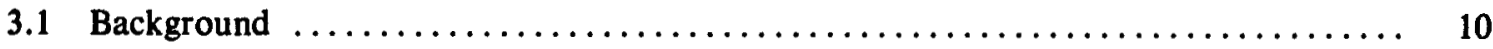

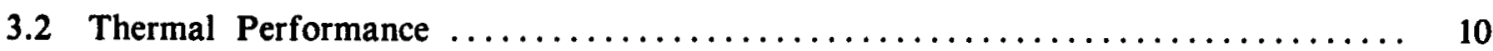

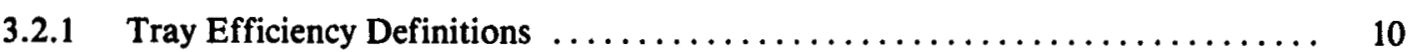

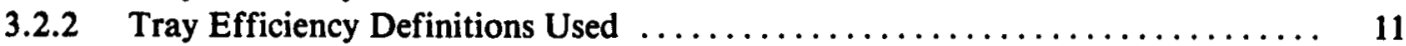

3.2.3 Column Pinch Point $\ldots \ldots \ldots \ldots \ldots \ldots \ldots \ldots \ldots \ldots \ldots \ldots \ldots \ldots \ldots$

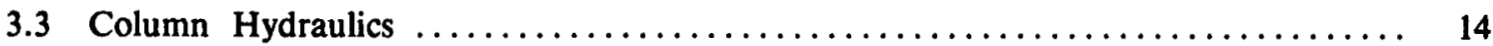

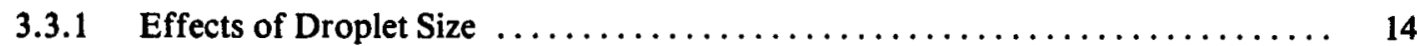

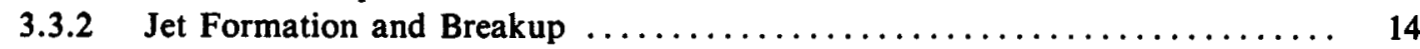

3.3.3 Maximum Geofluid Throughput $\ldots \ldots \ldots \ldots \ldots \ldots \ldots \ldots \ldots \ldots \ldots \ldots, 16$

4. BASELINE PERFORMANCE TESTS WITH ISOBUTANE $\ldots \ldots \ldots \ldots \ldots \ldots \ldots \ldots \ldots$

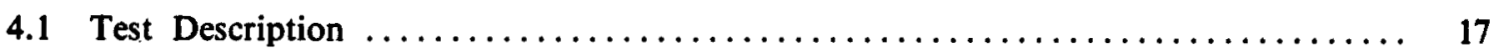

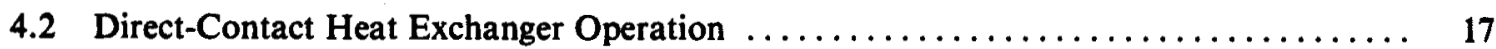

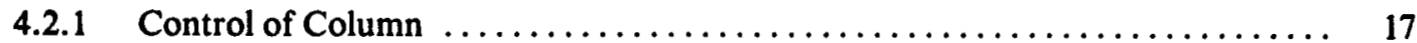

4.2.2 Operating Near the Flooding Limit $\ldots \ldots \ldots \ldots \ldots \ldots \ldots \ldots \ldots \ldots . \ldots \ldots$

4.2.3 Column Startup ....................................... 19

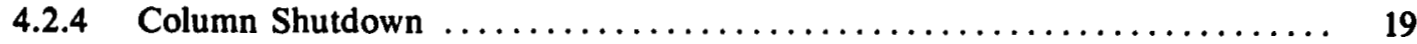

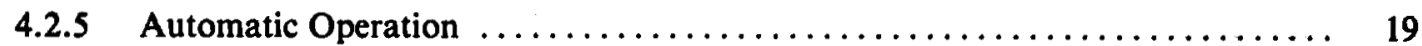

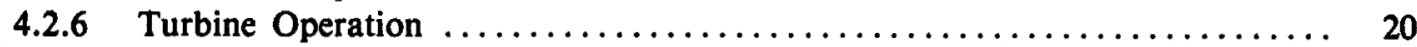

4.2.7 Cold Weather Problems $\ldots \ldots \ldots \ldots \ldots \ldots \ldots \ldots \ldots \ldots \ldots \ldots \ldots \ldots, 20 \ldots \ldots$ 


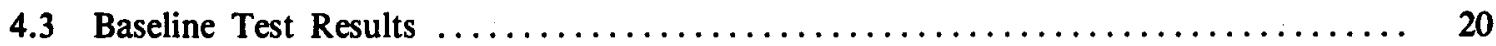

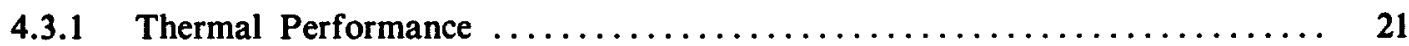

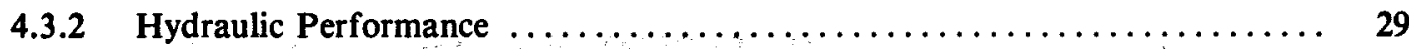

5. TESTING WITH MIXED-HYDROCARBON WORKING FLUIDS $\ldots \ldots \ldots \ldots \ldots \ldots \ldots$

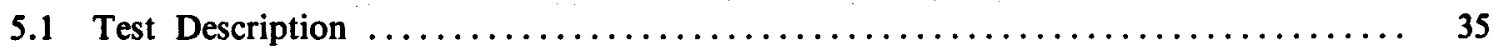

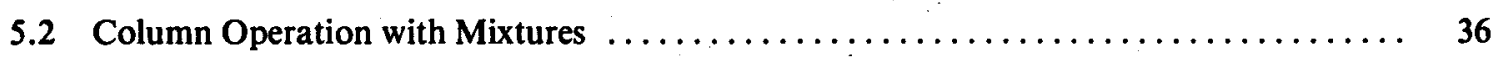

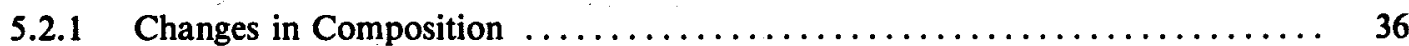

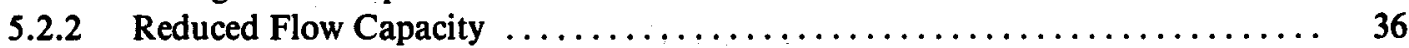

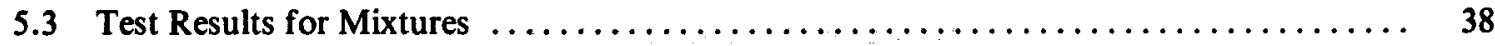

5.3.1 Thermal Performance $\ldots \ldots \ldots \ldots \ldots \ldots \ldots \ldots \ldots \ldots \ldots \ldots \ldots \ldots \ldots, \quad 38$

5.3.2 Column Hydraulics Test Results $\ldots \ldots \ldots \ldots \ldots \ldots \ldots \ldots \ldots \ldots \ldots \ldots .41$

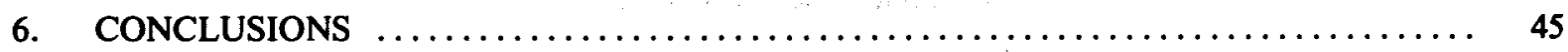

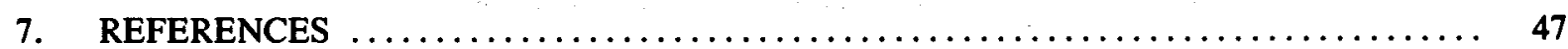

APPENDIX A-DESIGN CONSIDERATIONS FOR A SIEVE-TRAY

DIRECT-CONTACT HEAT EXCHANGER $\ldots \ldots \ldots \ldots \ldots \ldots \ldots \ldots \ldots \ldots \ldots \ldots \ldots, 49 \ldots \ldots \ldots \ldots$ 


\section{NOMENCLATURE}

ASME American Society of Mechanical Engineers

CW Cooling water

DCHX Direct-contact heat exchanger

DOE Department of Energy

DSS DSS Engineers, Incorporated

GF Geothermal fluid or geofluid

HCRF Heat Cycle Research Facility

INEL Idaho National Engineering Laboratory

NPSH Net positive suction head

ORNL Oak Ridge National Laboratory

TEMA Tubular Exchanger Manufacturers Association

WF Working fluid

\section{Symbols}

$\begin{array}{ll}\mathrm{C}_{3} & \text { Propane } \\ \mathrm{iC}_{4} & \text { Isobutane } \\ \mathrm{iC}_{5} & \text { Isopentane } \\ \mathrm{C}_{6} & \text { Hexane }\end{array}$




\section{THERMAL AND HYDRAULIC PERFORMANCE TESTS OF A SIEVE-TRAY DIRECT-CONTACT HEAT EXCHANGER VAPORIZING PURE AND MIXED-HYDROCARBON RANKINE CYCLE WORKING FLUIDS}

\section{INTRODUCTION}

As part of the Department of Energy (DOE), Division of Geothermal Energy effort in conversion technology, EG\&G Idaho, Inc., has been investigating different methods of utilizing the energy contained in a moderate temperature $\left(280^{\circ} \mathrm{F}\right)$ geothermal resource at the Idaho National Engineering Laboratory (INEL) Raft River Geothermal Test Site. The major emphasis of the conversion technology effort has been the testing of binary power cycles with a test facility that has been in operation since 1978; the facility has recently been named the $60-\mathrm{kW}$ Mobile Heat Cycle Research Facility (Mobile HCRF). This report will present the results of that portion of the latest sequence of tests conducted from April 1981 to July 1982 utilizing a direct-contact heat exchanger (DCHX) as the preheater/evaporator with hydrocarbon working fluids.

Interest in DCHXs for geothermal applications has developed because these devices have the potential to provide efficient heat transfer service without the scaling or corrosion problems that could arise with conventional heat exchangers. Because the working and geothermal fluids physically contact each other during the heat exchange process, there is no physical heat transfer surface (tube wall) to foul or corrode due to exposure to a hot brine, or geothermal fluid, containing varying levels of dissolved solids. This lack of a physical boundary between the two fluids also presents problems to a system using these heaters in that some contamination of the secondary working fluid occurs (in the form of noncondensable gases and water vapor) due to the exposure to the geothermal fluid; despite the fact that the two fluids are relatively insoluble, some working fluid is dissolved and/or mechanically entrained in the brine leaving the unit. Both the working fluid losses and the contamination of the working fluid system represent cost and power penalties to a facility using these exchangers. These penalties must eventually be traded off against the capability for using the more corrosive and fouling geofluids.

Present testing of the DCHX investigated the performance of a sieve-tray, or perforated platetype direct-contact column. In addition to testing the performance of the unit with a single component working fluid, isobutane, the DCHX was also operated with several mixtures of hydrocarbon working fluids. The first series of mixture tests were made with different combinations of isobutane and hexane, followed by a series of tests with the propane/isopentane family of fluids. The pure fluid testing with isobutane provided the baseline performance data for the column. This report presents the thermal and hydraulic results for testing with both pure and mixed fluids, and provides some insight relative to improvements in direct-contact heat exchangers for use with hydrocarbon mixtures. 


\section{FACILITY DESCRIPTION}

\subsection{System Description}

The major systems and components in the facility are similar in function to those in a fullscale geothermal power plant although smaller in size. The facility differs considerably from that of a conventional power plant in that its primary purpose is to test components and/or different systems or cycles rather than generating power. Since the HCRF is intended to be used as a test facility it is built with the flexibility to allow for operation in a variety of configurations. The description of the plant is more easily understood if one refers to the plant flow schematic in Figure 1, which shows the major cycle components, but not the auxiliary systems (fire protection, flare, storage, vent-and-drain, control, etc.).
The facility was equipped with two heater units, a tube-and-shell heat exchanger, and a DCHX. It could be operated with either of these units, which are used to preheat and vaporize the working fluid. In the tube-and-shell heat exchanger, hot geothermal fluid is circulated through the tube side of the unit where it is cooled as heat is transferred to the working fluid. The isobutane working fluid circulating past the outer tube surface is first preheated to the saturation temperature corresponding to boiler pressure and then vaporized. The vapor leaving the boiler/preheater can then be expanded through a turbine that drives a generator producing electrical power, or expanded through a turbine bypass valve that provides the required pressure drop between the boiler and condenser. The low pressure gas leaving

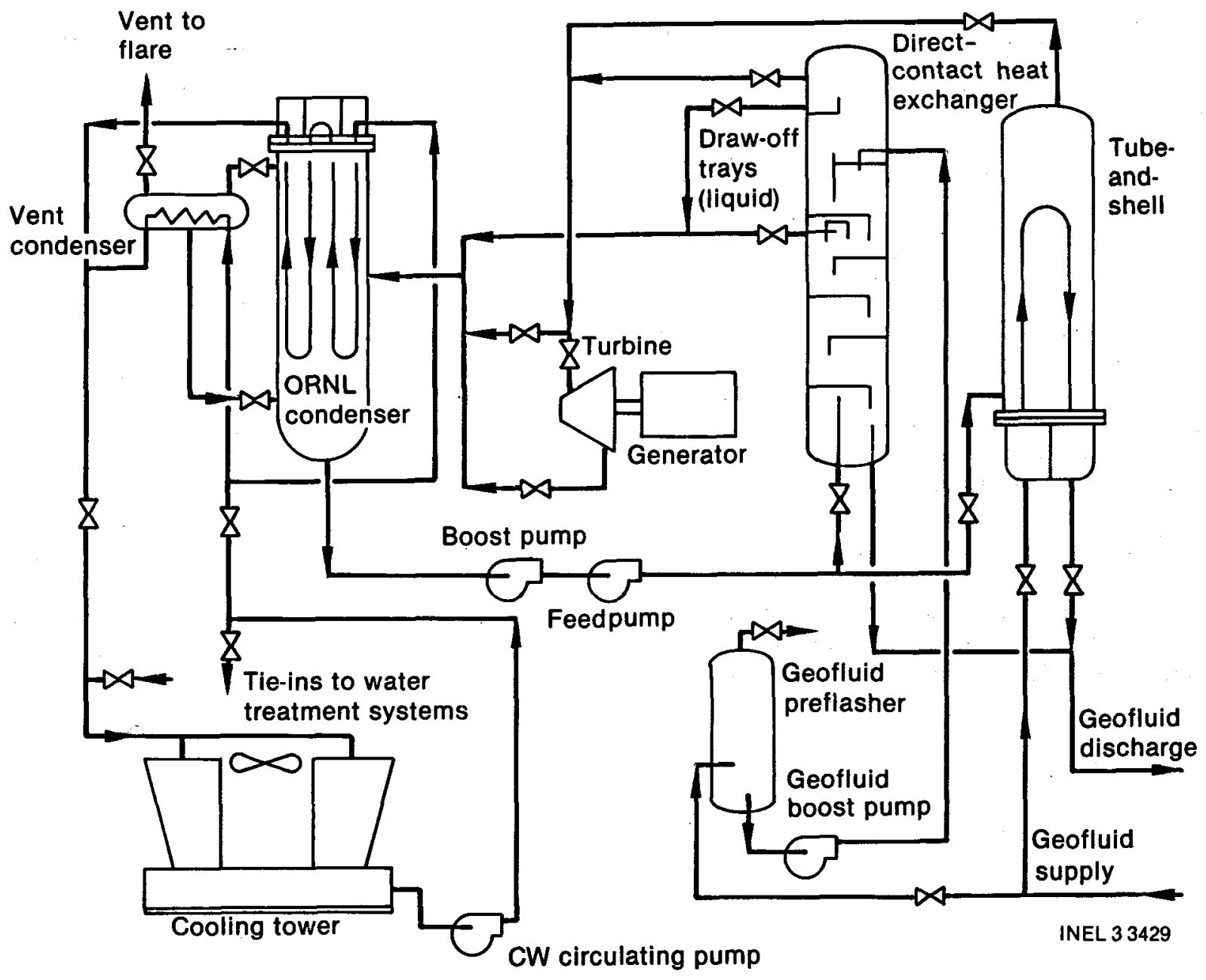

Figure 1. Facility flow schematic. 
the turbine or bypass valve is discharged to the condenser where the working fluid is cooled and condensed to the liquid state. Cooling water circulating through the tube side of the condenser is heated by the process of desuperheating and condensing of the working fluid on the outer tube surfaces. The cooling water is circulated through a wet cooling tower where the heat, added to the cooling water in the condenser, is rejected to the atmosphere. The liquid working fluid in the condenser is then circulated back to one of the heat exchanger units using boost and feed pumps in series.

When the DCHX was used, the tube-and-shell heat exchanger was isolated from both the working fluid and geothermal fluid systems. The directcontact unit serves the same function as the tubeand-shell heat exchanger; that is, it first preheats and then vaporizes the working fluid using the geothermal fluid as the heat source. It differs from the tubeand-shell unit in that throughout the heat exchange process the two fluids are in physical contact with each other, thus the name direct-contact heat exchanger (DCHX). Since the two fluids are in physical contact in the unit, both fluids must be pumped to the pressure at which boiling or vaporization occurs. For the working fluid, the boost and feed pumps provide the required pressure boost. When the direct-contact unit is used, a geothermal fluid boost pump raises geofluid pressure to the heater operating pressure.

During the boiling process in the direct-contact unit, noncondensable gases dissolved in the geothermal fluid come out of solution and are introduced into the working fluid system. These noncondensable gases leave the unit in the working fluid vapor stream and accumulate in the condenser until their partial pressure is sufficient to dissolve some of the noncondensables in the working fluid condensate. These noncondensables, which go into solution in the working fluid, come back out of solution in the direct-contact unit and reenter the condenser in the working fluid vapor stream. Besides adding their partial pressures to the condenser pressure these noncondensables tend to blanket the tube surfaces and retard the condensing process. To minimize the effect of noncondensables a preflasher unit was installed immediately upstream from the geothermal fluid boost pump. The function of this flasher unit is to reduce the geothermal fluid pressure sufficiently to cause the noncondensables to come out of solution and be vented to the atmosphere prior to the geothermal fluid entering the DCHX.
This flasher unit can remove most, but not all of the noncondensable gases. To remove those noncondensables that enter the working fluid system, the condenser has a vent line to the flare system located near the top of the condenser unit. This system allows the condenser to be vented at a controlled rate while the plant is being operated. The venting process removes working fluid vapor as well as noncondensables from the condenser. To minimize working fluid losses during the venting a secondary condenser was installed in the vent system to recover a portion of the working fluid in the vent stream that might otherwise be lost to the flare system.

The physical layout of the facility, as configured during the testing reported here, is shown in Figure 2. The two vertical vessels mounted within the major support tower are the condenser and tube-and-shell preheater/boiler. In the separate tower to the right is the DCHX. In the foreground is the turbine/pump skid, which contains the working fluid boost and feedpumps, the turbine and its gearbox, and the generator.

\subsection{Component Description}

2.2.1 Direct-Contact Heat Exchanger. The DCHX is a sieve-tray, or perforated plate column in which the energy from the hot geothermal fluid is used to first preheat and then vaporize the working fluid. The column was designed and built for this application by the Wahl Company, Claremont, California. Countercurrent flow between the two fluids is maintained by the density difference between the two insoluble liquids and the resulting buoyant force on the lighter fluid. In this application the lighter working fluid is the dispersed fluid that flows through the perforations in each plate and rises as droplets through the continuous geothermal fluid.

The column and tray configurations are shown schematically in Figure 3. The lower 17 plates comprise the preheating section where the working fluid is heated up to the boiling temperature corresponding to the DCHX column pressure. The upper two plates (18 and 19) make up the boiling section where the working fluid is vaporized. Plate $\mathbf{1 7}$ has dual functions in that it serves as a preheating tray and is designed to allow a portion of the working fluid to be removed from the column near its saturation temperature (to simulate multiple boiling cycles). This tray is referred to as the drawoff tray, but was not used as such in the present tests. 


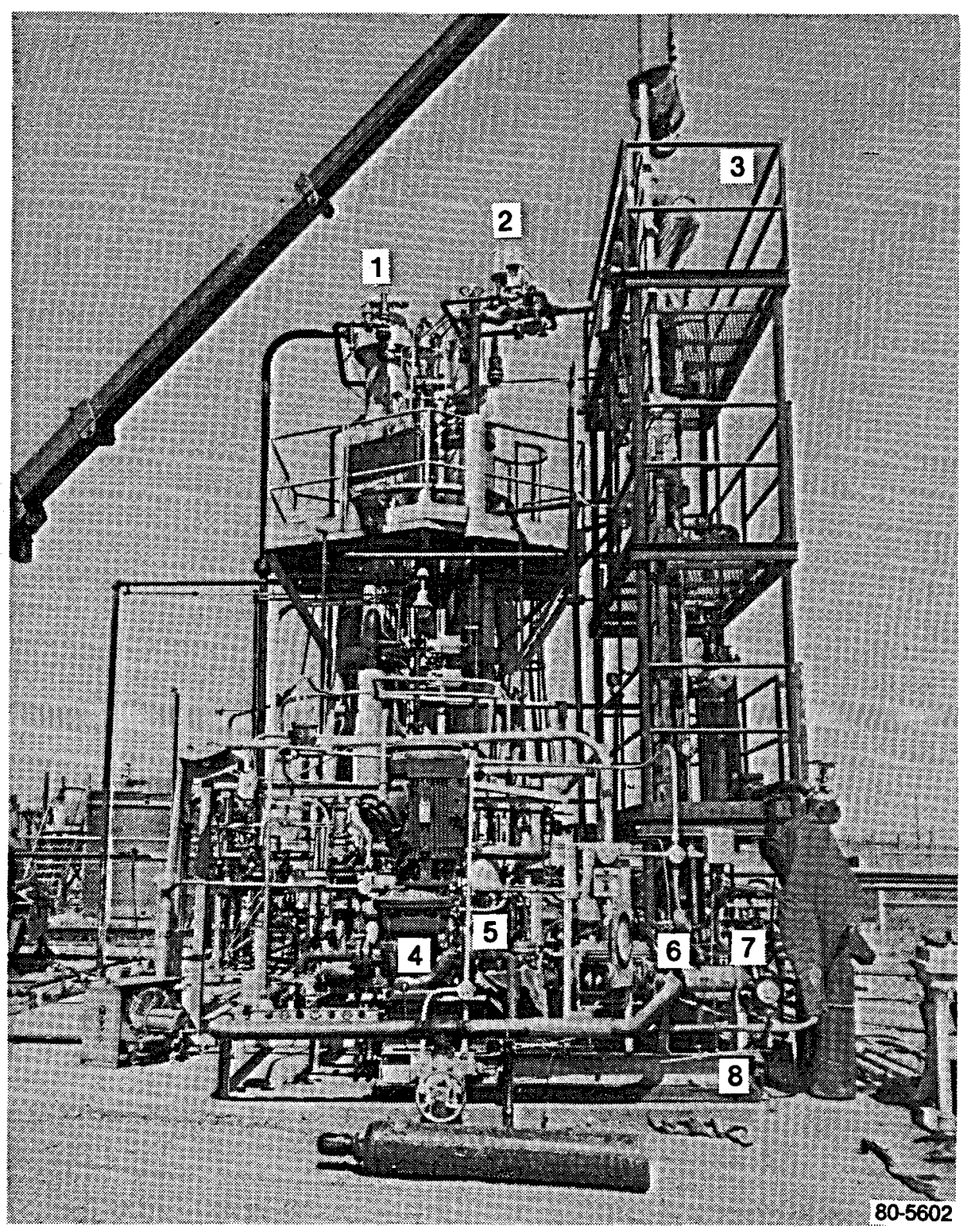

1. Condenser

2. Tube-and-shell preheater/boiler

3. Direct-contact preheater/boiler
4. Feed pump

5. Turbine

6. Generator

7. Boost pump

8. Turbine/pump skid

Figure 2. Facility overall layout. 


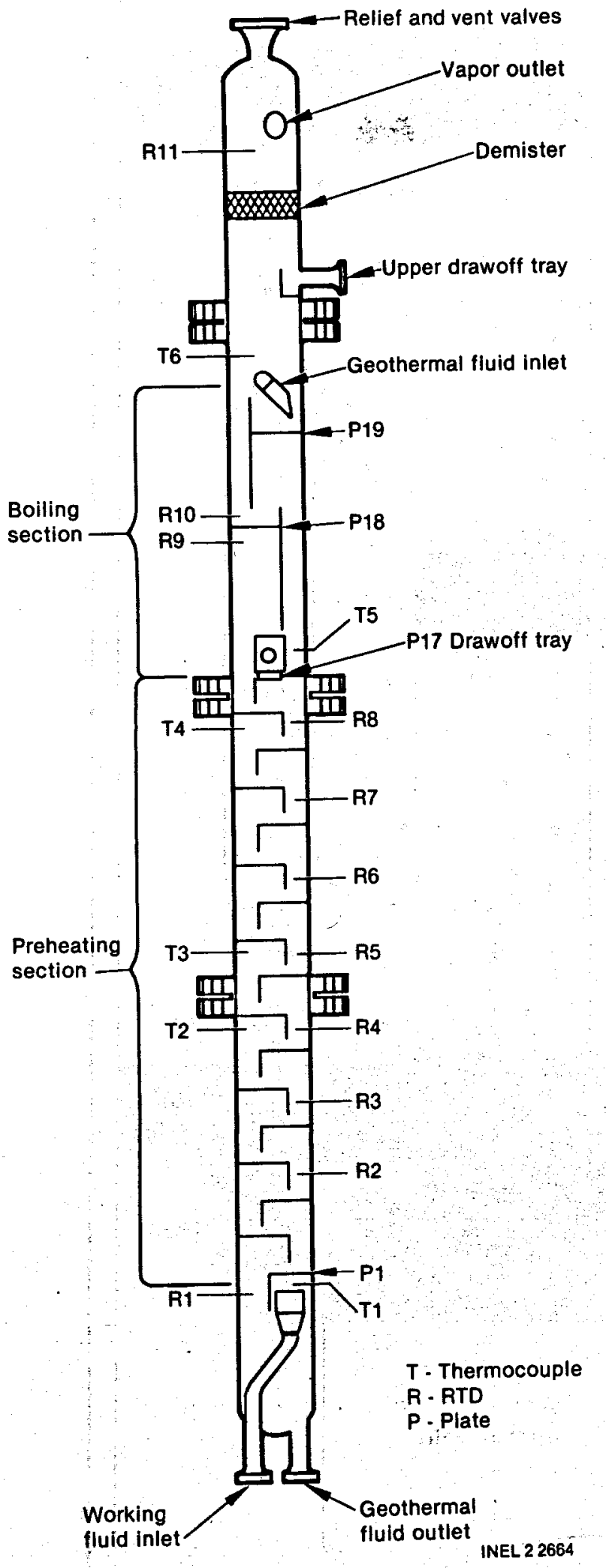

Figure 3. Direct-contact heat exchanger schematic.
The geothermal fluid enters the DCHX column just above Plate 19, the upper boiling tray (see Figure 3). Being the heavier of the two fluids, the geofluid flows down through the column over the top of each plate, in a sense cascading down the column. The cooled geothermal fluid discharges at the very bottom of the unit. The working fluid condensate from the condenser enters at the bottom of the column and discharges in the area immediately under the bottom plate, Plate 1 , as shown in Figure 4. The working fluid collects in a layer under the plate, flows through the perforations in the plate, and is dispersed as droplets rising up through the geothermal fluid flowing across the top surface of the plate. These droplets rise and coalesce in the region below the next plate enclosed by the downcomer. This process of droplet formation and then coalescence is repeated at each plate as the working fluid moves up the column. As the droplets rise through the geothermal fluid in the region between the plates, the heat and mass exchange takes place between the two fluids.

When the working fluid reaches its saturation temperature (or bubble point with mixtures) it begins to vaporize. This boiling process is intended to begin in the region above Plate 18 and is completed in the area above Plate 19. In the boiling section, the geothermal fluid is no longer the continuous fluid. To ensure that both fluids are in contact with each other in the region above each of the boiling plates where the heat exchange process occurs, both boiling plates have dams or weirs to ensure that there is a layer of geothermal fluid on the top surface of each plate. The region above Plate 19 and the geothermal fluid inlet is a vapor dome where the working fluid vapor rises and leaves the column. To minimize the amount of liquid droplets, or carryover, entrained in the working fluid vapor a demister is located just below the vapor outlet nozzle. This demister consists of a section of steel wool $\sim 4$ in. thick.

The DCHX is $\sim 19-1 / 2 \mathrm{ft}$ long and $1 \mathrm{ft}$ in diameter. It was fabricated with two preheating sections with the intent that one section might be removed if so desired. The vessel was designed for a maximum working pressure of 530 psi. The plates in the preheating section are spaced at 6 in. intervals with $1 / 8$-in. sized holes in all the plates. The specifications for the individual plates, including the boiling plates are given in Table 1 .

The DCHX is instrumented with 17 internal temperature sensors as shown schematically in 


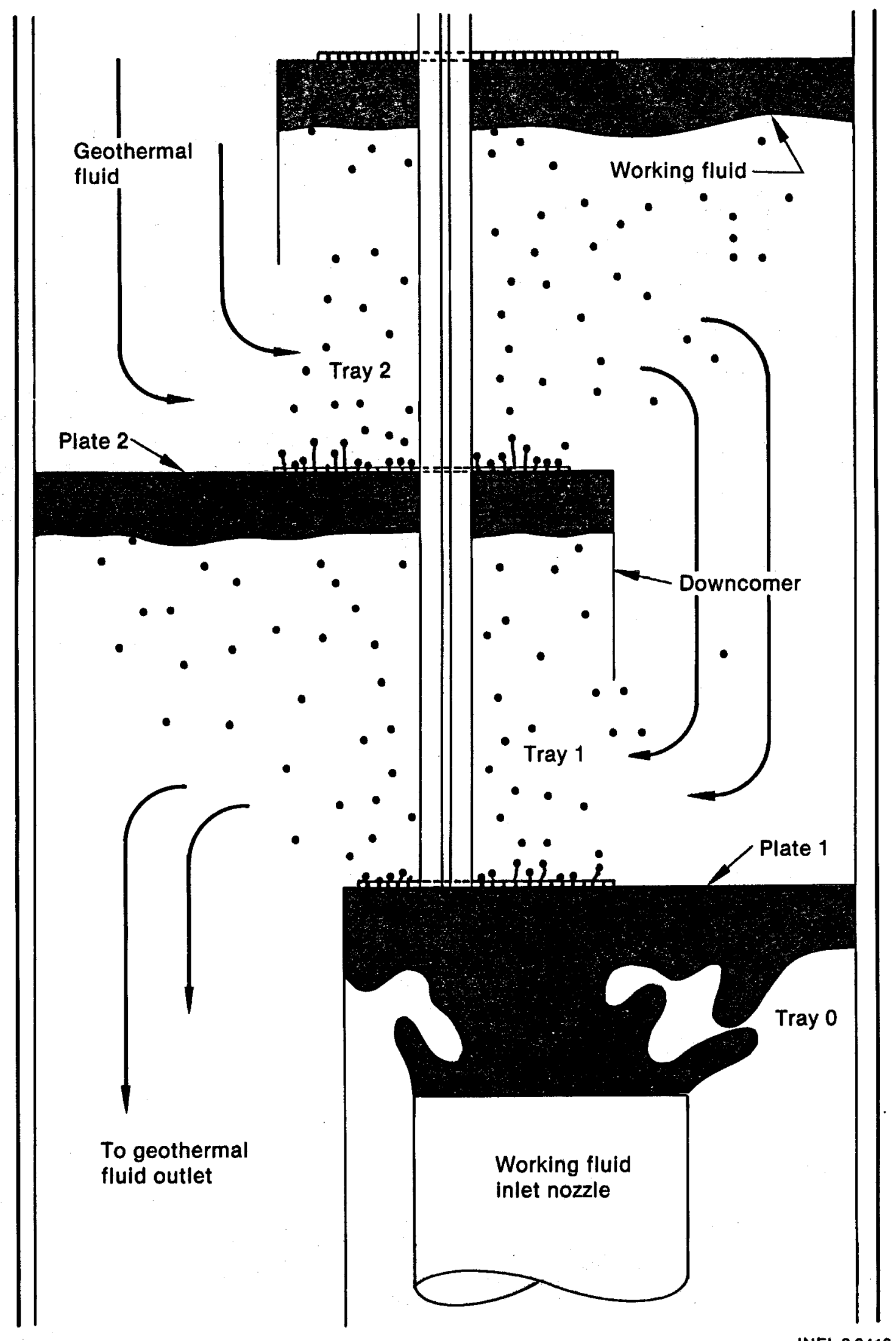

INEL 33416

Figure 4. Schematic showing lower tray configurations. 
Table 1. Specifications for prototype DCHX plates

\begin{tabular}{|c|c|c|c|c|c|c|}
\hline $\begin{array}{c}\text { Plate } \\
\text { Number }\end{array}$ & $\begin{array}{l}\text { Area } \\
\left.\text { (in. }{ }^{2}\right) \\
\end{array}$ & $\begin{array}{c}\text { Diameter } \\
\text { (in.) }\end{array}$ & $\begin{array}{c}\text { Number } \\
\text { of } \\
\text { Rows } \\
\end{array}$ & $\begin{array}{c}\text { Spacing } \\
\text { of } \\
\text { Plates }^{\mathrm{a}} \\
\text { (in.) } \\
\end{array}$ & $\begin{array}{c}\text { Downcomer } \\
\text { Length } \\
\text { (in.) } \\
\end{array}$ & $\begin{array}{c}\text { Weir } \\
\text { Height } \\
\text { (in.) }\end{array}$ \\
\hline 1 & 11.0 & $1 / 8$ & 20 & - & 6 & - \\
\hline 2 to 5 & 12.6 & $1 / 8$ & 23 & 6 & 3 & - \\
\hline 6 to 16 & 13.7 & $1 / 8$ & 25 & 6 & 3 & - \\
\hline $17^{b}$ & 5.8 & $1 / 8$ & 19 & 8 & 5 & - \\
\hline 18 & 14.3 & $1 / 8$ & 26 & 22 & 17 & $3-1 / 4$ \\
\hline $19^{c}$ & 17.0 & $1 / 8$ & Maximum & 15 & $12-1 / 4$ & 6 \\
\hline
\end{tabular}

a. Spacing of plates given above lower plate.

b. Fifty holes located in drawoff lid.

c. Plate 19 , holes cover entire plate.

Figure 3. Nine of these temperature sensors are located in downcomers to provide a temperature profile of the geothermal fluid through the preheating section. Four of the temperature sensors are located just under $(<1 / 2 \mathrm{in}$.) four of the preheating tray plates. These sensors provide working fluid temperatures in the preheating section. With the exception of a temperature sensor at the top of the column near the vapor outlet, the remaining sensors are located in the boiling section. The pressure in the column is measured near the top of the unit in the vapor dome region. The unit was also instrumented with three level indicators in the boiling section of the column. The lower boiling tray had a differential pressure indicator across the downcomer length to measure the liquid height in this region. The upper boiling tray also had a differential pressure indicator across the plate to measure the height of fluid over the plate. The third level indicator was a float type located between the lower boiling tray and the demister to sense high levels in the column. The level indicator at the lower boiling tray provided input to the level control valve that maintained the geofluid level in the column. The geofluid level in the column is controlled by this indicator because the geofluid is to be maintained as the continuous fluid in the preheating section below this tray.

2.2.2 Turbine/Pump Skid. The turbine/pump skid was designed and built by Barber-Nichols
Engineering Company of Arvada, Colorado. This skid, as originally constructed, consisted of the working fluid boost and feed pumps, turbine, turbine gearbox, induction motor/generator, and speed reducing gearbox for the feed pump. The pumps and/or their gearboxes were driven by the interconnecting shaft between the turbine gearbox and the motor/generator. When the facility was operated producing electrical power, the turbine provided power to operate the pumps as well as turn the generator producing electrical power. The original $60-\mathrm{kW}$ rating for the plant was based on this configuration and on operation at very low condensing temperatures. The feed pump used for the DCHX testing has its own driver coupled to it so that its power requirements are no longer provided by the turbine or induction motor/generator.

A brief description of each of the skid components as configured during the DCHX testing follows.

2.2.2.1 Working Fluid Feed Pump. The function of the working fluid feed pump is to provide the head necessary to overcome the boiler pressure and circulate the working fluid through the plant.

The feed pump is a Sundstrand pump, Model LMV-222. It is rated at $43 \mathrm{gpm}$ at $17,100 \mathrm{rpm}$ and $1,960 \mathrm{ft}$. The driver is a $460-\mathrm{V}, 3$-phase, $50-\mathrm{hp}$ 
explosion-proof motor. The assembly has an intermediary gearbox that steps up the driver shaft speed from 3,550 rpm to the 17,100-rpm pump speed.

2.2.2.2 Boost Pump. The function of the working fluid boost pump is to increase the pressure of the working fluid leaving the condenser enough to satisfy the net positive suction head (NPSH) requirements of the feed pump.

The boost pump is a multistage centrifugal pump manufactured by Gould Pumps. The pump is equipped with 3 stages and is rated at $54 \mathrm{gpm}$ at $2,400 \mathrm{rpm}$ and $65 \mathrm{ft}$ head with an NPSH requirement of $<3 \mathrm{ft}$. The pump is belt driven from the interconnecting shaft between the turbine gearbox and the motor/generator.

2.2.2.3 Turbine-Generator. The turbine is an axial flow impulse type unit fabricated specifically for this facility by the Barber-Nichols Engineering Company. It operates at $22,470 \mathrm{rpm}$ to give 107-hp output at 313-psia inlet pressure, 53-psia exhaust pressure, and $13,000-\mathrm{lb} / \mathrm{h}$ saturated isobutane vapor flow driving the induction motor/generator through a gearbox. The gearbox has a 6.135:1 speed ratio giving a shaft output of $3,600 \mathrm{rpm}$. The generator is a standard induction motor/generator manufactured by Marathon Electric. The motor/generator 'ias a rating of $100 \mathrm{hp}$ at $3,560 \mathrm{rpm}$ and requires (or produces) 3-phase, $440-\mathrm{V}, 125$-amp, $60-\mathrm{Hz}$ electrical power. It is explosion proof and fan cooled. (The turbine was not used during the present DCHX testing.)

\subsubsection{Heat Rejection System}

2.2.3.1 Oak Ridge National Laboratory Condenser. The condenser unit was designed and built for use with the facility by Oak Ridge National Laboratory (ORNL). This unit utilizes enhanced heat exchange tube surfaces to improve the thermal performance of the exchanger. The exchanger has 104 tubes and is a 4-pass unit (two groups of U-tubes). Cooling water flow is through the tube side of the unit, while working fluid vapor is condensed on the outer surfaces of the tube. The heat exchange tubes are nominally 0.98 -in. outside diameter with 0.065 in. wall fabricated from Admiralty Brass material [American Society of Mechanical Engineers (ASME SB111)]. There are 60 flutes on the outside diameter along the length of the tube. These flutes are equally spaced and are $\sim 0.026 \mathrm{in}$. wide by 0.025 -in. deep. The total heat transfer area of the unit is $-600 \mathrm{ft}^{2}$. The condenser was designed and built to Section VIII of the ASME and TEMA (Tubular Exchanger Manufacturers Association) Class $\mathbf{R}$ for a shell side pressure of $375 \mathrm{psig}$ at $300^{\circ} \mathrm{F}$. The design heat load is $2 \times 10^{6} \mathrm{Btu} / \mathrm{h}$ for a cooling water flow rate of $300 \mathrm{gpm}$ and a water temperature rise of $13^{\circ} \mathrm{F}$.

The condenser was installed in the vertical position with the tube U-bend at the bottom of the vessel. Cooling water enters and leaves at the top of the vessel. The working fluid vapor from the turbine or turbine bypass valve, enters the unit $\sim 33$ in. above the tube bundle U-bend and is directed upward by internal baffling. As the working fluid condenses on the tube surfaces, the condensate is removed or stripped from the tube at these baffles and is directed to inactive downcomers that remove the condensate to a condensate storage area region in the shell below the tube bundle.

2.2.3.2 Cooling Tower. The facility cooling tower, manufactured by Marley Cooling Tower, is a mechanical draft, crossflow type. The heat load in the tower is $\sim 2 \times 10^{6} \mathrm{Btu} / \mathrm{h}$ during normal operation of the plant. The tower is equipped with a 30-hp Johnson vertical turbine pump that circulates water through the plant cooling system and a 5-hp fan that induces airflow through the tower.

2.2.3.3 Vent Condenser. The vent condenser is a heat exchanger installed in the vent line off the main condenser. This vent system is used to remove noncondensables, introduced during the operation of the direct-contact unit, from the condenser. The function of the secondary vent condenser is to condense working fluid in this vent stream and return the condensate to the main condenser. The unit is a single-pass heat exchanger with cooling water on the tube side and the vent gas on the shell side. The Admiralty Brass tubes are 3/8 in. in diameter and $-2 \mathrm{ft}$ long. The heat exchange surface area is $\sim 23 \mathrm{ft}^{2}$. The unit is a standard, off-the-shelf, item purchased from Basco.

2.2.4 Geothermal Fluid Supply System. The geothermal fluid predominately used during the DCHX tests was from the RRGE-1 well. The geofluid was delivered to the facility at a flowing temperature of 260 to $275^{\circ} \mathrm{F}$ and a pressure of 
-100 psia. Through a set of valves the geofluid could be flowed through either the tube-and-shell boiler or the DCHX. When flow was directed to the DCHX, it first passed through a preflasher unit to remove noncondensables and was then elevated in pressure with a boost pump so that it could be introduced into the DCHX at its operating pressure. The spent geofluid leaving either the tube-and-shell heater or the DCHX was discharged to a holding pond at Site 1 and held for later reinjection. Before entering the large holding pond, the spent brine from the DCHX was discharged into a cement tank located in a pit beneath the flare pilot. This tank was open to the atmosphere and any working fluid entrained or dissolved (down to $\sim 12 \mathrm{ppm}$ ) came out of solution and was burned off on the water surface of the tank. When the flare pit (in which the tank was located) filled to a certain level the geofluid spilled over into the Site 1 holding pond. (A brief description of the boost pump and preflasher is given below:)
2.2.4.1 Geofluid Boost Pump. The geofluid boost pump increases the geothermal fluid pressure sufficiently to overcome the direct-contact boiler pressure and circulate the geothermal fluid through the unit. This pump is a multistage centrifugal pump manufactured by Gould Pumps (Model 3935). At $45 \mathrm{gpm}$ and 3,600 rpm, this pump will develop $1,140 \mathrm{ft}$ of head. The driver for the pump is a $460-\mathrm{V}, 3$-phase, 30-hp explosion proof motor.

2.2.4.2 Geofluid Preflasher. The geofluid preflasher is used to reduce geofluid pressure to a set value and allow noncondensable gases dissolved in the geothermal fluid to come out of solution. These gases are continuously vented to the atmosphere along with some steam. The remaining geothermal fluid (liquid) leaves the bottom of the unit and is pumped up to the direct-contact column pressure by the geothermal fluid boost pump. The flasher unit is a Penn flasher separator, Model 14-56. 


\section{FACTORS INFLUENCING DIRECT-CONTACT HEAT EXCHANGER PERFORMANCE}

\subsection{Background}

In the DCHX both the geothermal fluid and the working fluid are in contact with each other during the heat exchange process (no tube wall or other physical boundary separates the fluids). The driving mechanism for moving both fluids through the column is the force of gravity and the density difference between the fluids. This process of the lighter working fluid rising up through the heavier geothermal fluid that is flowing down and out of the bottom of the column produced the countercurrent flow patterns desirable in the heat transfer process. The countercurrent flow path and lack of a tube wall or other boundaries between fluids allows these units to be built and operated as a single-heater/vaporizer unit without special considerations other than providing sufficient flow area and volume for preheating and boiling to occur. Since boiling at constant pressure is a constant temperature process (with a single component working fluid), the countercurrent flow path for the fluids is not necessarily desired during boiling, provided a large enough volume is available to vaporize all the working fluid. In evaluating the performance of the prototype DCHX the main emphasis was placed on the preheating section.

The DCHX most frequently used or tested in geothermal applications is the spray or Elgin tower. This type of column is characterized by its simplicity (it contains no special internals other than distributor plates or nozzles used to introduce the two fluids into the column). The DCHX, whose test results are reported here, is a sieve-tray column that uses internal trays and downcomers to provide for an ordered repeated mixing and separation of the fluids as they move through the column. These internals eliminate the recirculation of fluids characteristic of Elgin towers, which tends to reduce thermal performance. The repeated formation and coalescence, i.e., heating and mixing, of the drops can also provide a potential improvement in thermal performance in that more of the fluid is exposed to the source of heat than in the case of a single drop rising in a spray column where the fluid at the center of the drop must be heated by conduction through the drop from its surface. (It has been suggested by
Ed Wahl that a design may be possible, which maximizes the heat transfer between the fluids while minimizing the mass transfer.)

\subsection{Thermal Performance}

3.2.1 Tray Efficiency Definitions. One indicator of the thermal performance of a sieve-tray DCHX is the tray efficiency. The tray efficiency is a measure of the actual thermal energy transferred between the two fluids in a tray or interaction zone, relative to the maximum energy that would be transferred if both fluids were allowed to reside in an ideal tray until their temperatures equilibrate.

More than one specific definition of tray efficiency can be established following work done analyzing analogous mass transfer processes in sieve-tray columns (References 1 and 2). Perhaps the simplest efficiency to find for a column where heat duty has been established experimentally, is the overall tray efficiency, which can be defined for a group of trays as the number of ideal trays required to exchange the same thermal energy in a counterflow DCHX as was transferred by a given set of actual trays. The overall tray efficiency can be found graphically by constructing a temperature-heat exchanged (T-Q) diagram for the two fluids involved in the heat transfer process, and finding the number of ideal trays required to transfer the heat exchanged by a group of actual trays in the column (Figure 5). The hot fluid enters the column at temperature $T_{\text {hot }}$ in, and leaves at $T_{\text {hot }}$ out. Similarly, the cold fluid enters at $T_{\text {cold }}$ in, and leaves at $T_{\text {cold }}$ out. Four ideal trays are shown in the figure. It can be seen that the heat transferred from the hot fluid in the ideal tray equals the heat transferred to the cold fluid in that tray, and both fluids leave the tray at the same temperature as defined by the horizontal line connecting the tray outlet conditions for the two fluids. If for this example, six actual trays were required to transfer the total amount of heat shown, the overall tray efficiency would be 4/6.

A second definition of tray efficiency is somewhat analogous to the Murphree tray efficiency taken from the mass transfer literature (Reference 1). This individual tray efficiency is defined as the heat transferred in an actual tray divided by the heat transferred in an ideal tray 


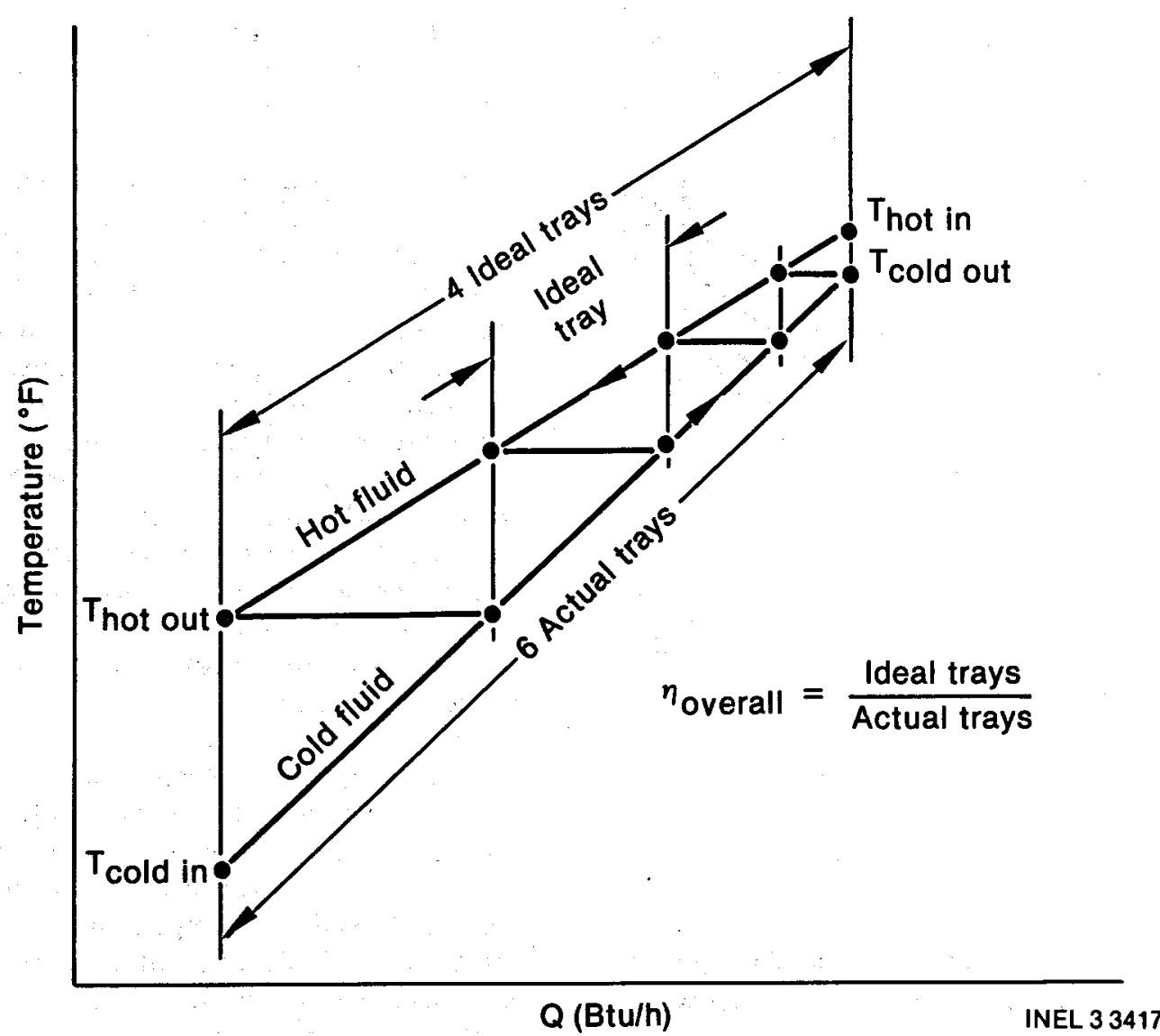

Figure 5. Temperature heat exchanged (T-Q) diagram illustrating overall efficiency.

$\left(\Delta Q_{A} / \Delta Q_{1}\right)$ in which the cold fluid enters, and the hot fluid leaves (see Figure 6) the actual and ideal trays at the same temperatures. It should be noted that for this definition each actual tray corresponds to a single ideal tray, whereas for the definition of overall efficiency each actual tray does not have a corresponding ideal tray; accordingly a definition such as $\eta=\Delta Q_{A} / \Delta Q_{I}$ is not meaningful for the overall efficiency. For this second definition of tray efficiency, the number of actual trays required can be determined easily (if the efficiency is assumed to be equal for all trays) by counting the number of ideal trays required to transfer heat to an imaginary cold fluid that follows the dashed $T-Q$ line as shown in Figure 6. At a given temperature the dashed $T-Q$ line is always the fraction of the distance, that is equal to the tray efficiency, between the actual hot and cold-fluid T-Q lines. For tray efficiencies $<100 \%$, the individual and overall efficiencies are not equal.

A third definition of tray efficiency can be used that is very nearly the same as the second. For this definition the efficiency, again, is equal to the heat transferred in an actual tray divided by that in an ideal tray $\eta=\Delta Q_{A} / \Delta Q_{I}$, but for this efficiency the ideal and real trays have hot fluids as well as cold fluids entering at the same temperatures (see Figure 7). For this third definition, as for the second definition, an ideal tray corresponds to each actual tray. However, the ideal trays corresponding to a given actual tray are not identical for the second and third efficiency definitions, so the efficiencies are different, numerically.

3.2.2 Tray Efficiency Definitions Used. The sieve-tray column treated in these experiments was designed, nominally, for heating and vaporizing isobutane; the major experimental investigations for the column were made using that working fluid. The features of the column were reviewed during the design to determine if significant incompatibilities existed relative to vaporizing mixed-hydrocarbon working fluids, particularly in view of the expectation of some boiling within the section normally providing preheating. It was 


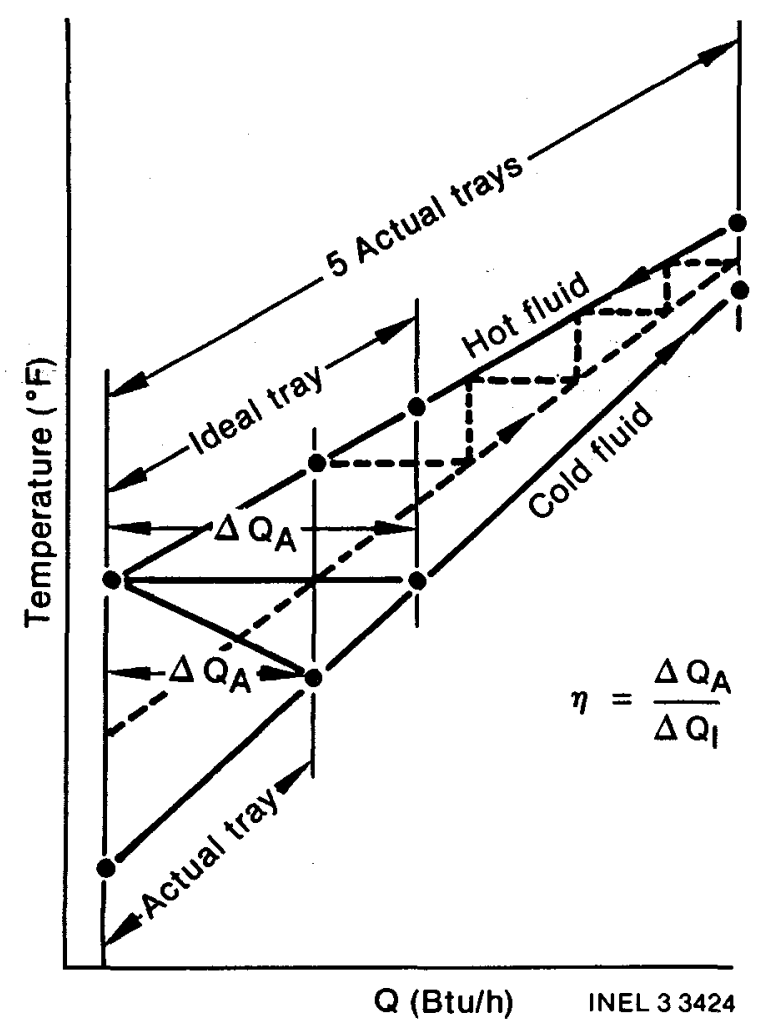

Figure 6. Temperature heat exchanged (T-Q) diagram illustrating Murphree tray efficiency.

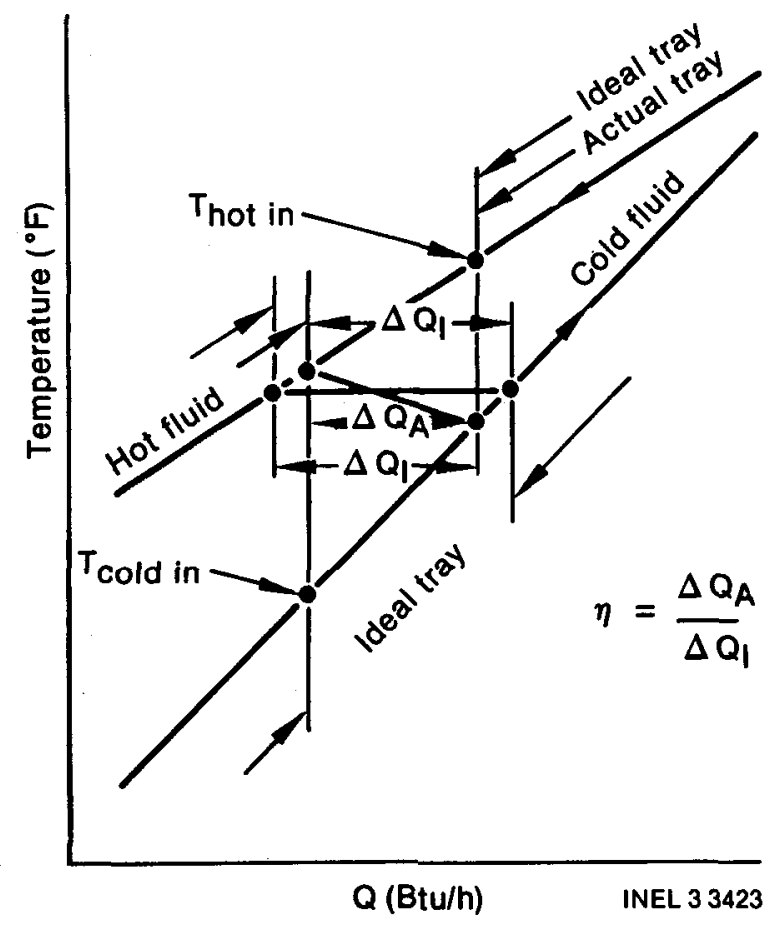

Figure 7. Temperature heat exchanged (T-Q) diagram illustrating individual tray efficiency as used in this report. judged that vaporization of mixtures could be accomplished in the column, so mixtures as well as isobutane were tested.

In order to evaluate the experimental tray efficiencies using isobutane, it was found preferable to find the single value of tray efficiency for Trays 1 through 17 that best fit all of the measured working fluid and geofluid temperatures in the preheating section, rather than to try to calculate individual values of tray efficiency from discrete temperature measurements. (Tray 1 is the bottom preheating tray; Tray 0 corresponds to the working fluid distribution zone under Tray 1.) Insufficient measurements and inadequate accuracy of measurements precluded using the latter approach, particularly in the region having flat temperature profiles in the top part of the preheating section.

To accomplish the determination of efficiency in the preheating section for the isobutane tests, a computer program was assembled for which the basic inputs consisted of (a) preheating tray efficiency, (b) geofluid temperature leaving Tray 1, (c) working fluid temperature entering Tray 1 , and (d) the ratio of isobutane flow entering to geofluid leaving the column. Isobutane and water properties were built into the computer program. The program calculated working fluid outlet and geofluid inlet temperatures for Tray 1; the calculations were then repeated for Trays 2 through 17. The flow ratio and efficiency values were perturbed systematically and the calculations repeated until a good fit of the data were obtained for the preheating section. Tray efficiencies in the boiling section (Trays 18 and 19) were calculated directly from measured column temperatures and the proper flow ratios as determined for the preheating section.

The third definition of tray efficiency was used in the computer program as

$\eta_{\text {individual }}=\frac{\Delta \mathrm{Q}_{\text {Actual }}}{\Delta \mathrm{Q}_{\text {Ideal }}}$

where the inlet temperatures are the same for the actual and ideal trays. This definition is fundamental and easy to interpret, and was selected in preference to the other definitions previously described. The results using this approach are described in Section 4. 
The time and effort required for modification of the computer program to handle fluid mixtures, which boiled during residence in the preheating section, and propane were in excess of the scope planned for this immediate task. Accordingly, overall efficiency values were determined graphically for the propane and mixed fluid tests using the first definition of efficiency and the approach illustrated by Figure 5 .

$\eta_{\text {overall }}=\frac{\text { number of Ideal trays }}{\text { number of Actual trays }}$

where the total heat duty is the same for the groups of ideal and actual trays. Determination of efficiency was accomplished in the same manner for the boiling and preheating regions of the column for these tests. To permit comparison of tray efficiencies for isobutane with those for propane and the mixed fluids, overall efficiency was determined graphically for isobutane Test Runs $1,2,3,4,6$, and 7. For convenience of comparison these results are included in Section 5.3 along with the results for mixedhydrocarbon working fluids.

To illustrate, quantitatively, the relationship between $\eta_{\text {overall and }} \eta_{\text {individual }}$ used in this report, Figure 8 shows the comparison obtained for Test Runs 1, 2, 3, 4, 6, and 7.

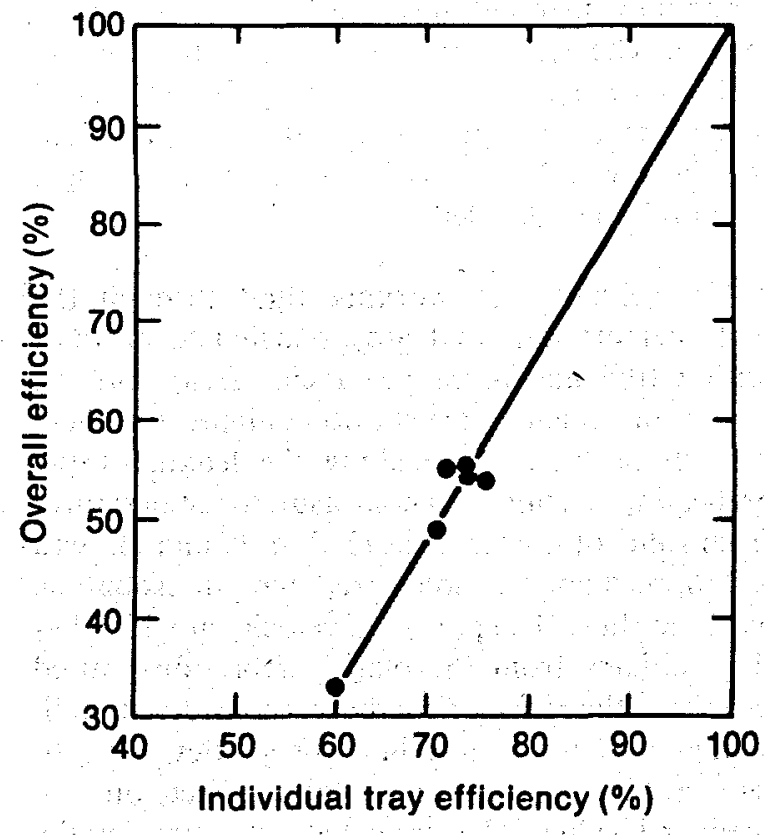

INEL 33421

Figure 8. Overall versus individual tray efficiency for preheating trays; isobutane tests.
3.2.3 Column Pinch Point. If the tray efficiencies are high and the column has a sufficient number of boiling and preheating trays, then the DCHX should be able to achieve small pinch points, as shown in Figure 9. (The pinch point is the minimum temperature difference between the two fluids, generally occurring at or near the point where the working fluid begins to boil.)

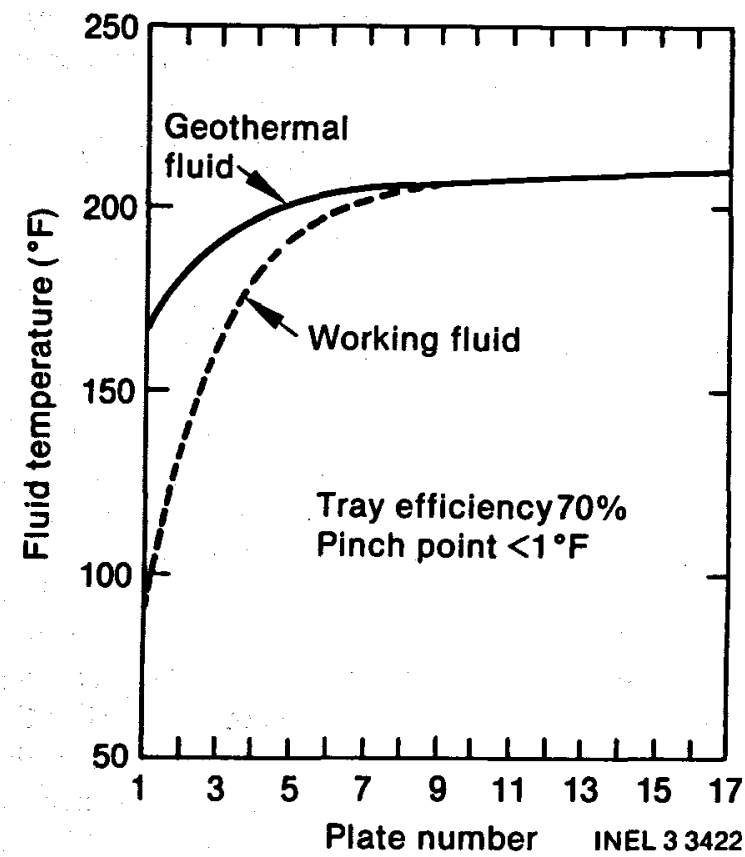

Figure 9. Predicted temperature profile for preheating section.

In conventional tube-and-shell heat exchangers, a typical pinch point temperature difference might be $10^{\circ} \mathrm{F}$ or higher. In order to achieve smaller pinch points, these units would require more area corresponding to higher costs. With the large number of preheating trays in the DCHX, it was anticipated that the unit would be able to operate with a pinch point of about $1^{\circ} \mathrm{F}$ or less. The predicted temperature profile in Figure 9 indicates that at an individual tray efficiency of $70 \%$, the DCHX would produce a pinch point of well under $1^{\circ} \mathrm{F}$ at the conditions for which the prediction was made. Lower preheating tray efficiencies would change the temperature profile and produce higher pinch points. [The uncertainty in the tray efficiency when designing the unit dictated that additional trays be added with the provision that Plates 9 through 16 (with Plate 1 being the lower plate) could be removed.] 


\subsection{Column Hydraulics}

3.3.1 Effects of Droplet Size. If the resistance to heat transfer between a working fluid drop and the geothermal fluid does not vary significantly with the drop diameter, then producing smaller drops and exposing more of the working fluid to the geothermal fluid i.e., more surface area, should increase the total amount of heat transferred in the regions between plates. The reduction in drop size to increase the amount of heat transferred, however, must be tempered by the increased mass transfer rate between fluids (working fluid going into solution in geofluid), and the consideration of the driving mechanism for the DCHX hydraulics. As mentioned earlier, the dispersed working fluid drops rise in the column due to the density difference between the fluids or the drop's buoyancy. The velocity at which the drop rises, or its terminal velocity, is approximately proportional to the square root of the drop diameter, thus smaller drops rise more slowly in the column. If the velocity of the continuous fluid exceeds the drop terminal velocity, then the drop will be swept along in the continuous fluid stream (mechanically entrained). Thus, the terminal velocity of the working fluid drop establishes the maximum velocity of the geothermal fluid in the column. The reduction in drop size to provide more heat transfer area must be traded off with reduced mass throughputs of both fluids and/or a larger vessel at higher costs.

3.3.2 Jet Formation and Breakup. The intent of the DCHX hydraulic and thermal performance tests was not to investigate the different mechanisms involved in the drop formation process, however, some consideration must be made of these mechanisms in interpreting the operating limits encountered. Investigations have found that at low orifice or hole velocities the drops will form at a uniform size and break off at regular intervals. (Some of the different correlations were used to predict the drop size at these low velocities and produced estimated diameters ranging from $0.6 \mathrm{~cm}$ to over $1 \mathrm{~cm}$.) As the velocity through the orifice is increased, a point is reached where the mechanism for the drop formation changes. A short jet of dispersed fluid extends from the nozzle and drops form by a necking-in at the top of the jet. The drops formed from the jet, while not as uniform in size as the drops formed prior to jetting, have some consistency in size at the lower jet velocities and their average diameter can be predicted. ${ }^{3}$ Although their average diameter can be predicted, jetting does produce a distribution of drop sizes; no data or study was found, however, which provides the expected distribution of sizes.

As the orifice velocity increases, the jet increases in length. Skelland and Johnson ${ }^{3}$ investigated the formation of drops from the breakup of jets and defined correlations that predict the conditions producing the maximum interfacial area. This condition defines the point where the interfacial or surface area between the contacting fluids is at a maximum. It is an important parameter in the design of liquid-liquid columns in mass transfer applications and would assume the same importance in the design of columns for liquid-liquid heat transfer applications in that it defines the conditions for maximum drop surface area (total) that corresponds to the minimum average drop size. The orifice velocity corresponding to this condition is recommended by Jacobs and Boehm ${ }^{4}$ as the maximum hole velocity to use in the design of a sieve-tray DCHX.

The jet length increases with the orifice velocity to a point where the length reaches a maximum after which the jet decreases in length as velocity increases. ${ }^{5}$ The maximum jet length condition defines the point where jet begins to break up in a random manner and the drops have no uniformity in size. The jet length will continue to decrease with increasing velocity until the point is reached where the jet disappears and the working fluid stream leaving the orifice is atomized producing a cloud of small droplets.

The velocities of working fluid through the plate perforations that are predicted to produce jetting (the maximum interfacial area) and the maximum jet length are shown in Figure 10. These predictions were made along the length of the preheating section using measured temperatures from some of the test runs $(2,3,4,6$, and 7$)$, with a 1/8-in.-diameter hole size, and an isobutane working fluid. The predicted velocity at which jetting initiates from the plate perforations varied little over the range of conditions considered, indicating variations in fluid properties due to temperature changes had little effect on the predicted value. The predicted velocities for the maximum interfacial area and jet length did vary both along the length of the preheating section and from run to run. For the prototype DCHX to 


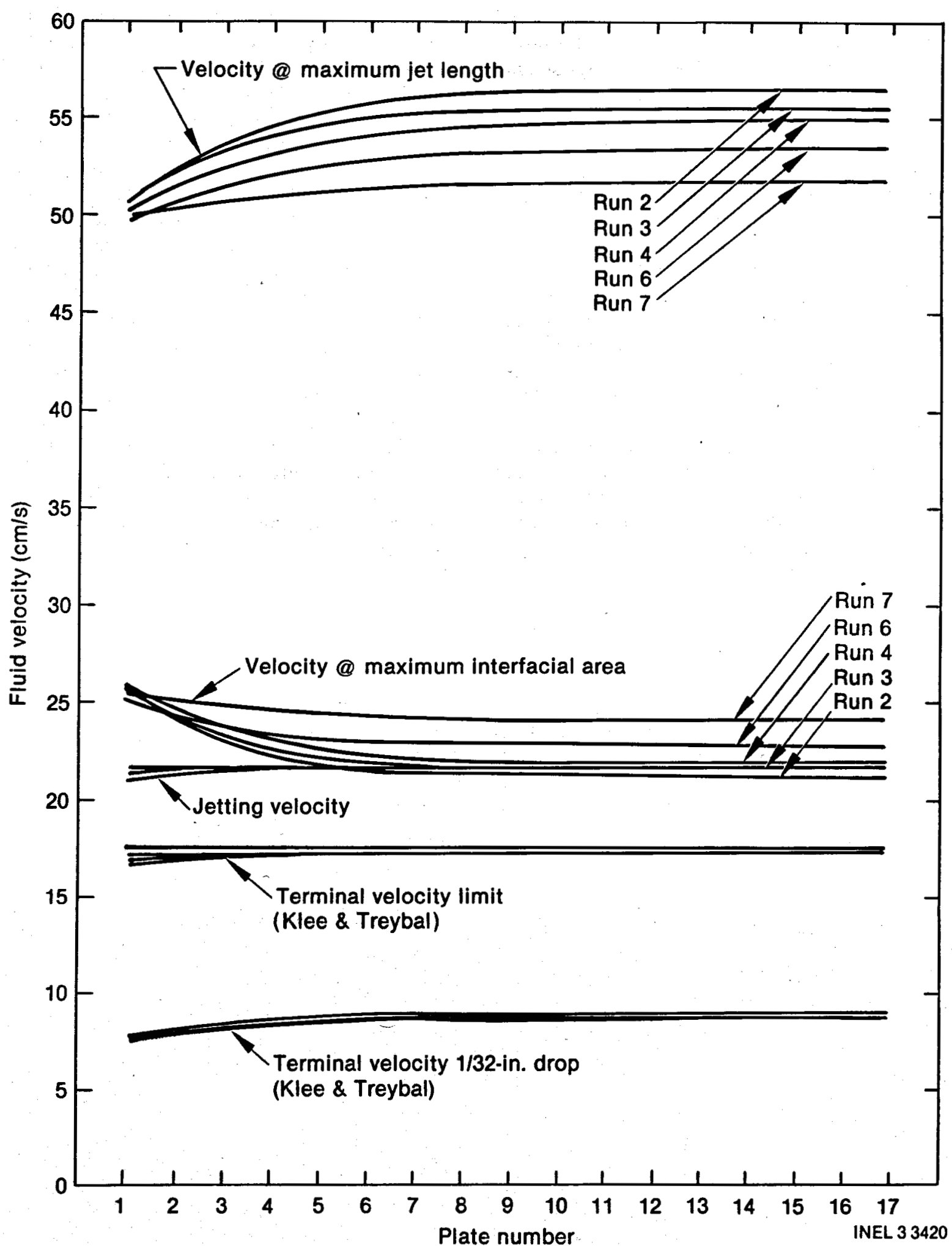

Figure 10. Direct-contact heat exchanger predicted working fluid velocities. 
operate around the recommended maximum interfacial area conditions, the plates should have working fluid velocities through the perforations of about 22 to $26 \mathrm{~cm} / \mathrm{s}$. These velocities should produce optimum thermal performance.

3.3.3 Maximum Geofluid Throughput. The geothermal or continuous fluid flow through the column is based on the terminal velocity of a drop as discussed previously. This analysis requires that the drop diameter be known in order for the velocity to be predicted, and assumes that the drop behaves as a solid sphere as it rises. Investigators of the formation of drops in liquid-liquid systems have noted that this assumption is valid to a certain drop diameter, after which the terminal velocity no longer increases and in some instances may decrease slightly with increasing drop in diameter. This transition is felt to be the result of internal circulation within the drop and oscillations and distortion of the drop surface that increase the drag forces on the drop. A correlation developed by Treybal and $\mathrm{Klee}^{6}$ was used to predict this limiting terminal velocity. The resulting velocity predictions are shown in Figure 10. This velocity represents the maximum continuous fluid velocity in the column. Higher geothermal fluid velocities would entrain any drop formed regardless of size. The design of a direct-contact column would not be based on this maximum or limiting terminal velocity. It would instead be based on the terminal velocity of the maximum sized droplet that would be allowed to be carried under. Usually this drop diameter is arbitrarily selected. Values commonly used in the design of sieve-tray columns are $0.0794 \mathrm{~cm}(1 / 32$-in.) and $0.1588 \mathrm{~cm}(1 / 16$-in.). 1 Both of these values are below the diameter at which the drop is predicted to no longer behave as a solid sphere $(0.18$ to $0.24 \mathrm{~cm})$. The predicted terminal velocities for a $0.0794 \mathrm{~cm}(1 / 32$-in.) drop for the range of operating conditions in the prototype DCHX are shown in Figure 10. The equations used to generate the predictions for the working fluid and the geothermal fluid downcomer velocities are given in Appendix A. 


\section{BASELINE PERFORMANCE TESTS WITH ISOBUTANE}

\subsection{Test Description}

The first sequence of performance tests with the prototype DCHX was to provide thermal and hydraulic performance data for the unit with an isobutane working fluid. These tests, which are outlined in Table 2, provide temperature data to be used in determining tray efficiencies and heat exchanger pinch points and the column flooding data that established the mass throughput limits for the column. Flooding in these direct-contact tests was defined as the point where the dispersed fluid was entrained in the continuous fluid at levels where the column operation became unstable. In conducting these performance tests, the DCHX was brought to the desired boiling conditions at flow rates well below the predicted flooding limits. Flow rates were then increased in regular increments (still maintaining the boiling conditions) until flooding occurred. This was repeated for each of the conditions listed in Table 2.

\subsection{Direct-Contact Heat Exchanger Operation}

The use of DCHX in place of the tube-and-shell preheater/boiler presented a different set of problems in starting up, operating, controlling, and shutting down the facility. Although the problems were resolved, the time spent on the learning curve was considerably longer for the DCHX than it was for the more conventional tube-and-shell unit. Some of these problems went beyond the initial lack of familiarity in operating a direct-contact column, and were the results of the physical constraints imposed by the cycle and control system design and components. Other problems were the result of trying to operate in a cold weather location.

4.2.1 Control of Column. The most common problems encountered with the DCHX were those associated with the control of the column, particularly during a transient process. The DCHX

Table 2. Baseline DCHX thermal and hydraulic performance tests

\section{Parameters $^{\mathrm{a}}$}

\begin{tabular}{|c|c|c|c|c|c|}
\hline \multirow[b]{2}{*}{$\begin{array}{c}\text { Run } \\
\text { Number }\end{array}$} & \multirow{2}{*}{$\begin{array}{c}\text { Boiler } \\
\text { Temperature } \\
\left({ }^{\circ} \mathrm{F}\right) \\
\end{array}$} & \multirow{2}{*}{$\begin{array}{c}\text { Boiler } \\
\text { Pressure } \\
\text { (psia) } \\
\end{array}$} & \multirow[b]{2}{*}{$\underset{\left(\dot{\mathrm{m}}_{\mathrm{iC}}{ }_{4} / \dot{\mathrm{m}}_{\mathrm{GF}}\right)}{\text { Flow Rate }}$} & \multicolumn{2}{|c|}{$\begin{array}{l}\text { Flow Rate at Flooding } \\
(\mathrm{lb} / \mathrm{h})\end{array}$} \\
\hline & & & & Geofluid & Working Fluid \\
\hline 1 & 250 & -450 & 0.26 to 0.53 & 14,100 to 15,100 & 3,600 to 7,000 \\
\hline 2 & 230 & -366 & 0.48 to 0.67 & 13,600 to 14,500 & 6,100 to 8,800 \\
\hline 3 & 220 & -330 & 0.53 to 0.74 & 13,400 to 14,200 & 7,200 to 9,500 \\
\hline 4 & 210 & -296 & 0.59 to 0.80 & 13,200 to 14,000 & 8,000 to 10,300 \\
\hline 5 & 200 & $\sim 265$ & 0.66 to 0.86 & 12,900 to 13,700 & 8,900 to 10,900 \\
\hline 6 & 190 & $\sim 237$ & 0.72 to 0.92 & 12,700 to 13,500 & 9,600 to 11,500 \\
\hline 7 & 150 & -146 & 0.97 to 1.13 & 12,000 to 12,600 & 12,100 to 13,500 \\
\hline
\end{tabular}

a. Cooling water flow rate through condenser $-\mathbf{3 0 0} \mathrm{gpm}$ or maximum flow rate than can be attained (not to exceed $300 \mathrm{gpm}$ ).

Preflasher: Operating, $\Delta \mathrm{T} \sim 1^{\circ} \mathrm{F}$.

Vent Condenser: Operating, $\mathrm{P}_{\mathrm{N} 2}<1$ psia. 
was operated with two automatic (or manual if so desired) control valves. The pressure of the column was maintained by a control valve in the working fluid vapor stream leaving the column and the geothermal fluid liquid level controlled by a valve in the geothermal fluid stream leaving the column. The flow rates into the column were manually controlled. The problems encountered with the control system are more easily understood if a column temperature profile is examined (a typical profile is given for Test Run 1 in Figure 11). From this profile it is apparent that much of the working fluid in the column is at or very near the saturation temperature corresponding to the column operating pressure. This large volume of liquid that was approaching its boiling point, was the principal cause of control system problems, when coupled with the slow response time of the column to changes in flow. On several occasions the column prematurely flooded because the level control valve kept opening in response to an apparent high liquid level in the column. In the control scheme the pressure control valve should close in order to maintain column pressure. Vapor should build up in the top of the vessel and the liquid level should fall. In general, however, the response to a change in the position of the level control valve was slow, and in the automatic mode, the level control valve would continue to open until a point was reached when the pressure control valve could no longer maintain column pressure. At this point, the column pressure would begin to drop and the large volume of liquid working fluid near saturation condition would begin to boil. The resulting vapor would lift the geothermal fluid above it giving an indication of a rapidly rising geothermal liquid level, and the level control valve would open further attempting to correct the apparent level increase. Column pressure would then decrease, and drive the boiling further down into the preheating section compounding the problem and resulting in flooding, both in terms of excessive carryunder and carryover.

This control problem was due in part to the excellent thermal performance of the unit that produced small pinch points, and to relatively slow response of the column to flow changes. At a typical terminal drop velocity of $17 \mathrm{~cm} / \mathrm{s}$, a drop of working fluid would take $\sim 18 \mathrm{~s}$ to rise to the top of the preheating section if no trays were present. The presence of the trays slows the rise of the working fluid, but to what degree is not known.

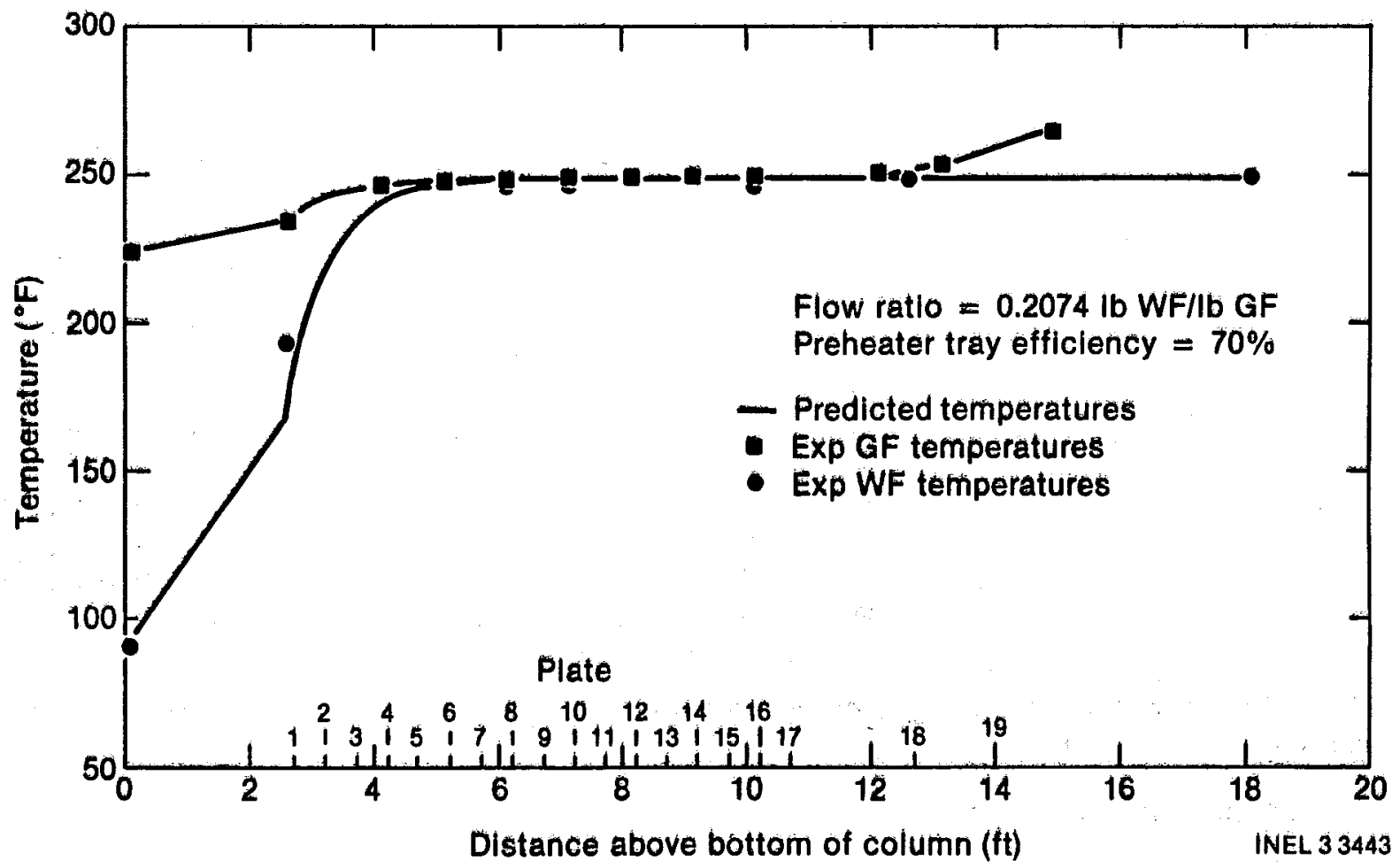

Figure 11. Column performance for Run 1 compared with design tray efficiency. 
Each tray must come to a new hydraulic equilibrium and the amount of time required is dependent upon the magnitude of the flow change. During the operation of the unit the time required for the column to respond to a flow change varied, however, once the column did respond the change in level or pressure occurred quite rapidly. The characteristics of the column required that when the column was being started up or shut down, or when a flow change was being made, the level control must be placed in manual and the pressure control valve in automatic. In this mode, the levels tended to drift with time and periodic manual adjustments of the control valve in the geothermal fluid discharge stream were required.

4.2.2 Operating Near the Flooding Limit. During these tests, the DCHX was brought up to the flooding limit slowly using small flow changes $(\sim 2 \mathrm{gpm})$ and allowing the column time to come to a thermal and hydraulic equilibrium each time a flow change was made. Once flooding started (usually due to excessive carryunder) it was not possible to decrease the flow rates slowly enough to stop the flooding. Flow rates had to be reduced by 20 to $30 \%$ in order to regain control of the column. Flow could then be increased again up to the flooding limit with control of the column. For a given set of operating conditions in the column, flooding limits were repeatable within $\pm 5 \%$.

Flooding for this column was defined as the point where the operation of the column became unstable due to excessive carryunder or carryover and could not be controlled. The carryunder of working fluid in the geothermal fluid leaving the column could be observed at the pond discharge where the geothermal fluid emptied into a concrete tank above which the flare pilot burned. When working fluid was carried under it would burn off on the water surface of the tank. Using this qualitative indication of carryunder, at a working fluid flow rate of $-18 \mathrm{gpm}$ the column began to carryunder working fluid, although flooding was not reached until higher working fluid flow rates.

4.2.3 Column Startup. The startup of the DCHX also presented a new set of problems that stemmed mainly from the lack of capacitance (or storage) in the working fluid feed system. If the DCHX was started up cold (filled with cool water) and working fluid was introduced into the column, the heater would not come up to boiler pressure until the geothermal fluid flow was established. If a small working fluid feed system flow was maintained, the heatup had to be rapid enough to get the unit up to pressure and establish vapor flow back to the condenser before the liquid condensate in bottom of the condenser (provides NPSH requirements for the working fluid pumps) was all pumped into the DCHX. The ability of the DCHX to store and then release working fluid caused significant variations in the condenser liquid level during startup (and normal operation) of the DCHX, making it necessary to introduce working fluid in pulses (flow into the DCHX until the condenser level approached the lower limit, then shut off the flow until vapor flow was established and the condenser level began to recover) until steady flow could be maintained. A hot startup where the geothermal fluid flow was established before introducing the working fluid was difficult to control as the working fluid began to boil shortly after entering the column, causing levels and pressures to change quite rapidly. If the column could be controlled during the hot startup, emptying the condenser of working fluid, which characterized cold startups, was not generally a problem.

4.2.4 Column Shutdown. A rapid shutdown of the DCHX generally produced a condition similar to flooding, particularly if the level control valve was not in a manual mode and it was not closed after the brine inlet flow was stopped. Without the flow of geothermal fluid, the vessel pressure would decrease faster than the DCHX would cool. As indicated previously, a large amount of working fluid in the DCHX is near the boiling temperature corresponding to the column operating temperature. With only a small drop in pressure, this fluid would start to boil giving a false indication of a rise in liquid level, thereby opening the level control valve that dropped column pressure causing more fluid to boil. The net result was generally a blowdown of a portion of working fluid that remained in the column after the geofluid and feed flows were shut off.

4.2.5 Automatic Operation. The operation of the column and the problems discussed to this point required that someone be in the control room prepared to make manual adjustments of control valves in the event of an upset condition or change in one of the parameters (level, flow, etc.). The column stability in the automatic control mode would not allow any long term unattended operation of the facility that was possible when the tube-and-shell preheater/boiler was used in place of the DCHX. 
4.2.6 Turbine Operation. The operation of the turbine was not part of the planned DCHX performance testing, although it was operated briefly. The primary reason that the turbine was not operated was that expected vapor flow from the DCHX would not allow the unit to produce more than 10 to $15 \mathrm{~kW}$ of power. Any data collected would have been sufficiently far from the turbine design point to lack significance. Accordingly, the turbine was not included in the baseline test plan, and was operated only to confirm that it could be brought on-line with the DCHX operating.

4.2.7 Cold Weather Problems. The operation of the DCHX at Raft River did pose a problem that would not have been present at a warm weather location. The water introduced into the working fluid system in the DCHX in the form of water vapor and entrained droplets in the working fluid vapor stream would condense in the vapor piping and collect in cold or dead leg piping lines (drain system piping, and sensing lines to pressure transmitters). The water would also collect in the liquid working fluid piping system dead leg lines (no flow circulating) if they were lower than the process piping by virtue of the density difference between the fluids. During cold weather, this water would freeze even when the plant was operating, damaging the equipment, giving false readings, and in some instances causing the column to flood due to a control valve being driven in one direction or another by the reading from a frozen transmitter. To minimize the problem that this freezing caused, the drain system, transmitters, etc., were heat taped and insulated, and where possible transmitters and sensing lines were filled with antifreeze. While this helped, the problem continued throughout the period the DCHX was operated.

\subsection{Baseline Test Results}

The sequence of thermal and hydraulic tests (listed in Table 2) were conducted with the prototype DCHX and the hydraulic throughput limits established for each of the conditions listed with two exceptions. It was not possible to reach the column flooding limit in Test Run 1 (the highest boiler pressure) primarily because the inlet geothermal fluid temperature $\left(-130^{\circ} \mathrm{C}\right.$ or $\left.266^{\circ} \mathrm{F}\right)$ was lower than the design value $\left(143^{\circ} \mathrm{C}\right.$ or $\left.290^{\circ} \mathrm{F}\right)$ requiring higher geothermal fluid flow rates to vaporize a given amount of working fluid. The upper flow limit of the geothermal fluid boost pump was exceeded before the column flooded. The second exception was Test Run 5 where premature flooding occurred as the result of instabilities in the control system.

Even though two of the seven test runs were not totally successful, a fairly wide range of operating conditions were obtained with the unit up to its flooding limits. The near flooding conditions for the column are listed in Table 3 except for Test Run 5 (maximum flow conditions for Test Run 1 are given). The trends in flow rates for both fluids, shown in Table 3, are consistent with the operating characteristics of other direct-contact columns (as the dispersed or working fluid flow increased, the continuous or geothermal fluid flow decreased).

Table 3. Near flooding conditions in the DCHX with isobutane

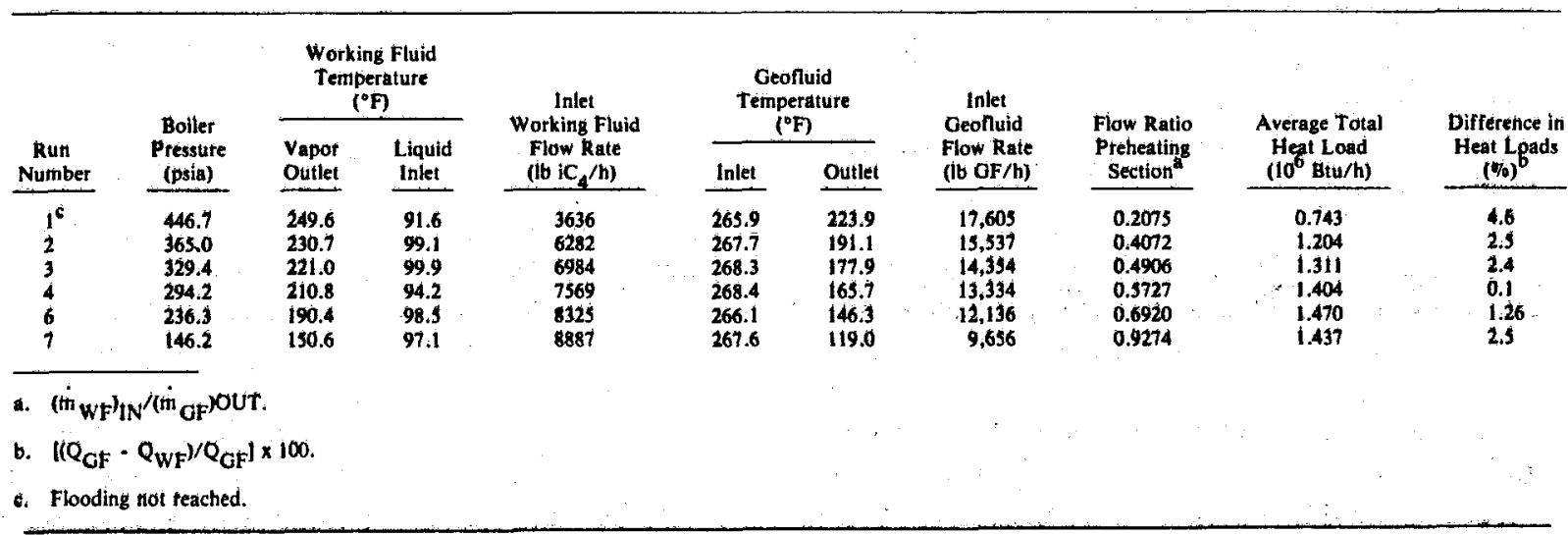


This trend did not follow terminal velocity prediction (see Figure 10), which estimated an almost constant terminal velocity over the range of conditions considered. It should be noted that the terminal velocity prediction considers only a single drop system (no interference from adjacent orifices) and does not consider the drop formation processes (the smaller drops formed at the higher orifice velocities).

4.3.1 Thermal Performance. The data provided in Table 3 indicates that with the exception of Test Run 1, the heat balances in the DCHX unit were good and all were within the range of error one might expect with the instrumentation used (within 5\% was considered acceptable). The data collected for each of the near flooding conditions listed in Table 3 were input into a program developed for the analysis of the thermal performance of the DCHX preheating section. The results of the DCHX thermal analysis for each of these conditions at the measured flows, temperatures, and the design individual tray efficiency of $70 \%$ are shown in Figures 11 through 16. These figures show the predicted column temperature profile for the measured parameters and the selected tray efficiency along with the measured column temperature profile. With some exceptions, the data in these figures fits the predicted performance curves fairly well. The exceptions are most apparent in the results for Test Runs 4 and 6 (Figures 14 and 15) where the predicted performance deviates from the actual data in the upper preheating section. It was found that the deviation at the upper end of the preheating section, i.e., Plates 8 through 17, were the result of a poor preheating section heat balance, which could be corrected through an adjustment of the flow rate and/or the temperatures. A deviation in the lower end of the preheating section i.e., Plates 1 through 8, resulted from an incorrect efficiency assumption.

4.3.1.1 Determination of Tray Efficiency. The data for each of the test runs was adjusted to balance the preheating section heat loads that produced good agreement between the measured and predicted temperature profiles in the upper preheating section (near the boiling trays). This was accomplished using two methods; adjustment of the mass flow ratio or adjustment of the geothermal fluid outlet temperature. The individual tray efficiency was then adjusted until the predicted geothermal fluid temperature profile best matched

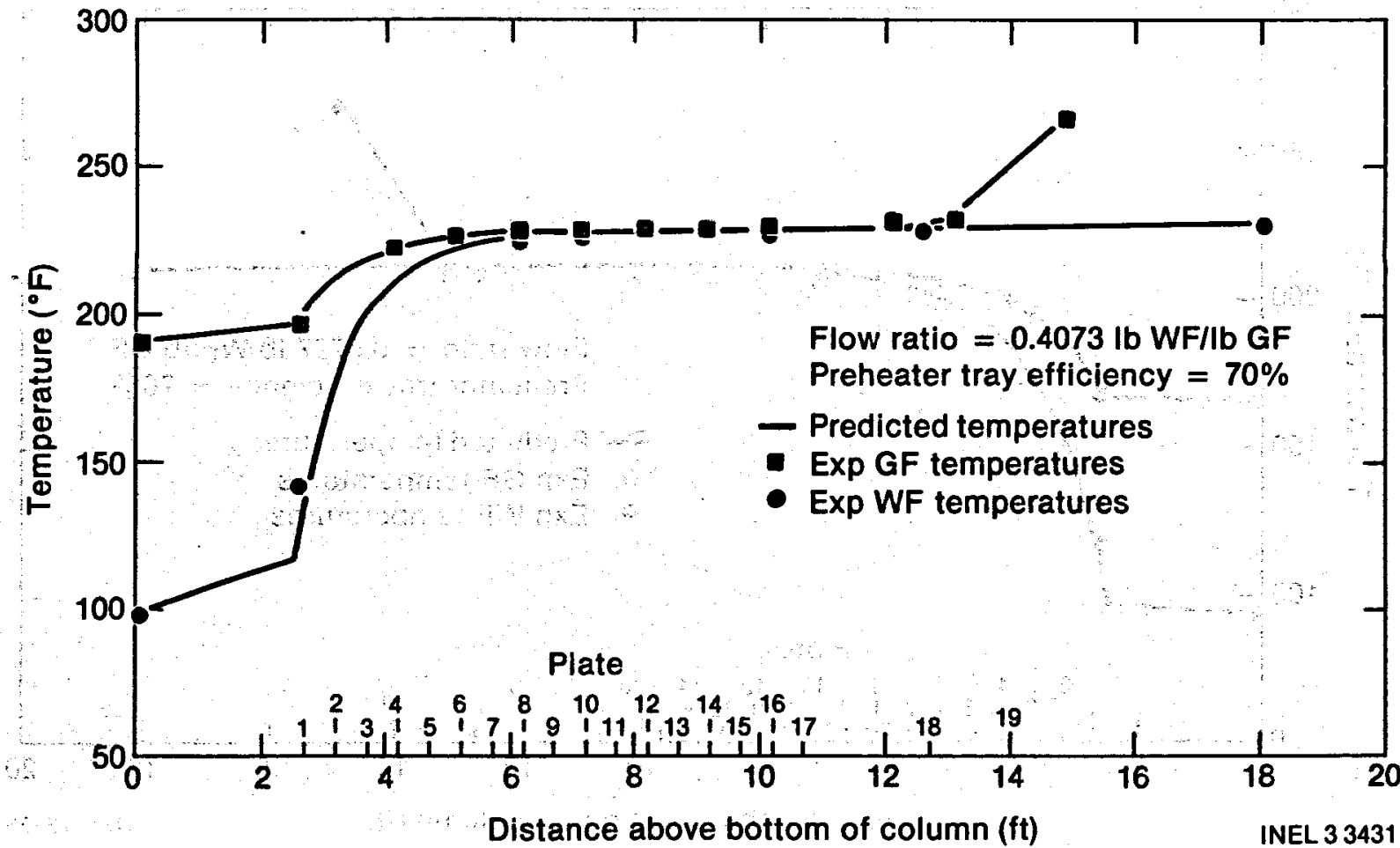

Figure 12. Column performance for Run 2 compared with design tray efficiency. 


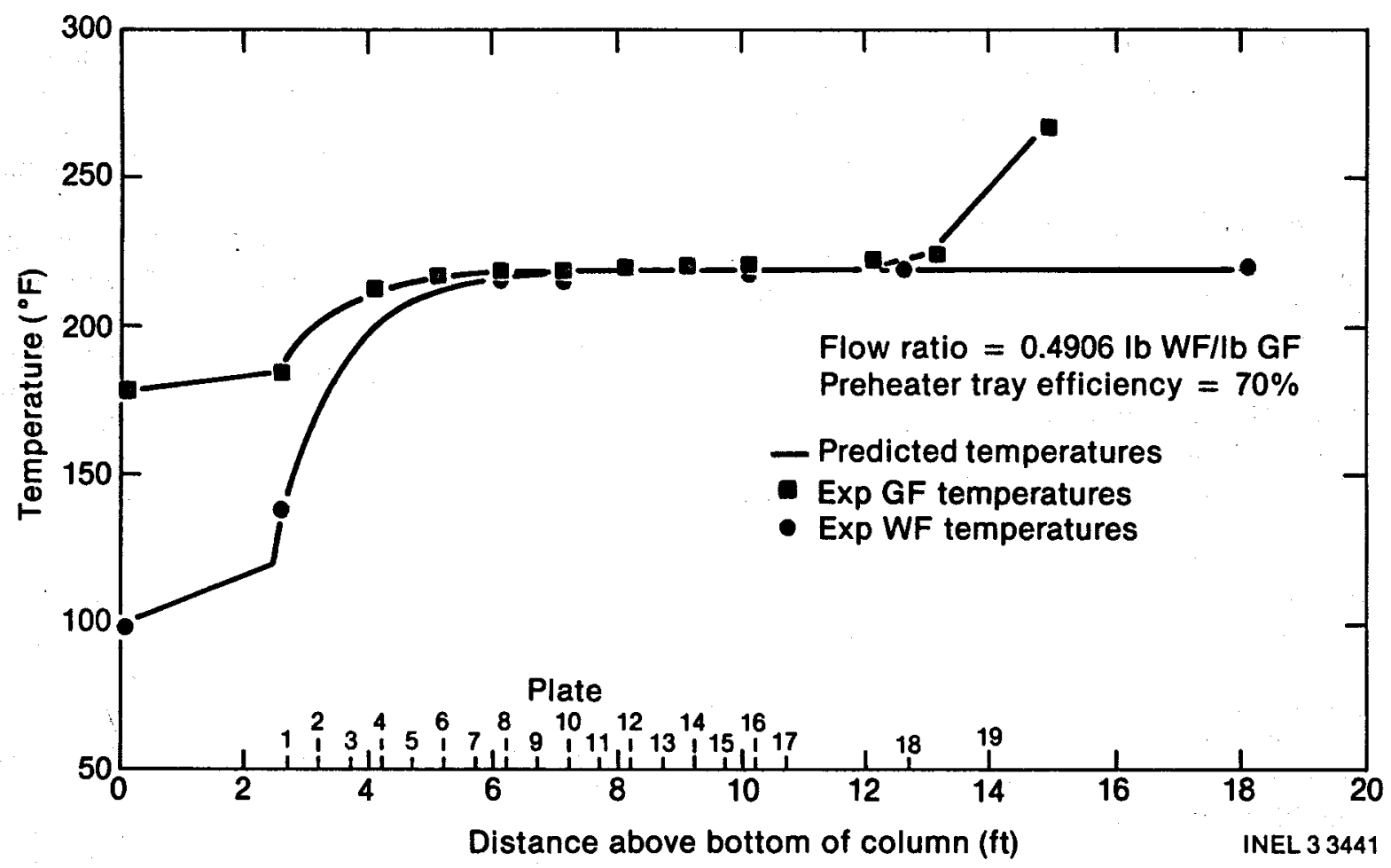

Figure 13. Column performance for Run 3 compared with design tray efficiency.

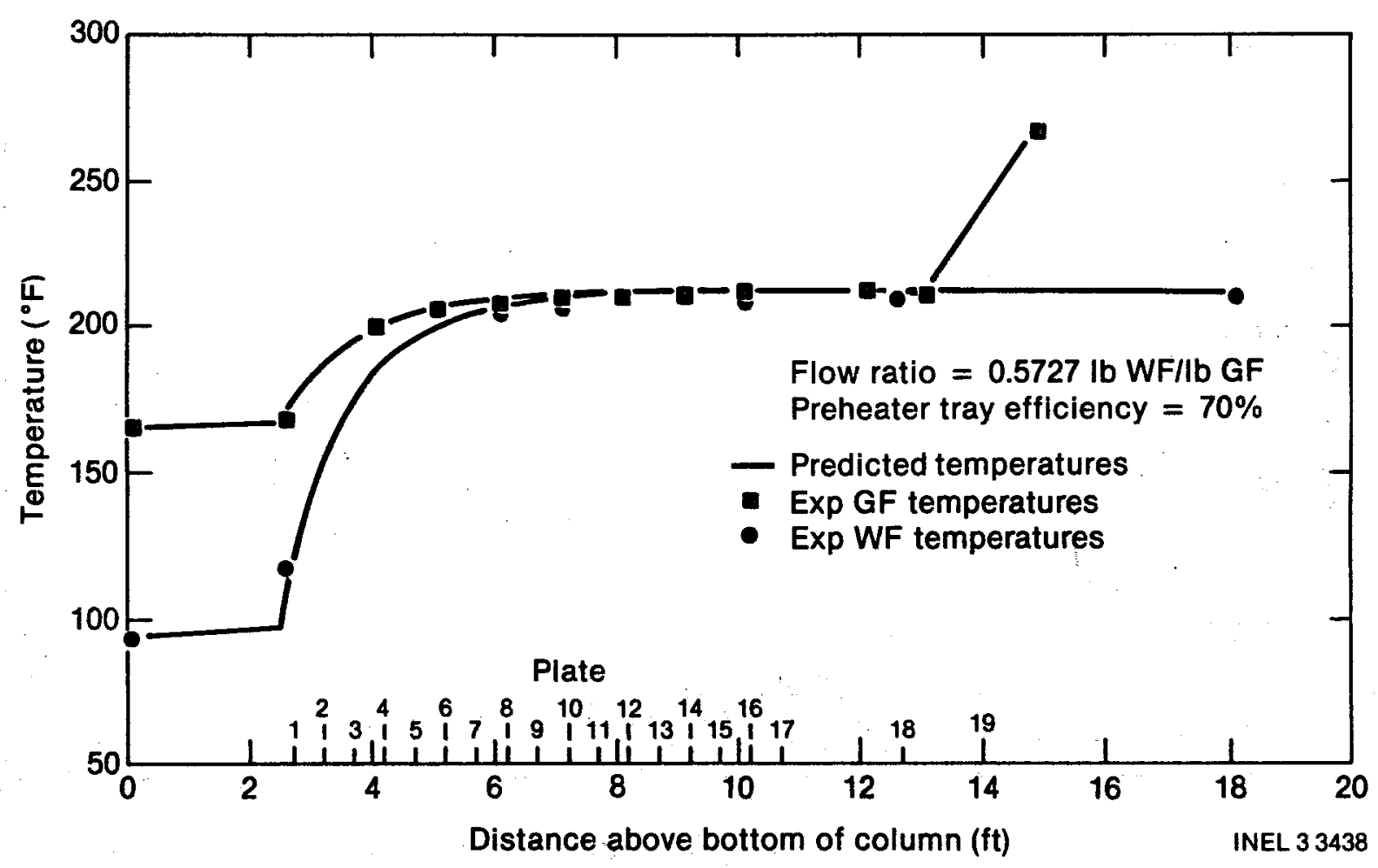

Figure 14. Column performance for Run 4 compared with design tray efficiency. 


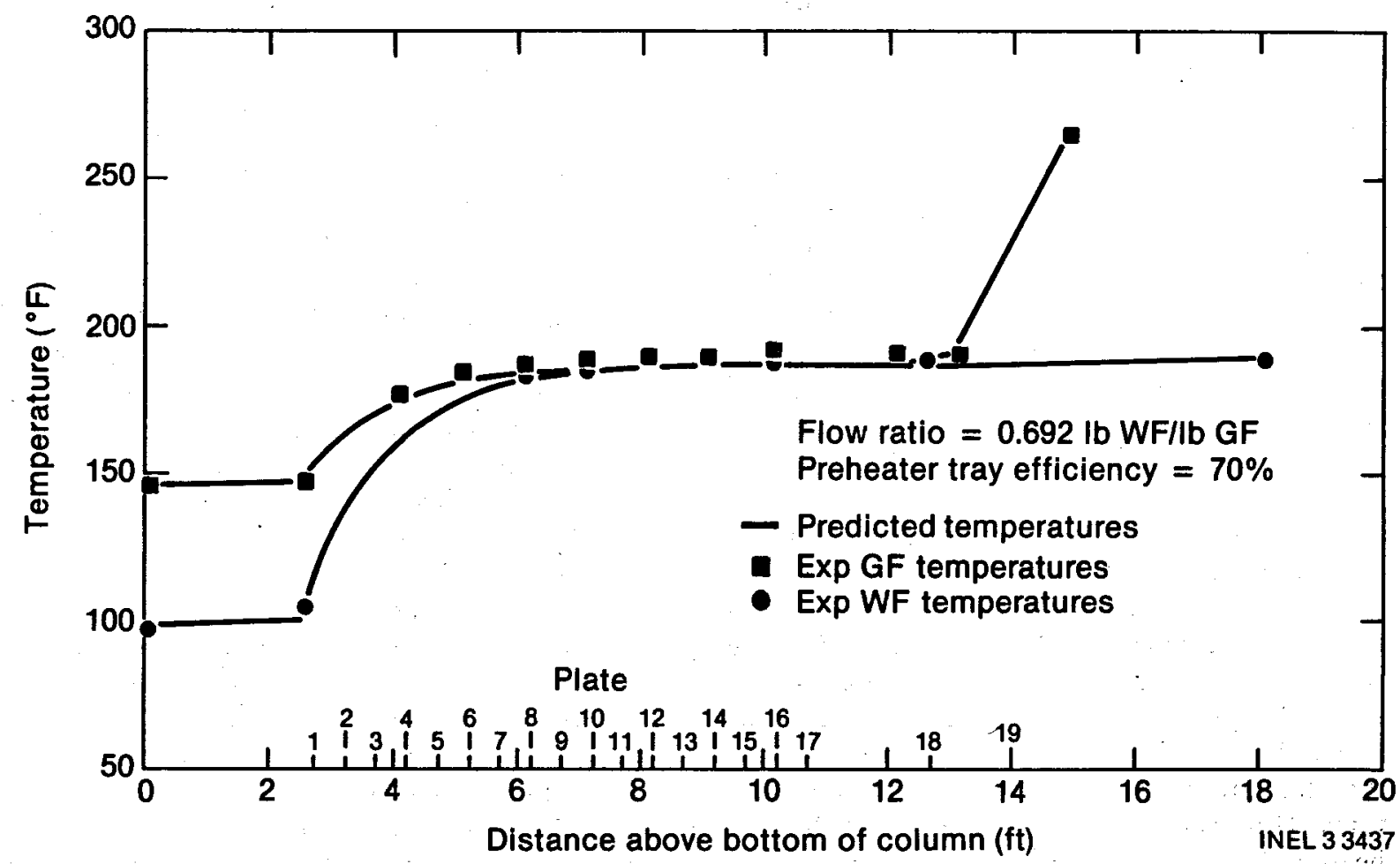

Figure 15. Column performance for Run 6 compared with design tray efficiency.

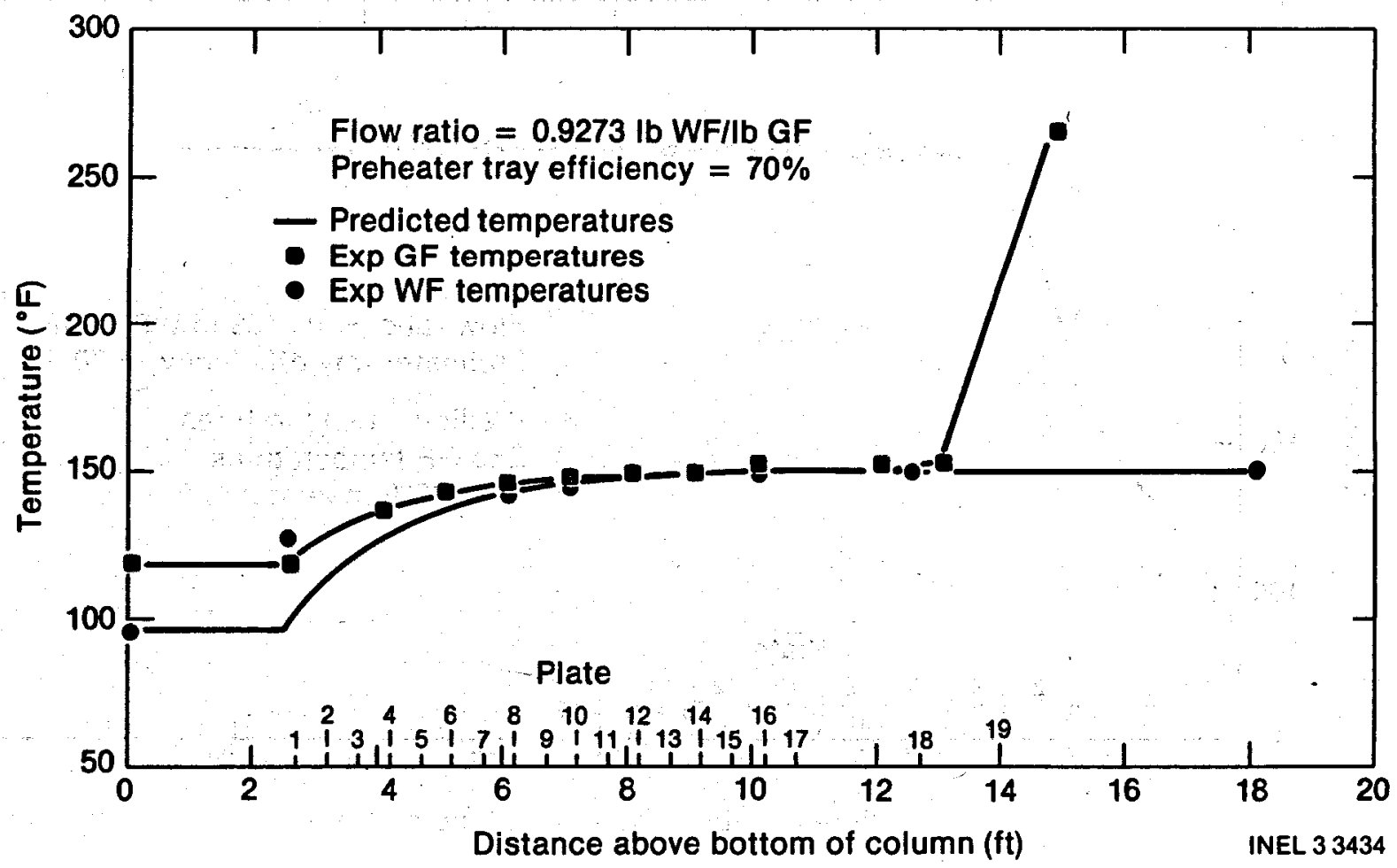

Figure 16. Column performance for Run 7 compared with design tray efficiency. 
the measured profile along the entire length of the column. The results of the heat balance and tray efficiency adjustment for the near flooding conditions are shown in Figures 17 through 22. For the analysis shown in these figures, the heat balances were adjusted by varying the mass flow ratio. When the outlet temperatures were adjusted, similar results were obtained. Except for Test Run 1 (Figure 17) the tray efficiencies that best fit the measured profile, were at the design value of $70 \%$ or slightly higher (up to $74 \%$ ) indicating that from the thermal standpoint, the column was performing as designed.

The effect of individual tray efficiency on the column temperature profile is demonstrated in Figure $\mathbf{2 3}$ for the conditions in Test Run 3. In this figure, predicted column temperature profiles are shown at three different efficiencies $(50,70$, and $90 \%$ ). In all three cases, by the time the fluids reach the last preheating tray, above Plate 17, they have reached essentially the same temperatures. However, in the lower portion of the preheating section, the assumed efficiency does have a considerable impact on the predicted profile. If the trays had an efficiency of $50 \%$, most, if not all, of the trays would be required to bring the working fluid up to the boiling temperature. At a $90 \%$ tray efficiency there is an excess of preheating trays in the column. It is apparent from these predicted profiles that for the conditions in this test run, a tray efficiency of $70 \%$ produces a temperature profile that comes quite close to matching the test data.

In the temperature profiles shown in Figures 11 through 23 , it is apparent that some heat transfer occurred in the column before the working fluid entered the first tray or heat transfer zone between Plates 1 and 2. This heat transfer was occurring in the tube (pipe) that brought the working fluid into the downcomer region under Plate 1 and in the region between the discharge of this nozzle and the coalescing working fluid layer under Plate 1 (see Figure 4). Initially it was suspected that the temperature probe had not been placed properly. In examining the profiles, however, it was noted that the geothermal fluid temperature decreased from the downcomer leaving Tray 1 (above Plate 1) to the column outlet. Since the column was not near the flooding conditions, this temperature change could not be attributed to working fluid carryunder and must have been the result of a heat exchange with the working fluid.

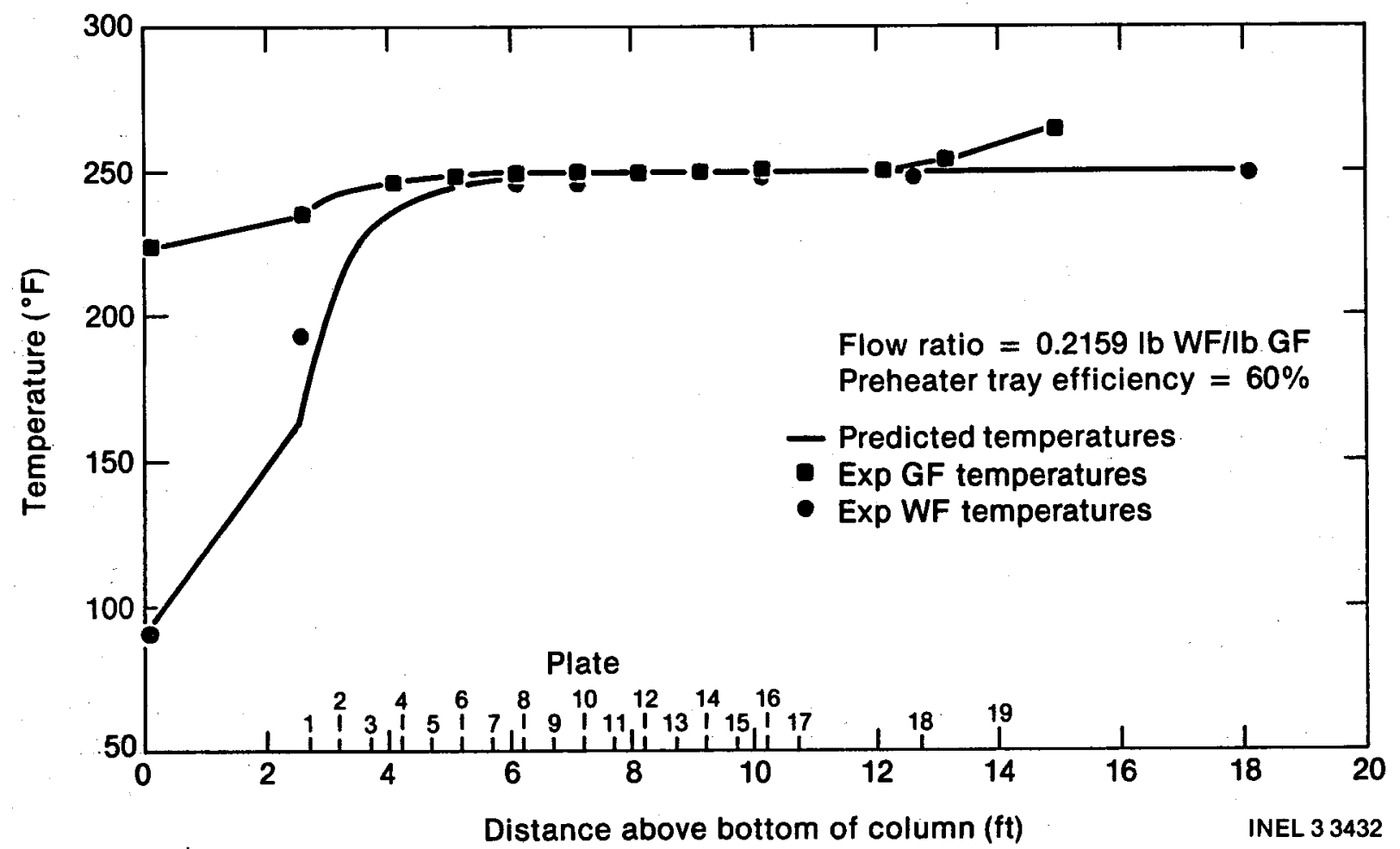

Figure 17. Column performance for Run 1. 


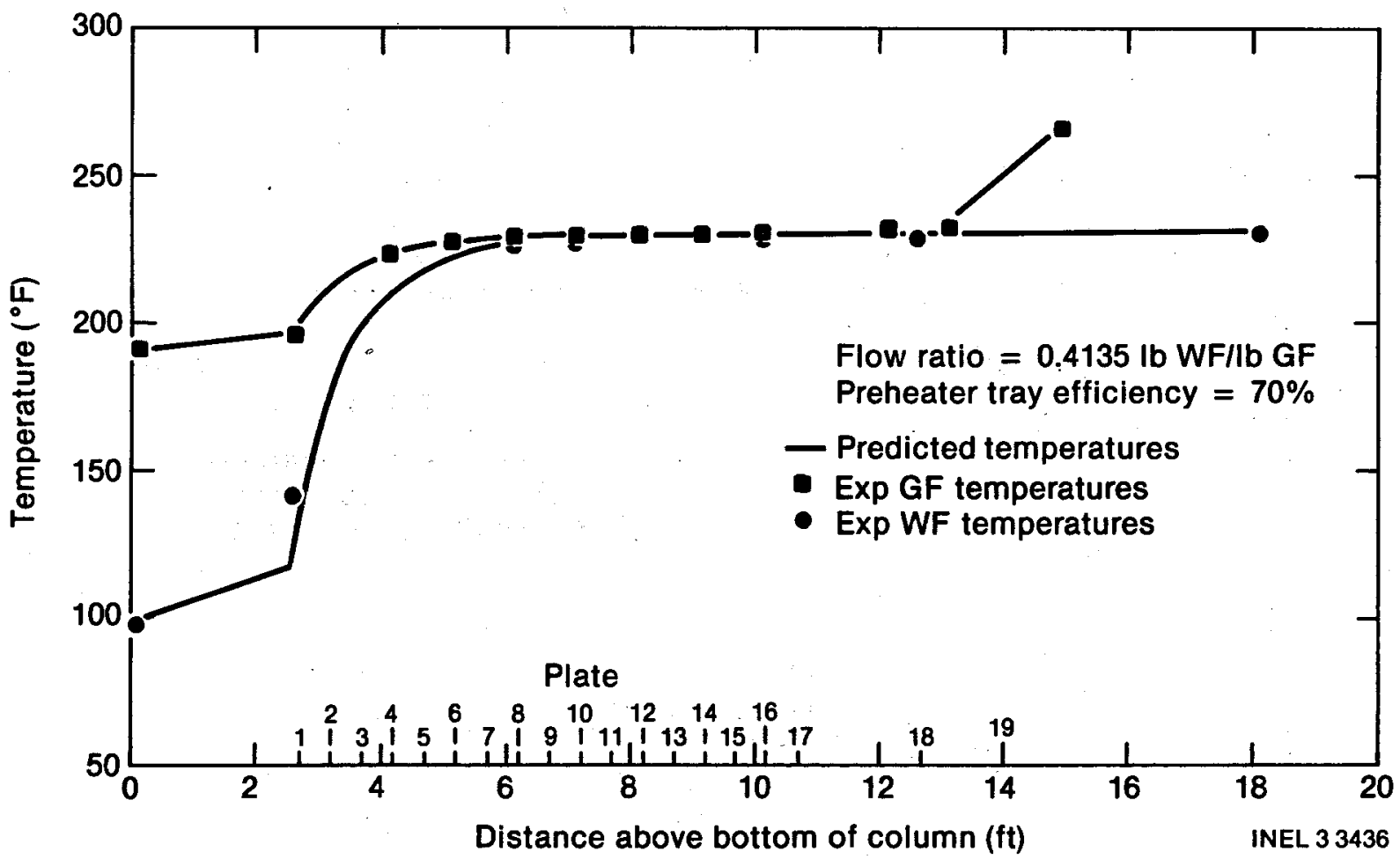

Figure 18. Column performance for Run 2.

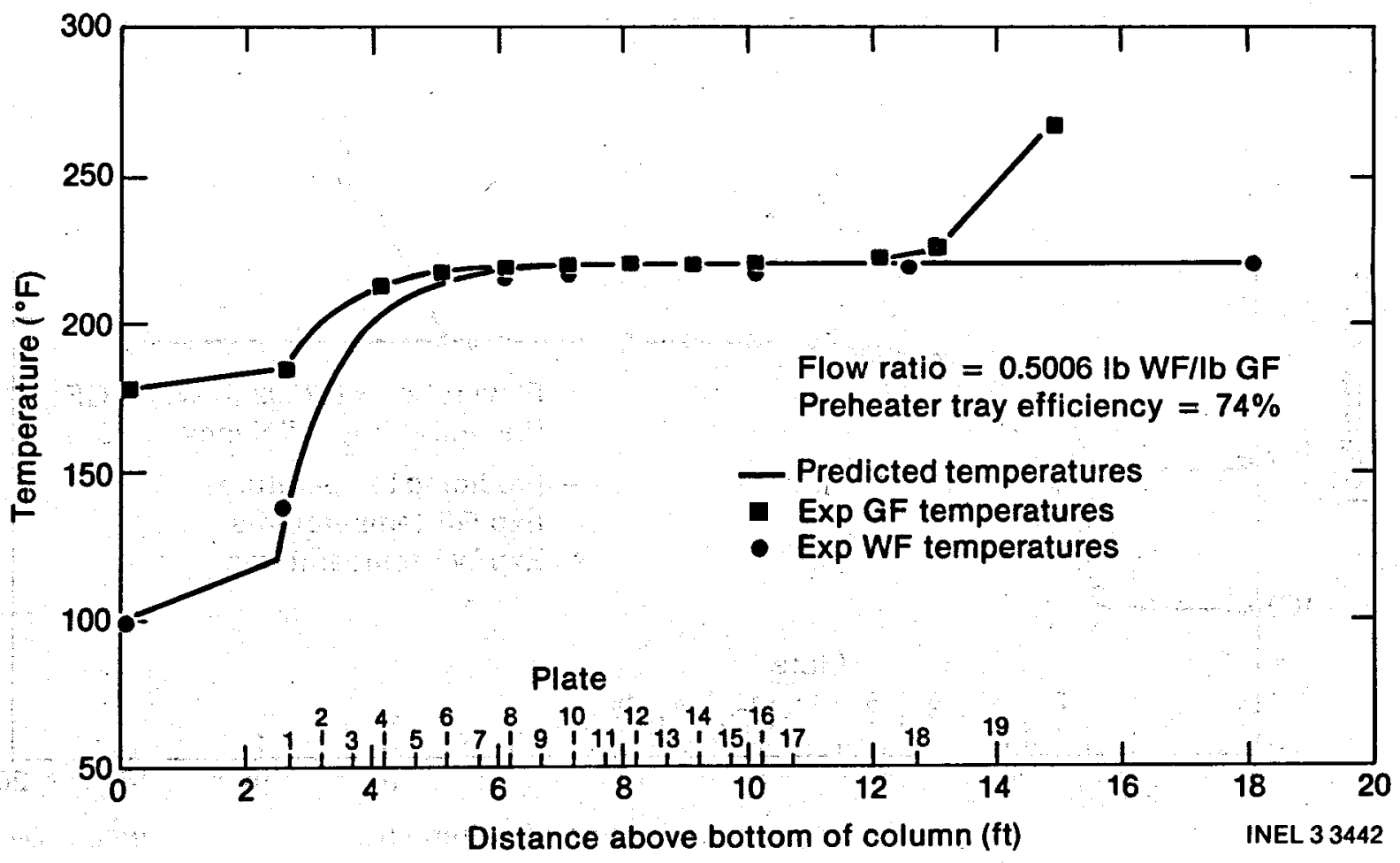

Figure 19. Column performance for Run 3. 


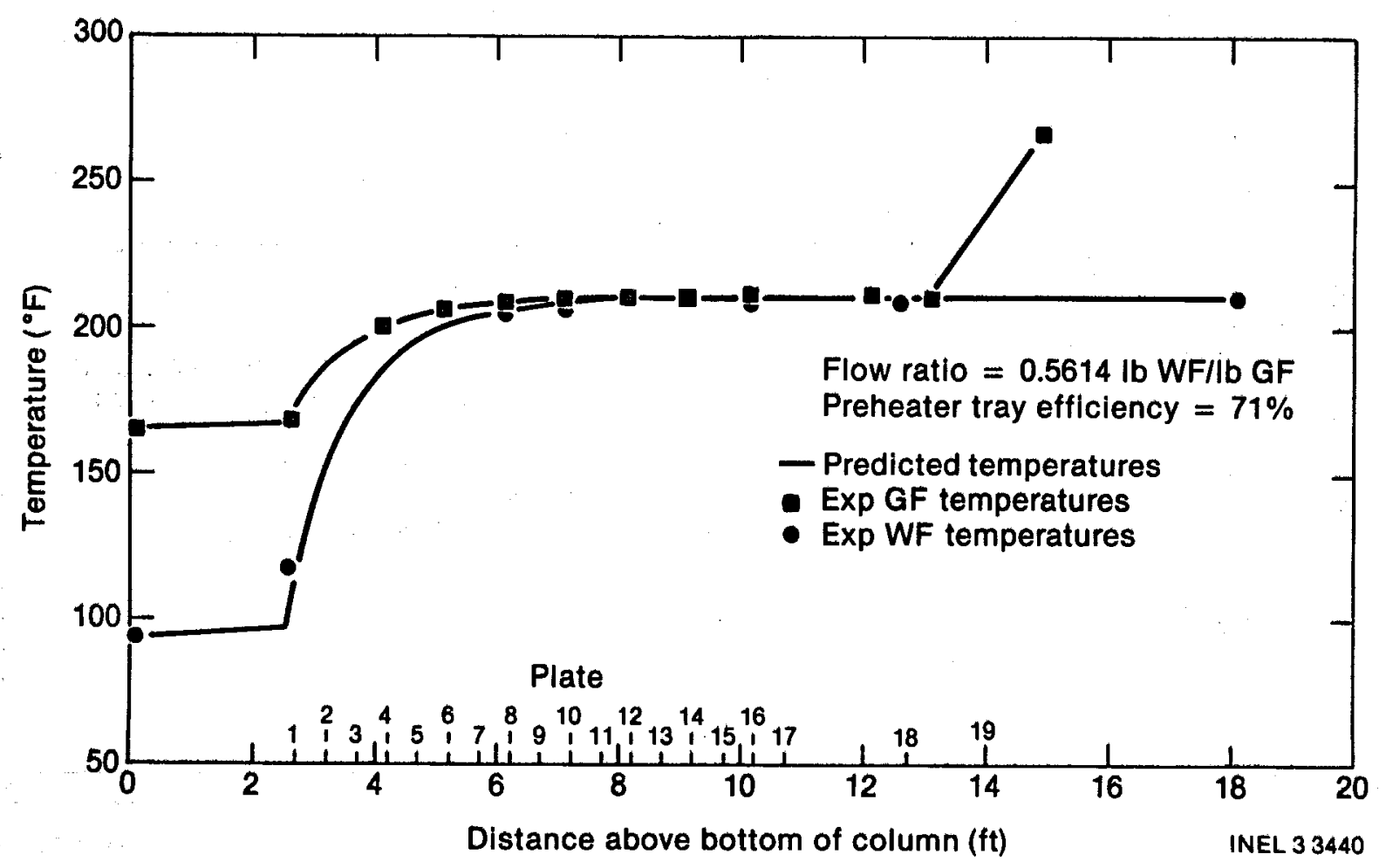

Figure 20. Column performance for Run 4.

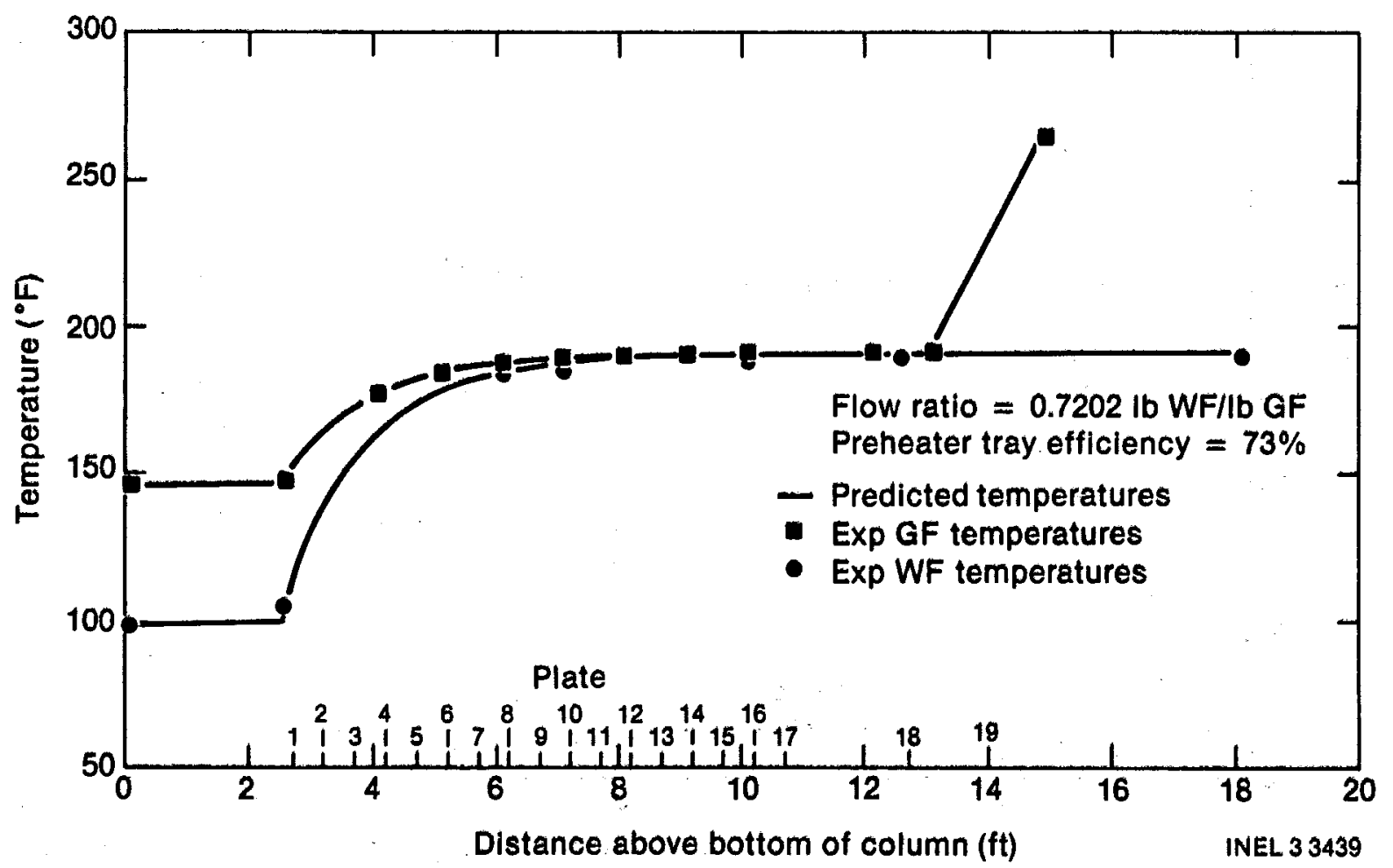

Figure 21. Column performance for Run 6. 


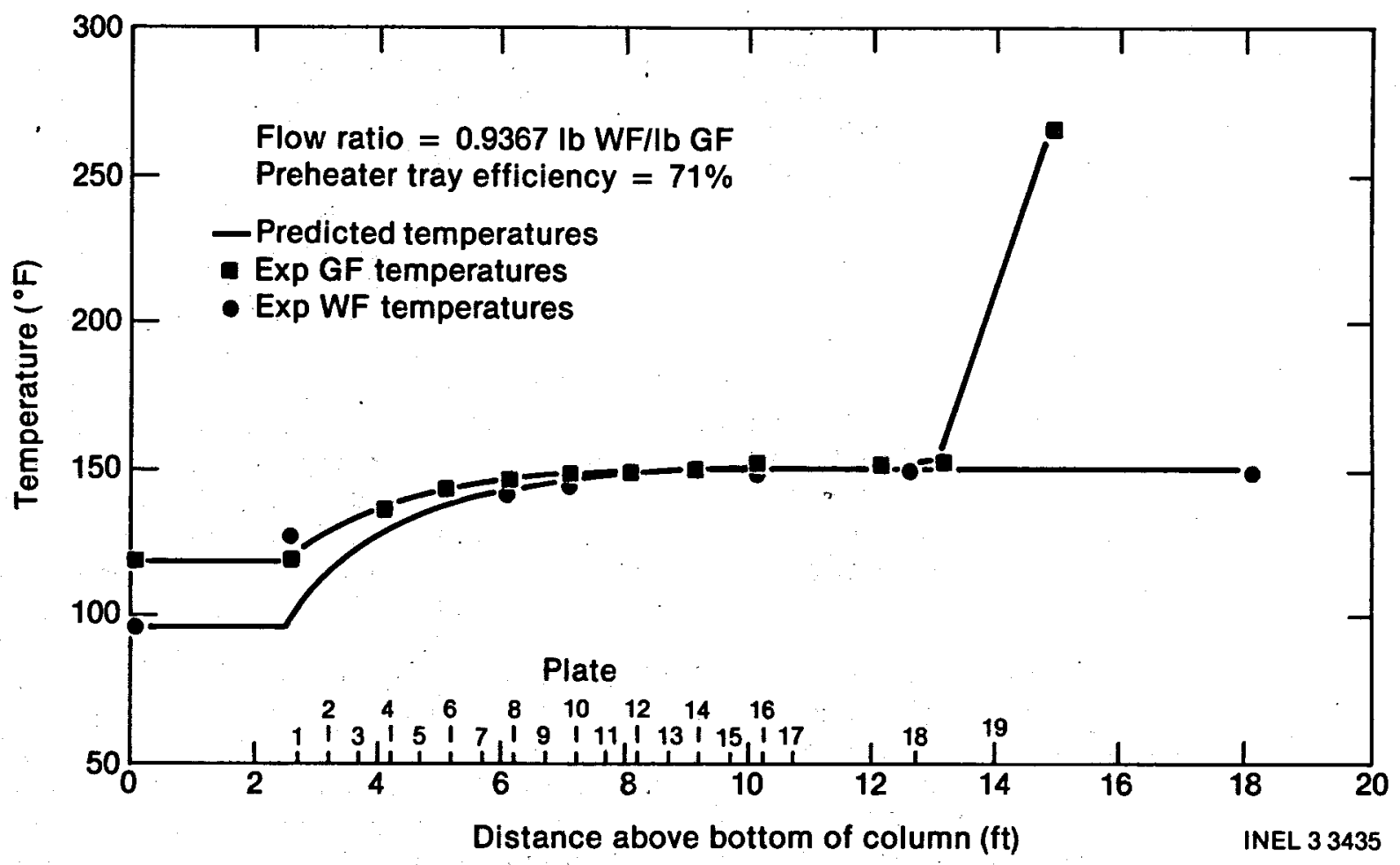

Figure 22. Column performance for Run 7.

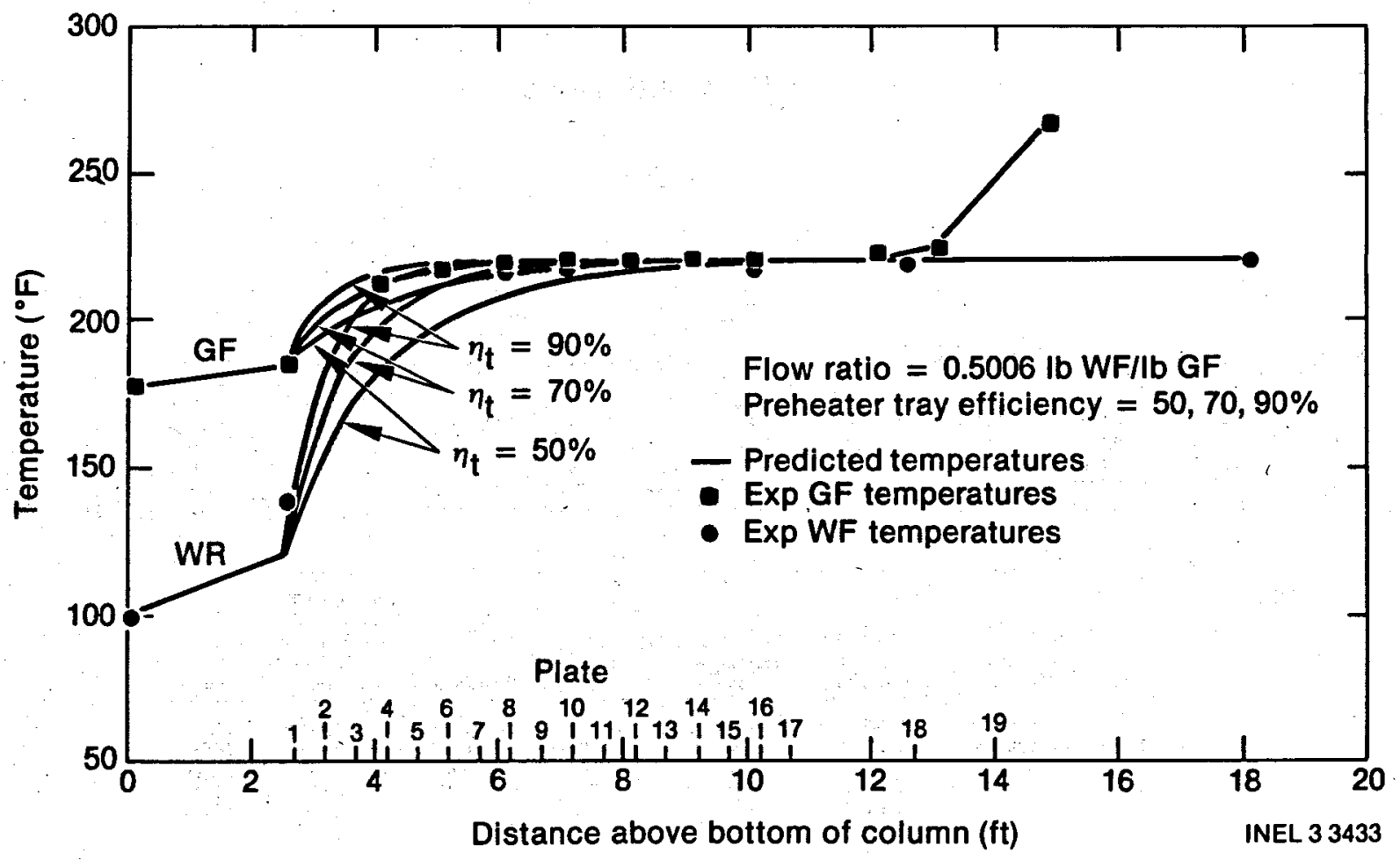

Figure 23. Column performance for Run 3 showing effects of tray efficiency. 
This temperature change was most significant at the lower working fluid flow rates (see data for Test Run 1, Figures 11 and 17) and decreased as the working fluid flow rate increased (see data for Test Run 7, Figures 16 and 22). Although the temperature change in the geothermal fluid decreased with an increase in the working fluid flow rate, the working fluid temperature measurement under Plate 1 continued to introduce inconsistencies (see data for Test Run 7) that were not resolved. In the analysis of the data, this region under Plate 1 was defined as a tray or heat transfer zone (named Tray 0 ) and an efficiency calculated for this area. This was done to account for the heat transfer occurring there and provide a more accurate determination of the efficiency of the trays designed to accomplish the heat transfer.

The DCHX thermal performance for these test runs is summarized in Table 4. The individual tray efficiencies are given for both methods of data adjustment for the preheating section, along with the pinch point, heat loads, and volumetric heat transfer coefficients. Trends in the efficiencies are not apparent except in the region under Plate 1 , which was termed the distributor tray, Tray 0 . This efficiency generally decreased with an increasing working fluid flow rate a behavior that would be expected because the layer of working fluid should become thicker as the flow rate increases, decreasing the size of this heat transfer zone. Although it is difficult to identify trends in the preheating tray efficiency, it is significant that the efficiencies obtained (except in Test Run 1 that was not brought to flooding) were equal to the design value of $70 \%$. Boiling tray efficiencies were calculated using a combination of temperature measurements and predicted enthalpy changes. The zero-percent tray efficiencies obtained in Test Runs 4 and 6 for Plate 18 are suspect given that this efficiency depends on a geothermal fluid temperature measurement in a region where neither fluid is the continuous fluid, and in a sense a boiling pot exists. It would appear from the data, that as the boiling heat load increases and working fluid flow rate increases (geothermal fluid flow rate decreases) the boiling shifts from occurring in both trays to occurring mainly in the top tray. This might be explained by the lower boiling tray assuming some preheating duty; however, from the analysis of the preheating tray performance, it would appear that there is an excess of preheating trays in the column. Given the uncertainty in obtaining an accurate intermediate geothermal

Table 4. Thermal performance of $\mathrm{DCHX}$ with isobutane

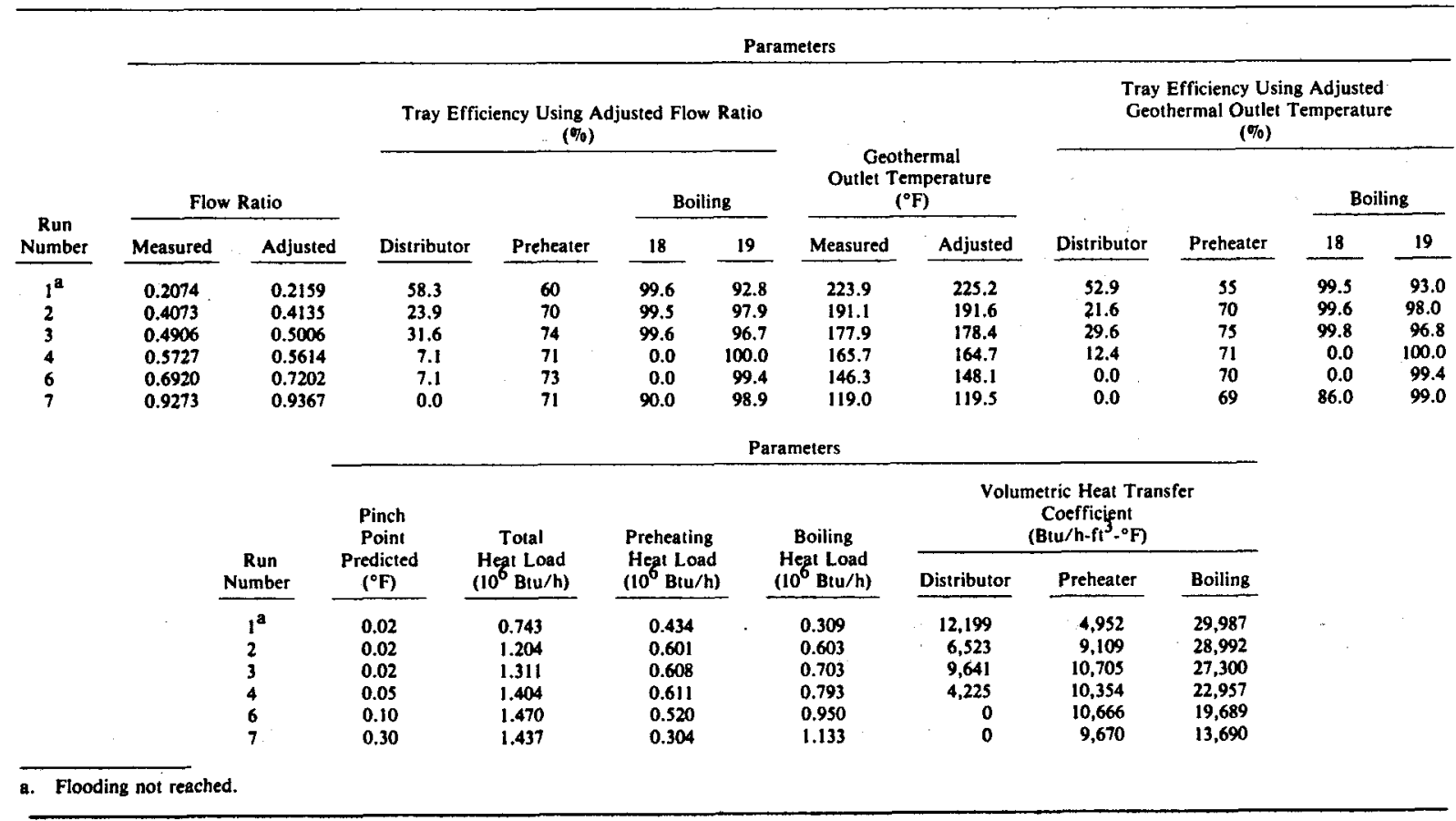


fluid temperature between boiling trays, any significance of apparent trends in boiling tray efficiencies is questionable. The only significant conclusion that one can define is that the two boiling trays, combined, had sufficient capacity for boiling single component working fluids such as pure isobutane.

4.3.1.2 Column Pinch Points. The pinch points for tests conducted were small, much smaller than could be accurately measured with the instrumentation available. In matching the preheating section temperature profile pinch points ranging from 0.02 to $0.30^{\circ} \mathrm{F}$ were obtained. These pinch points increased as the heat load for the column increased. It would appear from the results obtained that the pinch point is more sensitive to the heat load in the boiling section than that in the preheating section (the largest pinch point obtained occurred at the lowest preheating heat load).

4.3.1.3 Volumetric Heat Transfer Coefficients. The volumetric heat transfer coefficients (Uv) were also calculated for the different runs and are presented in Table 4. These values were defined using the heat transfer that occurred in these sections, the total volume in this section where heat transfer could have occurred, and the log mean temperature difference. The log mean temperature differences in the preheating and boiling sections were defined using the pinch point obtained in matching the preheating section temperature profiles. The distributor tray volume was defined as the volume between the working fluid inlet nozzle and Plate 1, enclosed by the downcomer leaving Tray 1. The preheating section volume was defined as the volume of the column from the top of Plate 1 to the bottom of Plate 18, less the volume of the downcomers. The boiling section volume was defined as the volume in the the column from the top of Plate 18 to the bottom of the demister. It should be noted that these volumes are not the volumes in which the heat transfer takes place, although the preheating section volume best approximates the actual volume. In the distributor tray and in the preheating section the layer of working fluid under each plate reduces the actual volume, and the heat transfer done in the inlet pipe is not considered. This layer may have been sufficiently thick in Test Runs 6 and 7 , that there was no space for heat transfer to occur thus producing a zero heat transfer coefficient. The volume used in defining the boiling section heat transfer coefficient is also larger than that actually used. In the boiling section it is difficult to estimate the thickness of the region in which boiling occurs. The bottom of the demister was selected, as this represents the upper limit as far as the thickness of the boiling region is concerned. (If the boiling occurred at a level above the demister, excessive carryover of water could occur and the column would be unstable.) Perhaps the most significant observation one might make from these heat transfer coefficients is that the Uv values for the preheating section are relatively constant. This may be due to the fact that the preheating occurs over a fairly well defined region, and there is not the same degree of uncertainty in the volume to use. The decreasing boiling tray Uv with increasing heat load is rather disturbing as it is expected that the volume actually required for boiling would increase with heat load. Thus the Uv values at the lower boiler heat loads would be even higher if actual volume were used. Trying to compare the Uv values between test runs or for different heat exchangers is difficult unless volumes and pinch points are well defined. In the case of this heat exchanger unit, questions relative to the actual pinch points and volumes in which heat transfer occurs produce sufficient uncertainty to not merit more detailed comparisons of Uv values with other heat exchangers.

\subsubsection{Hydraulic Performance}

4.3.2.1 Fluid Velocities Near Flooding. The fluid flow rates listed in Table 3 are those obtained in the DCHX unit just before the flow change that produced flooding and approximate the upper mass throughput limits for this column. As mentioned earlier, flooding in the DCHX, as defined in this report, was that point where the operation of the column became unstable and was characterized by very large carryunder. Carryunder in this instance is a qualitative indication measured by the size of the flame present over the tank into which the geothermal fluid discharged. (A continuous pilot flame was maintained over the tank to burn off any working fluid in the geothermal fluid.) Carryunder was noted at lower flow rates (again as a flame on the tank water level), however the column operated stably at these flow rates ( $\sim 16$ to 20 gpm working fluid).

The velocities for the "near flooding" conditions in Test Runs 2, 3, and 4 are shown in Figure 24 as the working fluid hole velocity and 


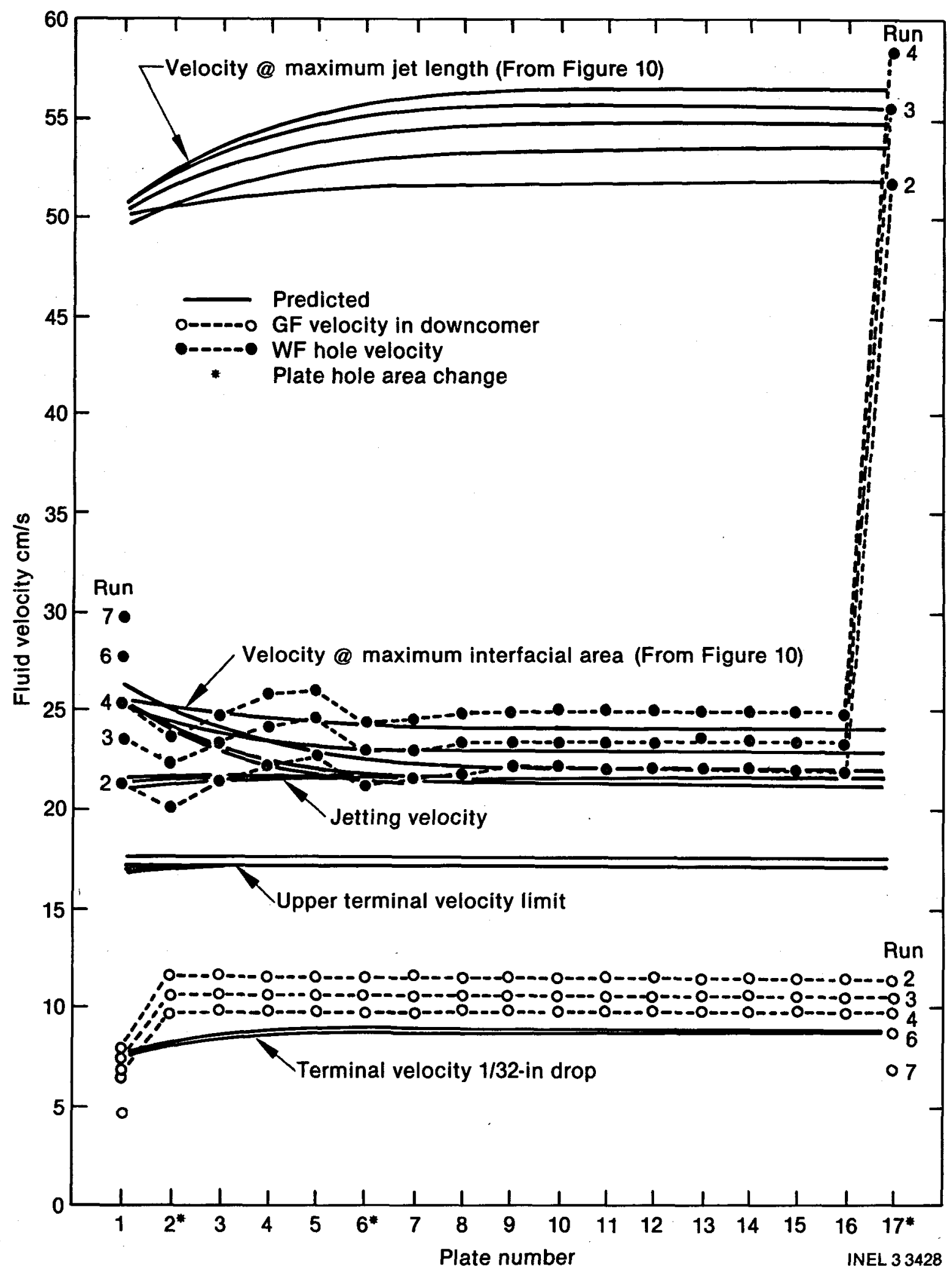

Figure 24. Comparison of predicted and near flooding fluid velocities. 
the geothermal fluid downcomer velocity for each plate in the preheating section. Also shown are the predicted velocities from Figure 10 and the geothermal fluid downcomer and working fluid hole velocities at Plates 1 and 17 for Test Runs 6 and 7.

The geothermal fluid velocities (shown as open circles) in the downcomer region are below the predicted limiting terminal velocity for all the test runs. For Runs 2, 3, 4, and 6, the geothermal fluid velocities in the downcomers for Plates 2 through 17 are equal to (Run 6$)$ or exceed $(2,3$, and 4$)$ the predicted terminal velocity for a $0.0794 \mathrm{~cm}$ (1/32-in.) drop. Geothermal fluid velocities were lower in the downcomer leaving Tray 1 as this downcomer was designed with $\sim 40 \%$ more crosssectional area to decrease the velocity and reduce the potential for mechanical entrainment of the working fluid in the outlet geofluid. The data implies that a downcomer sized for a $0.0794 \mathrm{~cm}$ (1/32-in.) diameter drop terminal velocity would allow for continuous fluid velocities near the operating limits encountered with the DCHX.

The working fluid hole velocities at the near flooding conditions for the test runs are, with the exception of Run 2 , above the velocity predicted for jet formation. The hole velocity for Run 2 is above the predicted jet velocity from all the plates, except Plates 2 and 6 where the hole area (total) increases. For the most part, the working fluid hole velocity data for all of the test runs approximates the predicted velocity where the maximum interfacial area (minimum average drop size) occurs. The plate hole area changes (increase in the number of perforations in the plate) designed into the column by the designer (Wahl), produced a working fluid velocity pattern similar to that predicted for maximum interfacial area velocity. The data implies that the working fluid throughput limits encountered by the column generally correspond to the predicted velocity that produces the minimum average drop size (maximum interfacial area) as the working fluid leaves the plate perforations. The correlation that predicted this average drop size produced an estimated average drop diameter in the range of $0.5 \mathrm{~cm}(\sim 1 / 5-$ in. $)$. A drop of this size would require a geothermal fluid velocity at the limiting terminal velocity to be mechanically entrained and carried under. Unfortunately, these correlations do not provide a drop size distribution so that one could estimate the number of these drops that might have been carried under at the geothermal fluid velocities encountered.
The DCHX was designed with the upper preheating tray (Plate 17) to allow a portion of the working fluid to be removed from the column at or near the saturation temperature. To ensure that the fluid under Plate 17 being removed was working fluid and not geothermal fluid, the total hole area in Plate 17 was reduced in order to backup or thicken the layer of working fluid under the plate. This reduction in hole area $(\sim 60 \%)$ resulted in very high working fluid hole velocities at the operating limits (see Figure 24). Except for the conditions in Test Run 2, the velocities from the performations in Plate 17 exceeded those predicted for maximum jet length and the resulting irregularity in the size of drops formed from the breakup of the jet. (The velocities for Test Runs 6 and 7, not shown in Figure 24, were 61.2 and 60.7 $\mathrm{cm} / \mathrm{s}$, respectively.) It appears that this condition was occurring in Plate $\mathbf{1 7}$ near the operating flow limits encountered, however, its effect on the column hydraulics is difficult to define. If a number of small drops were formed and entrained in the geothermal fluid leaving Tray 17, they could begin rising when the geothermal velocity slows over Plate 16, or they could be carried on farther and/or out the bottom of the column.

At this point, without removing or modifying Plate 17, it is not possible to associate the column operating hydraulic limits with either the maximum jet length velocity at Plate 17 , or the maximum interfacial area velocity in the remainder of the column. It is also possible that neither of these represent an operating limit, though at this time they are the most logical candidates.

4.3.2.2 Working Fluid Velocity for Maximum Host Transfer. The working fluid velocity at the maximum interfacial area condition is recommended by Jacobs and Boehm ${ }^{4}$ as the maximum hole velocity to use in designing a sieve-tray direct-contact heat exchanger. If this velocity does produce the maximum surface area it should provide the most efficient heat transfer operating condition. The tray efficiencies of two of the test runs (Runs 3 and 4) were examined as a function of flow rate as the column was brought to the flooded condition. In both cases the tray efficiency increased as the flow rate increased, although at the highest flow for Test Run 4, the efficiency decreased slightly. The tray efficiencies for these two runs as well as the efficiencies at the maximum flow conditions for the other test runs are shown in Figure 25. Also shown are the flow rates at which jetting and the maximum interfacial area condition are predicted to 


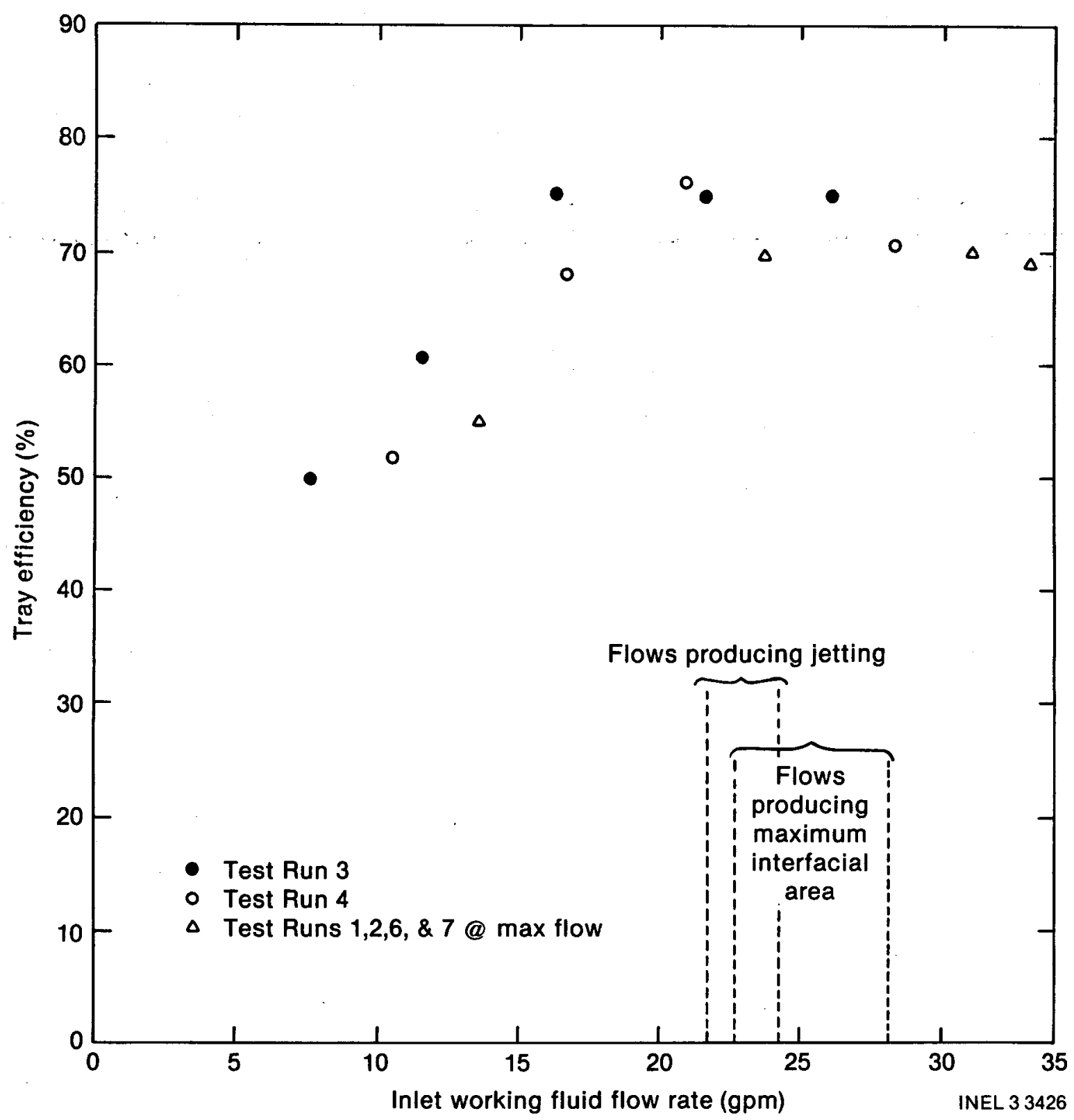

Figure 25. Variation in DCHX preheater tray efficiency with working fluid flow.

occur in the column. The data indicates that the tray efficiency does increase with working fluid flow, and suggests that it may peak at an inlet flow rate around $20 \mathrm{gpm}$ and decrease slightly as flow continues to increase. The data also indicates that the tray efficiency reaches its peak (if it does in fact peak) or plateau before the predicted maximum interfacial area and before jetting is predicted. At this point no explanation is offered other than the predicted velocity values may have used a interfacial surface tension higher than the actual value. The interfacial surface tension was estimated as the difference between the individual surface tensions. Perry ${ }^{6}$ indicates that this method can be used when data on the mixture is not available, although it does provide a predicted value higher than the actual interfacial tension. If a lower interfacial surface tension were used, the predicted velocities would be lower and a little better agreement between predicted and data would have been obtained.

It is interesting to note that during the operation of the DCHX, carryunder, as indicated by a flame 
on the surface of the geothermal fluid discharge tank, was first noted at the working fluid flow rates of 15 to $20 \mathrm{gpm}$. This corresponds roughly to the flows where the tray efficiency approaches or reaches its maximum. Except for Run 1, where carryunder was noted earlier and geothermal flow rates were higher, this carryunder of working fluid occurred at roughly the same flow each time suggesting perhaps a change in the drop formation mechanism producing smaller drops (perhaps jetting).

4.3.2.3 Comparison with Spray Towers. In comparing spray tower and sieve-tray direct-contact columns as heat exchange devices, the sieve-tray column is reputed to have a thermal advantage, but is said to have a lower mass throughput capacity than a spray tower of similar dimensions. ${ }^{4}$ The tests conducted with the prototype DCHX confirm that the sievetray column provides excellent heat exchange performance. To determine mass throughput capacity of the sieve-tray unit relative to spray towers, the superficial velocities of the sieve-tray DCHX were compared to those of the DSS Engineers Incorporated (DSS) spray tower ${ }^{8}$ and the Barber-Nichols Engineering Company $500 \mathrm{~kW}$ spray tower. ${ }^{9}$ This comparison is shown in Figure 26. The superficial velocity, which was defined as the volume flow rate of a fluid at the bottom of the column divided by the total column cross-sectional area, enables vessels of different diameters to be compared on an equivalent basis. The prototype DCHX data in Figure 26 generally follows the trends indicated by Treybal 10 in his discussion of the flooding limits of different types of direct-contact columns (in mass transfer applications). It is difficult to draw detailed conclusions about the throughput capacity of the sieve-tray unit relative to the spray towers. The throughput performance of the sieve-tray column compares favorably with the design point for the $500 \mathrm{~kW}$ spray tower. This design point, however, does not represent the throughput limits as the $500 \mathrm{~kW}$ column was not operated to flooding. The operating data from the DSS spray tower indicates that during the low temperature cycle testing (low brine inlet and working fluid outlet temperatures), the DSS unit operated at higher relative throughputs than the sieve-tray column. During the high temperature cycle tests, the maximum flow rates at which the DSS spray tower operated stably produced superficial velocities lower than those obtained during operation of the sievetray DCHX. It is not apparent whether this limit

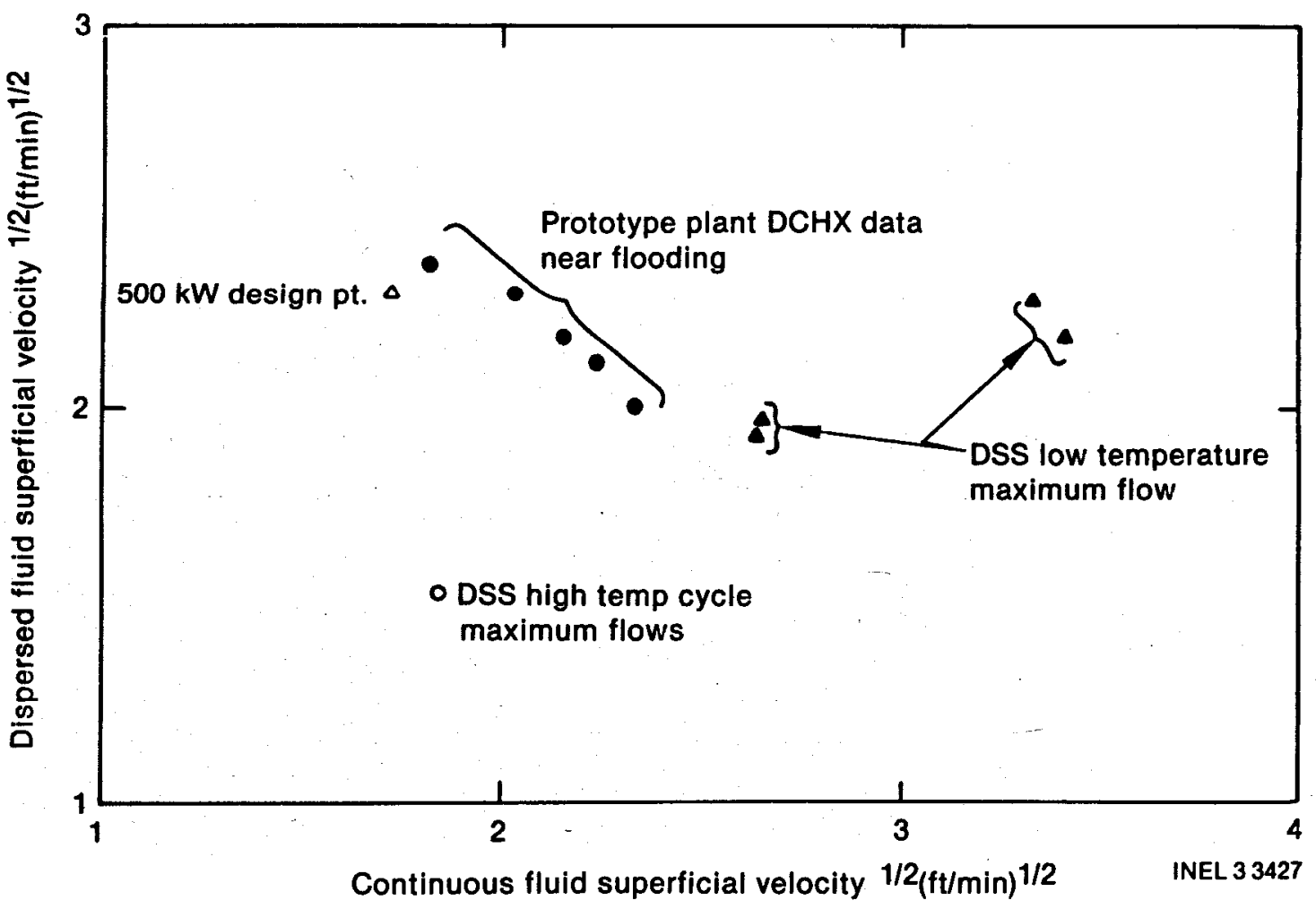

Figure 26. Direct-contact heat exchanger throughput comparison. 
encountered during the high temperature cycle testing is due to flooding or some other factor. Given the throughputs obtained during the low temperature cycle tests, the DSS unit should be able to operate at higher superficial velocities when operated at higher temperatures without flooding (data should follow a trend similar to the sieve-tray DCHX data). If it is assumed then that the higher DSS throughput values represent the flooding limit of that spray tower, the sieve-tray DCHX does have a lower relative throughput capacity. 


\section{TESTING WITH MIXED-HYDROCARBON WORKING FLUIDS}

\subsection{Test Description}

Following the completion of the baseline tests with isobutane, the second sequence of tests with working fluids consisting of different mixtures of hydrocarbons was started. The first fluid tested was a 0.95 isobutane $/ 0.05$ hexane (mass fraction) followed by $0.90 \mathrm{iC}_{4} / 0.10 \mathrm{C}_{6}$ and $0.85 \mathrm{iC}_{4}$ ' $0.15 \mathrm{C}_{6}$ fluids. The plant was then drained and filled with propane and was tested briefly to get a reference data point. Isopentane was then added to the plant working fluid system and the mixture adjusted to a $0.95 \mathrm{C}_{3} / 0.05 \mathrm{iC}_{5}$ composition. After testing this mixture, $0.90 \mathrm{C}_{3} / 0.10 \mathrm{iC}_{5}$ and $0.85 \mathrm{C}_{3} / 0.15 \mathrm{iC}_{5}$ fluids were tested. The different column conditions that were tested are listed in Table 5. Each of the mixtures was tested at three different pressures, however because of the limited time available to complete the mixtures testing, the column was brought to flooding at only one of these pressures. For the other two pressures, the column was brought up to flow rates that began to produce carryunder, allowed to stabilize, and data collected.

Table 5. DCHX mixed fluids test conditions

\begin{tabular}{|c|c|c|c|c|}
\hline \multirow[b]{2}{*}{$\begin{array}{c}\text { Run } \\
\text { Number }\end{array}$} & \multicolumn{4}{|c|}{ Parameters $^{\mathbf{a}}$} \\
\hline & $\begin{array}{c}\text { Mixture } \\
\text { Composition } \\
\end{array}$ & $\begin{array}{l}\text { Working Fluid } \\
\text { Vapor Outlet } \\
\text { Temperature } \\
\left({ }^{\circ} \mathrm{F}\right) \\
\end{array}$ & $\begin{array}{c}\text { Boiler } \\
\text { Pressure } \\
\text { (psia) } \\
\end{array}$ & $\begin{array}{c}\text { Flow Ratio } \\
\left(\dot{\mathrm{m}}_{\mathrm{WF}} / \dot{m}_{\mathrm{GF}}\right)\end{array}$ \\
\hline MX1 & $0.95 \mathrm{iC}_{4} / 0.05 \mathrm{C}_{6}$ & 200 & 223 & 0.47 to 0.72 \\
\hline $\mathrm{MX2}$ & $0.95 \mathrm{iC}_{4} / 0.05 \mathrm{C}_{6}$ & 210 & 252 & 0.41 to 0.66 \\
\hline MX3 & $0.95 \mathrm{iC}_{4} / 0.05 \mathrm{C}_{6}$ & 220 & 284 & 0.34 to 0.61 \\
\hline MX4 & $0.90 \mathrm{iC}_{4} / 0.10 \mathrm{C}_{6}$ & 200 & 192 & 0.51 to 0.73 \\
\hline MX5 & $0.90 \mathrm{iC}_{4} / 0.10 \mathrm{C}_{6}$ & 210 & 219 & 0.44 to 0.67 \\
\hline MX6 & $0.90 \mathrm{iC}_{4} / 0.10 \mathrm{C}_{6}$ & 220 & 248 & 0.37 to 0.61 \\
\hline MX7 & $0.85 \mathrm{iC}_{4} / 0.15 \mathrm{C}_{6}$ & 200 & 166 & 0.44 to 0.72 \\
\hline MX8 & $0.85 \mathrm{iC}_{4} / 0.15 \mathrm{C}_{6}$ & 210 & 191 & 0.45 to 0.66 \\
\hline MX9 & $0.85 \mathrm{iC}_{4} / 0.15 \mathrm{C}_{6}$ & 220 & 218 & 0.38 to 0.60 \\
\hline MX10 & $0.95 \mathrm{C}_{3} / 0.05 \mathrm{iC}_{5}$ & 170 & 392 & 0.90 to 1.15 \\
\hline MX11 & $0.95 \mathrm{C}_{3} / 0.05 \mathrm{iC}_{5}$ & 180 & 440 & 0.80 to 1.10 \\
\hline MX12 & $0.95 \mathrm{C}_{3} / 0.05 \mathrm{iC}_{5}$ & 190 & 494 & 0.70 to 1.00 \\
\hline MX13 & $0.90 \mathrm{C}_{3} / 0.10 \mathrm{iC}_{5}$ & 170 & 349 & 0.80 to 1.10 \\
\hline MX14 & $0.90 \mathrm{C}_{3} / 0.10 \mathrm{iC}_{5}$ & 180 & 395 & 0.75 to 1.05 \\
\hline MX15 & $0.90 \mathrm{C}_{3} / 0.10 \mathrm{iC}_{5}$ & 190 & 446 & 0.70 to 1.00 \\
\hline MX16 & $0.85 \mathrm{C}_{3} / 0.15 \mathrm{iC}_{5}$ & 180 & 352 & 0.70 to 1.00 \\
\hline MX17 & $0.85 \mathrm{C}_{3} / 0.15 \mathrm{iC}_{5}$ & 190 & 400 & 0.70 to 1.00 \\
\hline MX18 & $0.85 \mathrm{C}_{3} / 0.15 \mathrm{iC5}$ & 200 & 436 & 0.65 to 0.99 \\
\hline \multicolumn{5}{|c|}{ Preflasher: opearting at $\sim 40$ psig. } \\
\hline \multicolumn{5}{|c|}{ Vent condenser: not operating. } \\
\hline Cooling & rate: $300 \mathrm{pgm}$. & & & \\
\hline
\end{tabular}




\subsection{Column Operation with Mixtures}

5.2.1 Changes in Composition. The operation, startup, and shutdown of the DCHX with the working fluid mixtures did not vary significantly from the column operation with pure fluids except for two differences. The first noted difference is not unique to a DCHX and would likely affect any binary system using a working fluid comprised of mixtures of hydrocarbons. During the operation with mixtures, it was noted that over a period of several hours of operating, the working fluid composition would change with the amount of the minor component becoming smaller. It was initially suspected that the minor component was being lost to carryunder. The only drops in the column that would be higher in the concentration of the minor component (and thus account for its loss) occur in the boiling region. In order to be carried under, these drops would have to be swept down the entire preheating region of the column without any mixing with the rest of the working fluid. While this may have been possible, it did not seem likely. This conclusion was confirmed when the column was operated with little if any carryunder and the concentration change was still noted.

The problem was resolved somewhat by accident by an observation made during the shutdown of the facility. Each night when the facility was shut down for the day, the water that accumulated in the various traps, strainers, drain lines, etc., in the working fluid system was drained in order to prevent any possible damage or failure due to freezing. This was done routinely during the testing with the pure fluids and was continued during the mixtures operation. During one of these drains, it was noted that the liquid being drained from the water trap was not water but hexane. The accumulation of hexane in this trap and other dead leg (no flow) portions of the working fluid system was then monitored. It was found that while the plant was running, the hexane and water were condensing in locations in the process vapor piping were there was no flow (these locations were cooler relative to the piping that had continuous vapor flow through it). It was suspected that the boiling in the DCHX was incomplete, and that some working fluid drops with higher concentrations of hexane were carried over the top. This may have contributed to the hexane buildup in these locations, however this accumulation was noted at low operating levels in the DCHX and with superheated working fluid vapor at low vapor flow rates. In order to minimize this accumulation of hexane, the dead legs were filled where possible with water. Fortunately the mixture testing was conducted in the spring and summer when freezing damage was minimal and the heat tapes and insulation provided adequate protection against freezing. Although some hexane continued to accumulate (as a liquid) in the process vapor piping after this time, the magnitude of the accumulation was significantly reduced.

5.2.2 Reduced Flow Capacity. The second, and most notable difference between the operation of the DCHX with pure fluids and mixtures was the reduced flow capacity of the column when mixtures were used. The throughput that the column could handle before flooding was inversely proportional to the concentration of the minor fluid (the throughput limit with a $95 \mathrm{iC}_{4} / 5 \mathrm{C}_{6}$ fluid was higher than the throughput with a $85 \mathrm{iC}_{4} / 15 \mathrm{C}_{6}$ fluid). It is felt that the basic cause for this reduced capacity was the inability of the preheating trays to handle boiling. The type of flooding and the level indications in the column were similar to the flooding described in Section 4.2 (operation with isobutane working fluid) when the control system became unstable and the pure component working fluid began to boil in the preheating region. This flooding was characterized by both excessive carryunder and carryover, whereas the flooding limit of the column with isobutane was generally caused by excessive carryunder.

The characteristic of a hydrocarbon mixture to not boil at a constant temperature for a fixed pressure is described below and shown in Figure 27, which is a T-Q plot for a $90 \mathrm{iC}_{4} / 10 \mathrm{C}_{6}$ working fluid. The point where the first vapor bubble is formed, or bubble point, occurs at a lower temperature than the point where the last liquid is vaporized, or the dew point. If one examines the column temperature profile for the same fluid and heater pressure, it is apparent that this working fluid reaches its bubble point while still in the section of the column designed for preheating (refer to Figure 28). Similar temperature profiles for the column operation with other mixtures confirm the observations noted during flooding that it appeared that boiling was occurring in the section of the column designed for preheating. A more detailed discussion of how boiling in this section of the column might adversely affect the column hydraulics is given in Section 5.3.2 on the hydraulic test results. 


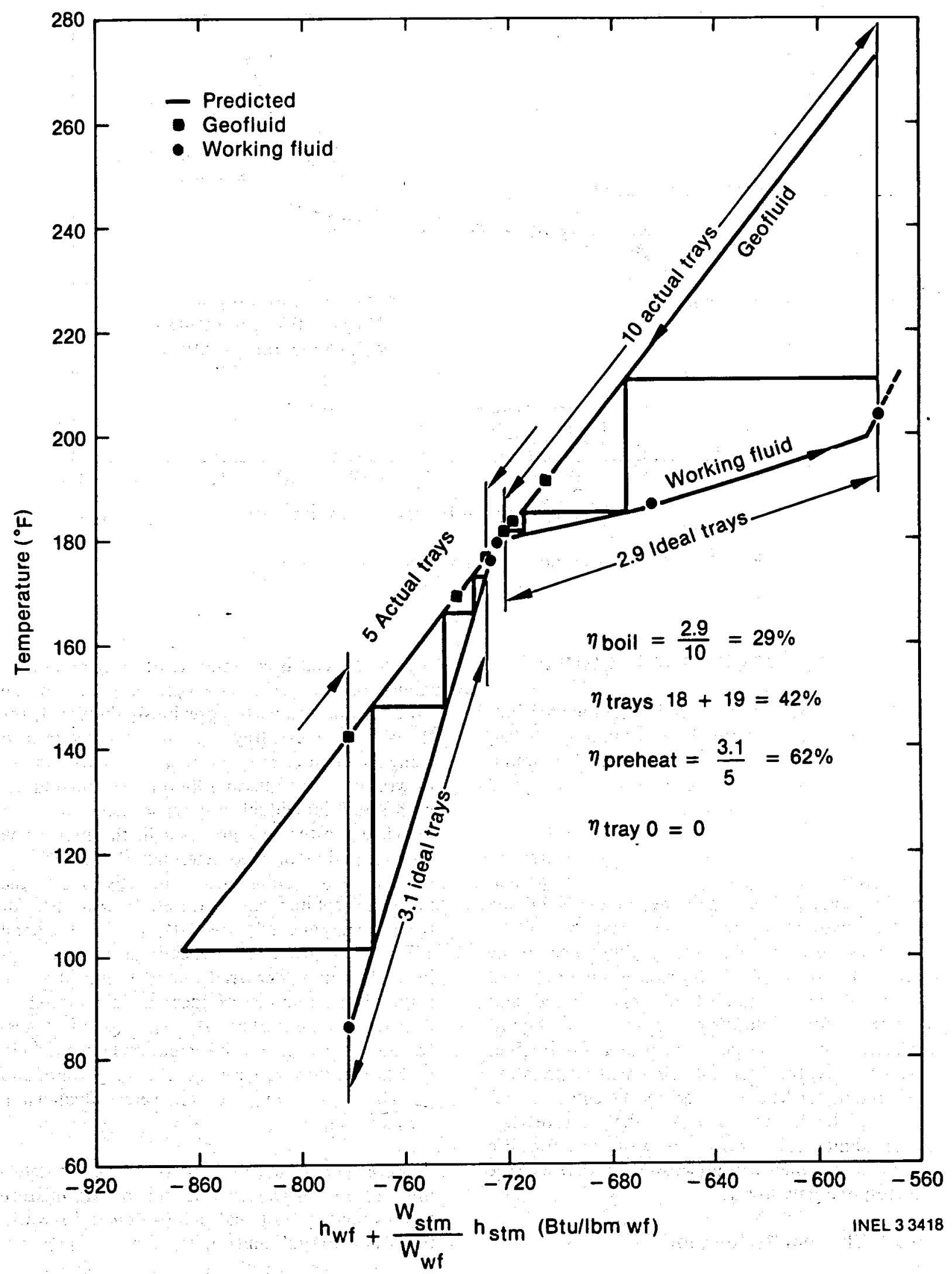

Figure 27. Temperature heat exchanged diagram for test Run MX4, 0.9 isobutane/0.1 hexane. 


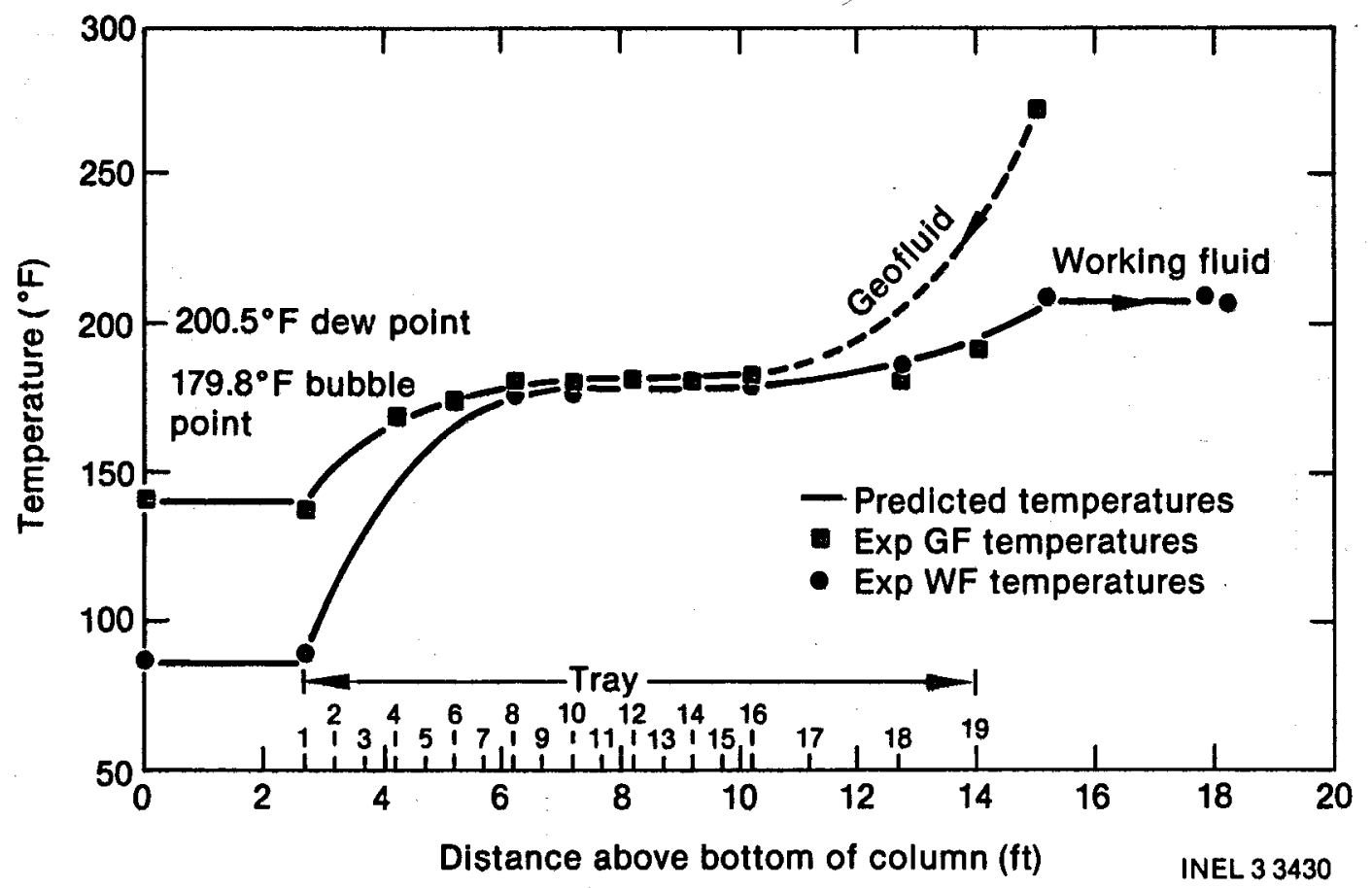

Figure 28. Column temperatures for test Run MX4, 0.9 isobutane/0.1 hexane.

\subsection{Test Results for Mixtures}

The test results in this section are divided into two parts: first, thermal performance, dealing with tray heat transfer efficiencies and minimum approach temperatures or pinch points, and second, column hydraulics.

Volumetric heat transfer coefficient determination would logically be presented in the thermal performance part as was done for the isobutane tests; however, for the mixture tests as will be discussed further, column throughput was on the order of half that for isobutane. Boiling occurred in a substantial number of trays spaced and designed for preheating. These trays showed relatively low efficiencies when used for boiling. Accordingly, for these tests a detailed examination of volumetric heat transfer coefficients was not made. Overall heat loads for the mixture tests reached magnitudes only $-60 \%$ of those for pure fluid, so volumetric heat transfer coefficients were correspondingly lower.

\subsubsection{Thermal Performance}

5.3.1.1 Data Analysis Approach. The data analysis conducted to describe the thermal performance of the DCHX consisted basically of determining the values of tray efficiency corresponding to the experimental results. As previously discussed, for the isobutane tests tray efficiency was determined using a computer program first, to find the values of working-to-geothermal fluid flow ratio and the preheating individual tray efficiency that best matched the temperature data in the preheating section, and second, to determine the efficiencies of the two boiling trays directly from the measured column temperatures. In contrast, for the propane and mixture tests, values of overall efficiency of groups of preheating trays and trays in which boiling occurred were determined as the ratio of the number of ideal trays required to transfer the same thermal energy as was transferred by those groups of actual trays. Generally, preheating trays were evaluated as one group, and trays in which boiling occurred were evaluated as a second group.

More specifically, the first step taken to determine overall efficiency for each of the mixture tests evaluated was to calculate a flow ratio (working fluid to geofluid) that formed an energy balance consistent with the measured column inlet and outlet state points. This calculated flow ratio and the measured column pressure were then used, 
along with thermodynamic properties of the working fluid mixture as estimated using Starling's modified Benedict Webb-Rubin equation of state, 11 to construct a temperature-heat exchanged (T-Q) diagram. An example of such a diagram for Test MX4 (0.9 isobutane/0.1 hexane) is shown in Figure 27. Temperature for the two fluids is plotted versus

$h_{w f}+\left(\frac{w_{s t m}}{w_{w f}}\right) h_{s t m}$

where $h_{w f}$ and $h_{\text {stm }}$ are the enthalpies of working fluid and water vapor that is mixed with the working fluid vapor, and

$\frac{w_{\text {stm }}}{w_{\text {wf }}}$

is the ratio of the weight flow of water vapor to working fluid at any point in the column. (For these calculations the ratio of water vapor to working fluid vapor at a given point in the column was estimated as the ratio of the specific volume of working fluid vapor at a given working fluid partial pressure and temperature to the specific volume of saturated water vapor at the working fluid temperature.) Measured working fluid and geofluid temperatures are plotted as $\mathbf{0}$ and $\mathbf{a}$, respectively, on the curves in order to identify the number of actual trays active in different regions of the T-Q plot. Figure 28 shows the temperatures of the two fluids for the same test run (MX4) plotted versus column height with tray numbers shown in the auxiliary scale. With this information the numbers of actual trays in major portions of the boiling and preheating regions were determined as shown in Figure 27.

Next, the number of ideal trays required to exchange the same energy as the groups of actual trays identified on Figure 27 were found graphically, as suggested in Section 3, and the several overall efficiency values were determined as shown in the figure. For this example the overall efficiencies for groups of 5 trays in the preheating section and 10 trays in which boiling occurred were 62 and $29 \%$. Similarly, the overall efficiency estimated for the two trays designed for boiling (Trays 18 and 19) combined, was found graphically to be $42 \%$.
Figure 28 shows that temperatures between Tray 1 and the bottom of the column (across Tray 0) did not change significantly, thus indicating no heat was transferred in that region; therefore the efficiency of Tray 0 (the working fluid inlet region) was presented as zero on Figure 27. (Operating experience has shown that for this situation the column was on the verge of flooding with substantial working fluid probably being carried with the geofluid down the first downcomer and cooling the geofluid at that location.)

In Figure 28 a dashed line was used in fairing the geofluid temperature curve between the inlet at the top of the column and Tray 16 in order to indicate particular uncertainty in this part of the curve. The geofluid temperature measurements leaving Trays 18 and 19 behaved unreliably for the mixture tests; apparently those temperatures were influenced by the presence of some working fluid in the downcomer regions.

5.3.1.2 Results for Isobutane-Hexane Mixtures. The procedure outlined for overall efficiency calculation was applied to data from a number of representative unflooded test runs covering isobutane $\left(\mathrm{iC}_{4}\right) /$ hexane $\left(\mathrm{C}_{6}\right)$ and propane $\left(C_{3}\right)$ /isopentane $\left(\mathrm{iC}_{5}\right)$ mixtures. Overall efficiencies for the isobutane/hexane mixtures and corresponding results for six pure isobutane tests are shown in Table 6. For a given working fluid, column pressures and outlet temperatures increase with decreasing ratios of working-to-geothermal flow. This behavior is illustrated for Test Runs 1 to 7, and for Test Runs MX4 and MX6. Tray 0, representing an interaction zone adjacent to the working-fluid distribution nozzle, is seen to be less efficient, in general, than the preheating trays. In particular, at the highest working fluid flows (approaching flooding) the Tray 0 efficiency dropped severely, probably due to working fluid carryunder down the lowest downcomer into the Tray 0 region, disengagement from the geofluid, and excessive accumulation under Tray 1 with little or no interaction space remaining between the working-fluid distributor nozzle and the coalesced working fluid layer under Tray 1 in which heat could be transferred. This effect is mentioned relative to the isobutane tests in Section 4.

The overall efficiencies of the preheating trays are in the same order of magnitude for all fluids 
Table 6. Tray efficiencies for isobutane/hexane mixtures

\begin{tabular}{|c|c|c|c|c|c|c|c|c|c|c|c|}
\hline \multirow[b]{2}{*}{$\begin{array}{c}\text { Run } \\
\text { Number }\end{array}$} & \multirow[b]{2}{*}{ Working Fluid } & \multirow{2}{*}{$\begin{array}{l}\text { Column } \\
\text { Pressure } \\
\text { (psia) }\end{array}$} & \multirow{2}{*}{$\begin{array}{c}\text { Outlet } \\
\text { Working Fluid } \\
\text { Temperature } \\
\left.\text { ( }{ }^{\circ} \mathrm{F}\right)\end{array}$} & \multicolumn{2}{|c|}{$\begin{array}{c}\text { Flow Rate } \\
(\mathrm{lbm} / \mathrm{h})\end{array}$} & \multirow[b]{2}{*}{ Tray 0} & \multicolumn{3}{|c|}{$\begin{array}{c}\text { Tray Efficiency } \\
(\%)\end{array}$} & & \multirow{2}{*}{$\begin{array}{c}\text { Trays } \\
\text { With } \\
\text { Boiling }\end{array}$} \\
\hline & & & & Working Fluid & Geofluid & & $\begin{array}{l}\text { Preheat } \\
\text { (overall) }\end{array}$ & $\begin{array}{c}\text { Boiling } \\
\text { (overali) }\end{array}$ & $\begin{array}{c}\text { Tray } \\
18\end{array}$ & $\begin{array}{c}\text { Tray } \\
19\end{array}$ & \\
\hline$\ldots 1$ & Isobutane $\left(\mathrm{iC}_{A}\right)$ & 446 & 250 & 3,640 & 17,600 & 58 & 33 & - & 100 & 98 & 2 \\
\hline 2 & Isobutane $\left(\mathrm{iC}_{4}^{4}\right)$ & 365 & 231 & 6,280 & 15,440 & 24 & 49 & - & 99 & 98 & 2 \\
\hline 3 & Isobutane $\left(\mathrm{iC}_{A}^{4}\right)$ & 327 & 220 & 6,980 & 14,350 & 39 & 54 & - & 100 & 98 & 2 \\
\hline 4 & Isobutane $\left(\mathrm{iC}_{a}^{4}\right)$ & 294 & 211 & 7,570 & 13,330 & 26 & 55 & - & 100 & - & 1 \\
\hline 6 & Isobutane (iC & 236 & 190 & 8,330 & 12,140 & 7 & 55 & - & 99 & - & 1 \\
\hline 7 & Isobutane $\left(\mathrm{iC}_{4}^{4}\right)$ & 146 & $150^{\circ}$ & 8,890 & 9,660 & 0 & 55 & - & 90 & $\overline{99}$ & 2 \\
\hline $\mathbf{M X} \mathbf{1}$ & $0.95 \mathrm{iC}_{4} / 0.05 \mathrm{C}_{6}$ & 222 & 202 & 5,220 & 8,520 & 45 & 60 & 62 & $50^{\mathrm{a}}$ & $50^{\mathrm{a}}$ & 3 \\
\hline MX4 & $0.90 \mathrm{CC}^{4} / 0.10 \mathrm{C}_{6}^{6}$ & 195 & 208 & 3,190 & 4,900 & o & 62 & 29 & $42^{a}$ & $42^{\mathrm{a}}$ & 10 \\
\hline MX6 & $0.90 \mathrm{iC}^{4} / 0.10 \mathrm{C}_{6}^{6}$ & 247 & 225 & 3,110 & 5,860 & 29 & 46 & 21 & $48^{a}$ & $48^{a}$ & 10 \\
\hline$M \times 7$ & $0.85 \mathrm{iC}_{4}^{4} / 0.15 \mathrm{C}_{6}^{6}$ & 166 & 204 & 2,200 & 3,730 & 34 & 47 & 23 & $52^{a}$ & $52^{a}$ & 12 \\
\hline
\end{tabular}

tested, with the possible exceptions of the propane test and the isobutane tests having the lowest flows. The magnitudes of overall efficiency generally were in the range of $54 \pm 8 \%$, which corresponds to individual tray efficiencies of about $73 \pm 5 \%$ (Figure 8 ). The highest preheating tray efficiencies for isobutane occurred at isobutane flows and orifice velocities corresponding approximately to the maximum interfacial surface area of the droplets forming above the tray orifices.

For pure fluids, boiling without superheating can be accomplished in a single ideal tray. The column was constructed with two boiling trays (18 and 19) to provide margin. For the pure isobutane tests boiling was accomplished in two and sometimes a single tray. For the isobutane runs, values of individual tray efficiency for each of the boiling trays as estimated from the measured temperatures are shown in Table 6. (For the runs where boiling was accomplished in Tray 19 alone, no efficiency was shown here for Tray 18.)

For the mixtures, the number of trays in which boiling occurred generally increased with increasing amounts of the minor hydrocarbon present, reaching as many as about 12 trays for the $0.85 \mathrm{iC}_{4} / 0.15 \mathrm{C}_{6}$ mixture. When boiling mixtures, Trays 18 and 19 (combined) showed efficiencies on the order of $50 \%$; trays designed for preheating generally showed overall efficiencies on the order of half of that when performing the vaporization task. Note that when severe boiling occurred in a large number of trays, geofluid may not have been continuous up through Tray 17 as assumed for the design. The preheating trays do not have a dam above the plates to ensure the presence of geofluid in the tray region if the geofluid ceases to be the continuous fluid, and may show low efficiency under conditions of heavy boiling. For the $0.95 \mathrm{iC}_{4} / 0.05 \mathrm{C}_{6}$ mixture, boiling only occurred in about three trays (Trays 17, 18, and 19), and overall efficiencies for both preheating and boiling were in the 50 to $60 \%$ range. This relatively high efficiency for Trays 17 , 18 , and 19 suggests that the geofluid level in the column was above Tray 17 for that test.

5.3.1.3 Results for Propane-Isopentane Mixtures. Results corresponding to those presented for the isobutane mixtures are shown in Table 7 for the propane-isopentane mixtures. As for the isobutanehexane mixtures, the efficiency of Tray 0 is significantly lower than that of the preheating trays. The overall preheating tray efficiency for the propane-isopentane mixtures is of the same general magnitude as for the isobutane-hexane mixtures. The overall preheating efficiency for the pure propane reached over $80 \%$, significantly higher than for any of the other fluids. The reason for the high preheater efficiency for the propane test, relative to the other fluids, is not known.

Boiling behavior for these mixtures was similar to that observed for the isobutane-hexane mixtures. Boiling occurred in two trays for the pure propane test; about four trays for 0.95 propane/ 0.05 isopentane, and about eight trays for 0.90 propane $/ 0.10$ isopentane. Overall efficiencies for the boiling trays were similar to those for the isobutane-hexane mixtures.

5.3.1.4 Estimation of Pinch Points. The pinch point is defined as the minimum temperature difference by which the fluids undergoing heat exchange 
Table 7. Tray efficiencies for propane isopentane mixtures

\begin{tabular}{|c|c|c|c|c|c|c|c|c|c|c|}
\hline \multirow[b]{2}{*}{$\begin{array}{c}\text { Run } \\
\text { Number }\end{array}$} & \multirow[b]{2}{*}{ Working Fluid } & \multirow{2}{*}{$\begin{array}{l}\text { Column } \\
\text { Pressure } \\
\text { (psia) }\end{array}$} & \multirow{2}{*}{$\begin{array}{c}\text { Outlet } \\
\text { Working Fluid } \\
\text { Temperature } \\
\left.\text { ( }{ }^{\circ} \mathrm{F}\right)\end{array}$} & \multicolumn{2}{|c|}{$\begin{array}{c}\text { Flow Rate } \\
(\mathrm{lbm} / \mathrm{h})\end{array}$} & \multicolumn{4}{|c|}{$\begin{array}{c}\text { Tray Efficiency } \\
(\%)\end{array}$} & \multirow{2}{*}{$\begin{array}{c}\text { Trays } \\
\text { With } \\
\text { Boiling }\end{array}$} \\
\hline & & & & Working Fluid & Geofnuid & Tray 0 & $\begin{array}{c}\text { Preheat } \\
\text { (overail) }\end{array}$ & $\begin{array}{c}\text { Boiling } \\
\text { (overall) }\end{array}$ & $\begin{array}{l}\text { Trays } 18 \text { and } 19 \\
\text { (combined) }\end{array}$ & \\
\hline PRP 6 & Propane $\left(C_{3}\right)$ & 484 & 182 & 4600 & 4750 & 20 & 82 & 98 & 98 & 2 \\
\hline MX11 & $0.95 \mathrm{C}_{3} / 0.05 \mathrm{ic}_{5}$ & 439 & 186 & 4380 & 4690 & 22 & 66 & 45 & 54 & 4 \\
\hline MX14 & $0.90 \mathrm{C}_{3} / 0.10 \mathrm{iC}_{5}$ & 393 & 183 & 2370 & 2800 & 30 & so & 26 & $-{ }^{a}$ & 8 \\
\hline
\end{tabular}

approach each other in the heat exchanger. Maintaining a small pinch is important for a binary Rankine cycle in producing the maximum turbine power for a given flow of geofluid. Accordingly, the pinch point achieved in a DCHX column is of interest. As mentioned earlier, pinch points estimated for the isobutane tests were very small, ranging from magnitudes as low as 0.02 to $0.3^{\circ} \mathrm{F}$.

Similarly, pinch points for the mixture tests were too small to be determined directly from temperature measurements. To estimate magnitudes of these pinch points the values of overall efficiency and number of actual preheating trays were taken from Tables 6 and 7. The number of

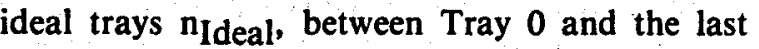
actual tray of the group being evaluated was calculated as: $n_{\text {Ideal }}=n_{\text {Actual }} \times \eta_{\text {overall }}$. The temperature difference between fluids then was found at the location on the T-Q plots (Figure 27) of the $n^{\text {th }}$ ideal tray from Tray 0 . Values obtained in this fashion ranged from 0.2 to $\sim 2.3^{\circ} \mathrm{F}$. The smaller values generally correspond to mixtures with the lower concentrations of the minor component, for which boiling only occurred in 3 or 4 trays and 15 or 16 were being used for preheating. The $0.85 \mathrm{iC}_{4} / 0.15 \mathrm{C}_{6}$ mixture, for example, produced a pinch point at the higher end of the range $\left(2.3^{\circ} \mathrm{F}\right)$. For given mixture concentrations, propane mixtures seemed to result in slightly larger pinch points than did the isobutane mixtures.

For columns specifically designed to preheat and boil mixtures no difficulty should be encountered in obtaining pinch points on the order of $1^{\circ} \mathrm{F}$; that magnitude is sufficiently small that further reductions in pinch point are not of major importance to cycle performance. Directcontact heat exchangers for vaporizing mixed hydrocarbons at supercritical pressures will not experience abrupt phase changes, and would not be expected to result in design or operational problems. It would be expected that geofluid would be maintained as the continuous phase to a level above the top tray, and that all trays would be of the type used for preheating in the present column. This approach was taken for vaporizing isobutane in a DCHX at supercritical pressures by Wahl and Boucher. 12

\subsubsection{Column Hydraulics Test Results}

5.3.2.1 Column Throughput. As indicated in the previous discussion of the column operation with mixtures, the DCHX throughput decreased when mixtures were used. The difference in properties between the mixtures and isobutane are not large enough to significantly alter the predicted hole velocities (those that produce jetting, maximum interfacial area, and maximum jet length) that are critical in the drop formation process in the liquidliquid preheating region. Thus, if the hydraulics were controlled by the region doing preheating for the mixtures, the hydraulic limits for isobutane and the mixtures would be similar. The decreased throughputs with mixtures imply that the region of the column doing the boiling is limiting the column hydraulically.

The temperature profiles for the column (examples are given in Section 5.3.1) show that a portion of the preheating trays are used for boiling when mixtures are used. The operational characteristics of the column and the fact that the throughput decreased as the concentration of the minor fluid increased (corresponding to more preheating trays being used for boiling) strongly suggest that the preheating trays were imposing a hydraulic limit on the column when used to do boiling. 
The throughputs obtained during the mixtures testing are shown in tabular form in Table 8 . The data in Table 8 that is indicated to be near flooding is also shown graphically in Figure 29. This figure gives the data presented in the baseline test results with the maximum throughputs obtained in the mixture tests. The decreasing flow capacity with increasing concentration of the minor component can be seen in this figure. It also appears that the geofluid throughputs for the propane family of fluids are less than those obtained with the isobutane family, although the dispersed phase throughputs are roughly equivalent. The sum of the square roots of the superficial velocities of the continuous and dispersed fluids is plotted versus the mass fraction of the major working fluid constituents for the isobutane-hexane and propaneisobutane families (Figure 30 ) for the near flooded test points. This figure illustrates the general trends of maximum throughputs observed in the tests.

5.3.2.2 Effects of Tray Spacing. Without a detailed evaluation of the test data (which is beyond the scope of available time) and perhaps additional testing with some of the preheating trays instrumented to provide additional data, it would be difficult to identify the mechanism that produced flooding. A comparison of the configuration of the preheating and boiling trays in the column identify several physical differences that could contribute to the hydraulic limit encountered. The preheating trays are relatively closely spaced (6 in. versus 22 in., and 15 in.), have short downcomers ( 3 in. versus 17 in., and 12-1/4 in.), and have no weirs to maintain a geofluid liquid over the plate surface.

With this small tray spacing, the column may not be able to pass the working fluid vapor being formed and still maintain the geothermal fluid flow across the plate as the continuous fluid. With those fluids where the minor component concentration is larger, several preheating trays are required for boiling. In these runs, perhaps $50 \%$ or more of the working fluid has been vaporized by the time it reaches the upper preheating trays. If the spacing is not large enough, the geothermal fluid can become entrained in the rising vapor. If this entrainment becomes large enough the column operation and stability would break down and the unit would flood. One of the test runs, MX15 $\left(0.9 \mathrm{C}_{3} / 0.1 / \mathrm{iC}_{5}\right)$ was evaluated using an entrainment correlation from Perry 7 for vaporliquid contacting in sieve-tray columns and the vapor portion of the working fluid flow. This method predicted a vapor flow corresponding to a total working fluid flow of $-3980 \mathrm{lb} / \mathrm{h}$. The last flow rate measured before the column flooded was $3900 \mathrm{lb} / \mathrm{h}$, which agrees fairly well with the predicted value and suggests a close approach to flooding. While this procedure approximates the process being evaluated, it is not a complete model.

\section{Table 8. DCHX mixture tests operating parameters}

\begin{tabular}{|c|c|c|c|c|c|c|c|c|c|c|}
\hline \multirow[b]{5}{*}{$\begin{array}{c}\text { Run } \\
\text { Number }\end{array}$} & \multicolumn{10}{|c|}{ Parameters } \\
\hline & \multirow[b]{4}{*}{$\begin{array}{c}\text { Mixture } \\
\text { Composition }\end{array}$} & \multirow{4}{*}{$\begin{array}{l}\text { Boiler } \\
\text { Pressure } \\
\text { (psia) }\end{array}$} & \multirow{2}{*}{\multicolumn{2}{|c|}{ Working Fluid }} & \multicolumn{3}{|c|}{ Geofluid } & \multirow{4}{*}{$\begin{array}{l}\text { Cooling } \\
\text { Water } \\
\text { Flow } \\
\text { (gpm) }\end{array}$} & \multirow{4}{*}{$\begin{array}{l}\text { Condenser } \\
\text { Pressure } \\
\text { (psia) } \\
\end{array}$} & \multirow[b]{4}{*}{$\begin{array}{l}\text { Flooding } \\
\text { Occurred }\end{array}$} \\
\hline & & & & & \multirow{3}{*}{$\begin{array}{l}\text { Flow } \\
\text { Rate } \\
(\mathrm{lb} / \mathrm{h})\end{array}$} & \multirow{2}{*}{\multicolumn{2}{|c|}{$\begin{array}{c}\text { Temperature } \\
\left({ }^{\circ} \mathrm{F}\right)\end{array}$}} & & & \\
\hline & & & \multirow{2}{*}{$\begin{array}{l}\text { Flow } \\
\text { Rate } \\
(\mathrm{lb} / \mathrm{h})\end{array}$} & \multirow{2}{*}{$\begin{array}{c}\text { Vapor Outlet } \\
\text { Temperature } \\
\left.\text { ( }{ }^{\circ} \mathbf{F}\right)\end{array}$} & & & & & & \\
\hline & & & & & & Inlet & Outlet & & & \\
\hline MX1 & $0.95 \mathrm{iC}_{4} / 0.5 \mathrm{C}_{6}$ & 222 & 5450 & 205 & 9030 & 270 & 149 & 277 & 51 & Yes \\
\hline MX2 & $0.95 \mathrm{iC}^{4} / 0.5 \mathrm{C}_{6}^{6}$ & 230 & 4980 & 216 & 9320 & 270 & 159 & 277 & 60 & Yes \\
\hline $\mathbf{M X 3}$ & $0.95 \mathrm{iC}_{4}^{4} / 0.5 \mathrm{C}_{6}^{6}$ & 284 & 3440 & 225 & 7470 & 270 & 170 & 279 & 42 & No \\
\hline MX4 & $0.90 \mathrm{iC}_{4} / 0.10 \mathrm{C}_{6}$ & 193 & 3290 & 197 & 5690 & 271 & 141 & 273 & 51 & No \\
\hline MX5 & $0.90 \mathrm{iC}^{4} / 0.10 \mathrm{C}_{6}^{6}$ & 220 & 3830 & 217 & 7570 & 273 & 154 & 276 & 54 & Yes \\
\hline MX6 & $0.90 \mathrm{iC}_{4}^{4} / 0.10 \mathrm{C}_{6}^{6}$ & 248 & 3250 & 225 & 7040 & 274 & 161 & 275 & 46 & No \\
\hline $\mathbf{M X 7}$ & $0.85 \mathrm{iC}_{\mathrm{d}} / 0.15 \mathrm{C}_{6}$ & 167 & 2810 & 202 & 4620 & 271 & 137 & 276 & 45 & No \\
\hline MX8 & $0.85 \mathrm{iC}_{6}^{4} / 0.15 \mathrm{C}_{6}^{6}$ & 192 & 3210 & 227 & 7430 & 274 & 155 & 275 & 45 & No \\
\hline MX9 & $0.85 \mathrm{iC}_{4}^{4} / 0.15 \mathrm{C}_{6}^{6}$ & 216 & 3460 & 223 & 6580 & 271 & 161 & 276 & 56 & Yes \\
\hline$M \times 10$ & $0.95 \mathrm{iC}_{3} / 0.5 \mathrm{iC}_{\mathrm{g}}$ & 391 & 3570 & 173 & 3610 & 265 & 114 & 275 & 135 & No \\
\hline MX11 & 0.95 ic $/ 0.5$ ic & 439 & 4390 & 188 & 4710 & 267 & 118 & 274 & 134 & Yes \\
\hline MX12 & $0.95 \mathrm{ic}_{3}^{3} / 0.5 \mathrm{ic}_{5}^{5}$ & 490 & 1765 & 192 & 2370 & 262 & 129 & 276 & 125 & No \\
\hline MX13 & $0.90 \mathrm{iC}_{3} / 0.10 \mathrm{ic}_{\mathrm{s}}$ & 349 & 3510 & 176 & 3640 & 271 & 110 & 275 & 131 & No \\
\hline $\mathrm{MX} 14$ & $0.90 \mathrm{iC}_{3}^{3} / 0.10 \mathrm{iC}_{5}^{5}$ & 394 & 3140 & 182 & 4110 & 257 & 122 & 274 & 130 & No \\
\hline MX15 & $0.90 \mathrm{iC}_{3}^{3} / 0.10 \mathrm{iC}_{5}^{5}$ & 444 & 3900 & 197 & 4640 & 270 & 128 & 274 & 134 & Yes \\
\hline MX16 & $0.85 \mathrm{ic}_{3} / 0.15 \mathrm{iC}_{\mathrm{g}}$ & 350 & 3490 & 192 & 4500 & 265 & 131 & 275 & 132 & Yes \\
\hline MX17 & $0.85 \mathrm{iC}_{3}^{3} / 0.15$ iC & 395 & 3220 & 196 & 4080 & 272 & 129 & 275 & 131 & No \\
\hline MX18 & $0.85 \mathrm{iC}_{3}^{3} / 0.15 \mathrm{ic}_{5}$ & 452 & 3367 & 207 & 4730 & 266 & 142 & 275 & 136 & Yes \\
\hline
\end{tabular}




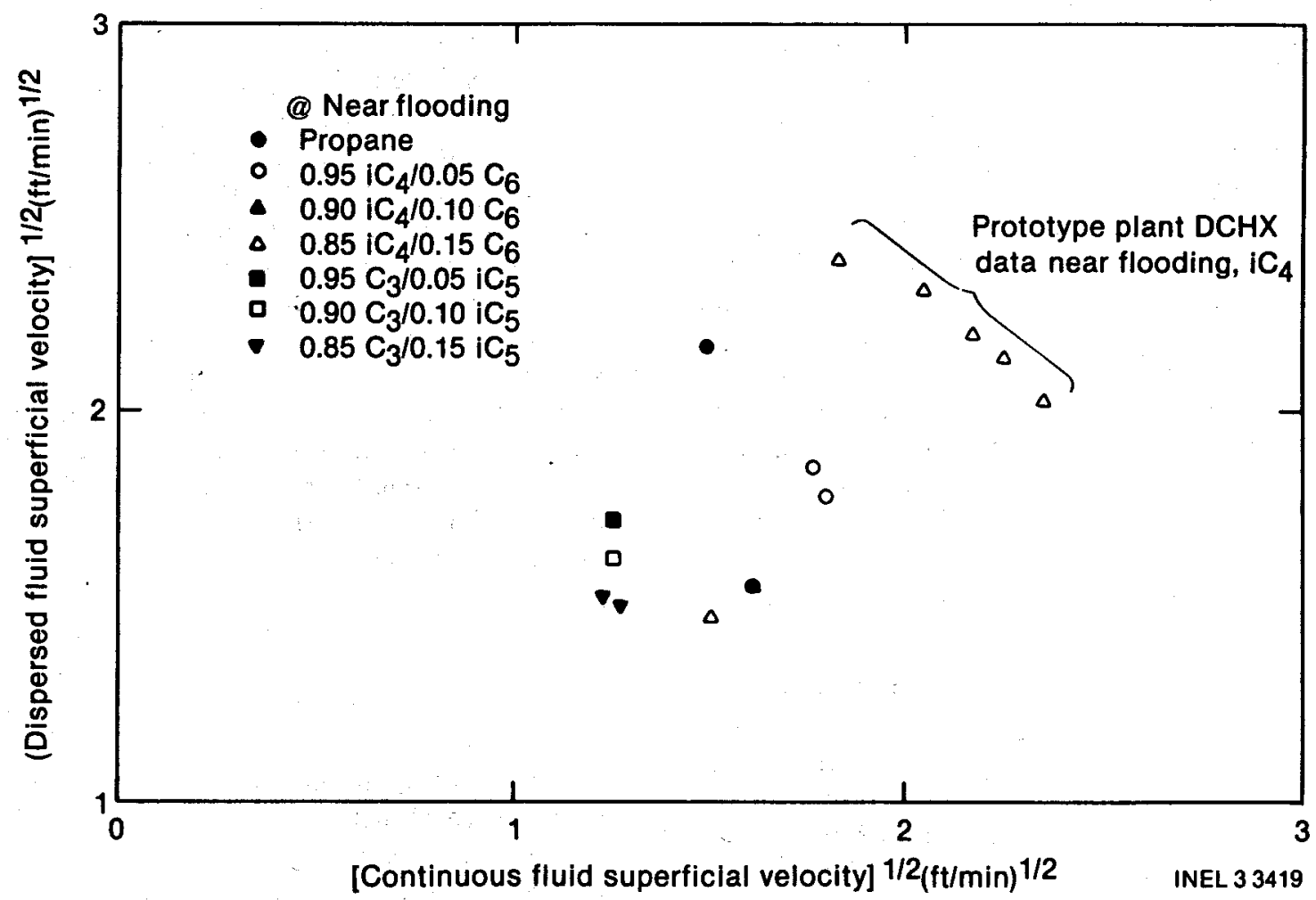

Figure 29. Throughputs of mixed working fluids relative to pure fluids.

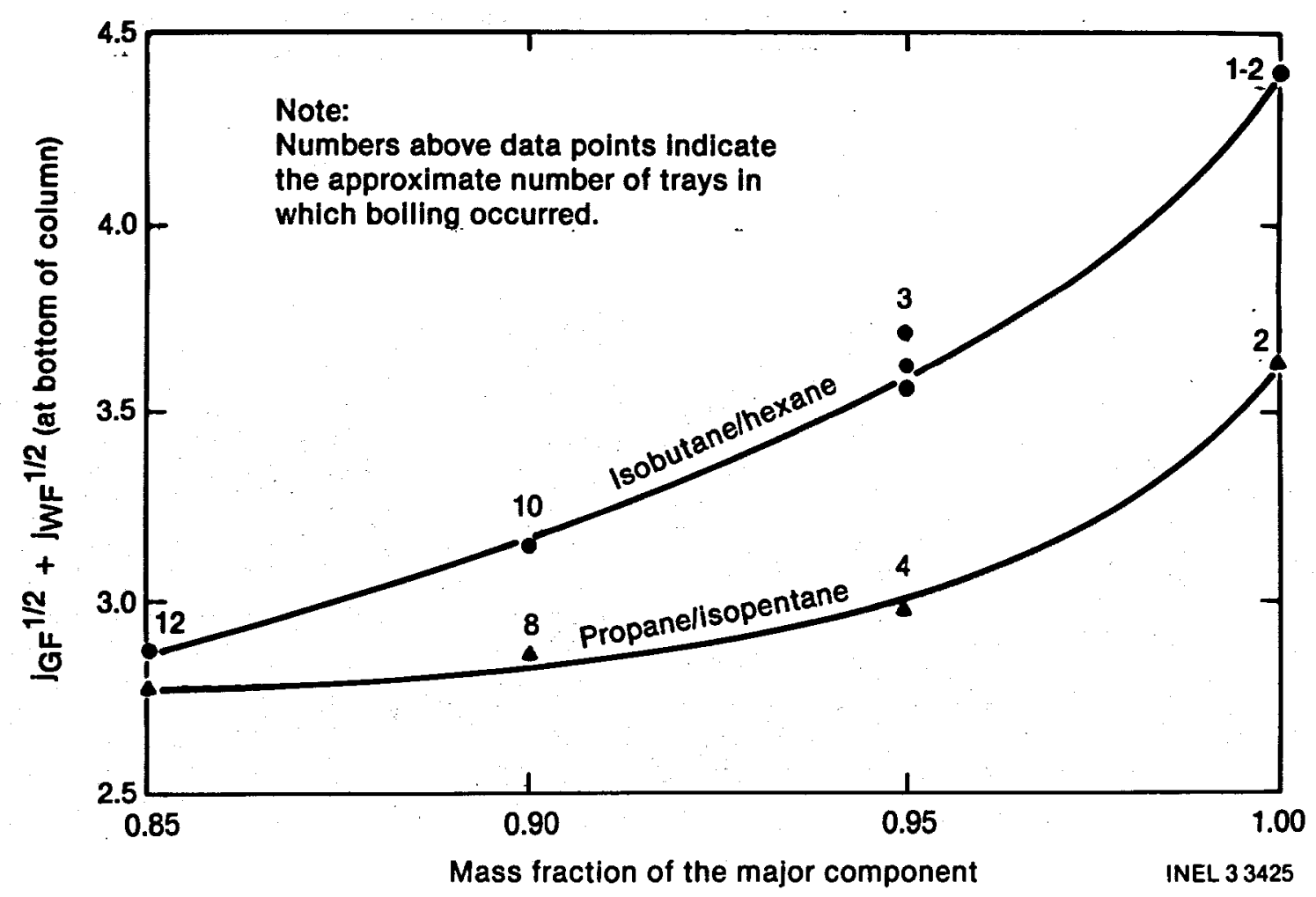

Figure 30. Volumetric throughputs near flooding. 
5.3.2.3 Weeping and Venting. In addition to entrainment of the geothermal fluid in the working fluid vapor, other factors could be contributing to or causing the flooding. With the large volume change of the working fluid as it boils, the volume under the preheating trays and downcomer may not be large enough to handle the working fluid flow (liquid and vapor). If not large enough, the working fluid would spill under the downcomer and begin rising up this region. The liquid head of water in the downcomer provides the driving mechanism for forcing the working fluid through the plate perforations. If one tray becomes vented to the next tray above it (a continuous vapor stream is established through the downcomer) then this driving head would be lost and the column hydraulics would break down.

Another potential contributor to breakdown of the column hydraulics could be weeping in these trays. Weeping occurs when the vapor flow is not high enough to support the liquid flow over the upper plate surface and the liquid begins passing through the plate perforations. This short circuits the tray section, reduces the liquid velocity in the downcomer, and increases the chance that venting could occur in the downcomer.

While venting and weeping are hard to quantitatively define, the column temperature profiles suggest that they might be occurring, particularly in the upper preheating region. If one examines the temperature in Figure 28 one can see that the geothermal fluid and the working fluid temperatures appear inverted or switched just below the bottom boiling tray (Plate 18). If this section had vented and weeping was occurring, the hotter geothermal fluid would be flowing through the plate perforations and past the working fluid temperature sensor, while the cooler working fluid vapor would rise above the brine temperature element in the downcomer. This inversion of temperature readings was common for the mixtures, and while the readings do not explicitly define whether weeping or venting occurred, they do suggest the possibility of their presence.

As was mentioned earlier, a detailed evaluation of the column performance with the mixtures and the existing configuration is beyond the scope of work at this time. The fact that the column appears to be hydraulically limited by trays during a service for which they were not designed does not make this analysis critical to the evaluation of the current column design. If the column is to be modified and used again with mixtures, the data should be evaluated in more detail, and the different phenomena examined to determine the likely hydraulic limits for the column and to define changes of the internal configuration that could extend those limits. 


\section{CONCLUSIONS}

The baseline performance tests with the DCHX confirmed that in thermal applications, the sievetray column is an excellent heat exchange device. Very small pinch points were obtained, well under the design goal of $1^{\circ} \mathrm{F}$ with the isobutane working fluid. During these baseline tests, the isobutane working fluid and the geothermal fluid temperatures were within $1^{\circ} \mathrm{F}$ of each other through the upper preheating section. Pinch points calculated from deduced tray efficiencies reached values as low as $0.02^{\circ} \mathrm{F}$. This would indicate that for conditions at which the unit was operated at Raft River, the number of trays in the preheating section and the column length could be reduced without a corresponding sacrifice in thermal performance. If the unit was operated at elevated brine inlet and working fluid vapor outlet temperatures, the existing configuration could be kept and still maintain an acceptable level of performance.

The mixture tests showed that these hydrocarbon mixtures could be preheated and vaporized in a sieve-tray DCHX. The thermal performance of the column, in terms of the approach temperature or pinch point obtained with mixtures, was not at the same level as with the isobutane working fluid. This does not mean that the thermal performance with mixtures was poor as pinch points from 0.3 to $2.3^{\circ} \mathrm{F}$ were obtained (the higher pinch point corresponded to those mixtures having the highest concentration of the minor component). It merely accentuates the level of thermal performance obtained in the baseline tests with isobutane.

The tray efficiencies (both individual and overall) in the section of the column doing the preheating were similar for both the mixtures and the isobutane fluids. The individual tray efficiency was at or above the design goal of $70 \%$ for most of the higher flow tests conducted. The high individual thermal efficiencies combined with the large number of preheating trays produced the small points that were obtained during the testing. The overall preheating efficiencies were on the order of $50 \%$ indicating that approximately two actual trays were required for each theoretical tray.

The efficiencies of the trays used for boiling were not as high for mixtures as they were for the isobutane fluid. For all of the pure fluid tests, the two boiling trays were more than adequate for the boiling heat duty. With the mixture fluids, the number of trays required for boiling increased and the two boiling trays were not adequate. As the amount of the minor component in the hydrocarbon working fluid mixture increased, the number of trays required for boiling increased. In the extreme case, for the $0.85 \mathrm{iC}_{4} / 0.15 \mathrm{C}_{6}$ fluid, 12 trays were necessary to complete the boiling of the fluid. With these mixtures, the two trays designed for boiling showed an overall efficiency of $-50 \%$. When the preheating trays were required for boiling, those trays had an overall efficiency on the order of one half the efficiency of the trays designed for boiling. The use of a portion of the preheating trays for boiling is the reason that the pinch points for the mixtures were higher even though preheating tray efficiencies were similar to those obtained with the isobutane fluid. Since fewer trays were available for preheating, the same small approach temperatures could not be achieved.

Although the column did not operate at a geothermal fluid flow rate corresponding to the design terminal velocity of a $1 / 16$-in. diameter drop during the baseline performance tests, it did operate at the working fluid velocities from the plate perforations recommended ${ }^{4}$ for the design of a sieve-tray column. The data suggests that premature flooding may have occurred due to the reduced total hole area in the upper preheating (drawoff) tray. The reduced hole area produced working fluid velocities from the holes in excess of the velocity limit beyond which the drops forming from the jet cease to have uniformity in size. This may have produced local flooding, i.e., carryunder of the smaller drops, or it may have produced a sufficient number of small drops that could have been swept down the length of the preheating section flooding the tower. The hole area for the plates in the rest of the preheating section provided working fluid hole velocities during the baseline tests, corresponding to the predicted values for producing the maximum interfacial area condition, or the minimum average drop size. This is the hole velocity recommended by Jacobs and Boehm. 4

Comparisons of the mass throughput capacities of a sieve-tray unit with a direct-contact spray tower are somewhat inconclusive. The baseline performance of the sieve-tray DCHX using isobutane compares favorably with the relative 
capacity of the $500 \mathrm{~kW}$ spray tower, however, this spray tower was never brought to a flooded condition and an increment in capacity performance could not be estimated. A comparison with the high temperature cycle test performance of the DSS spray tower indicates the sieve-tray DCHX had a throughput advantage. When compared to the low temperature cycle test performance of the DSS unit, the spray tower had an advantage. Given the general trends for flooding of spray towers, the DSS unit performance during the low temperature cycle tests probably represents the maximum limit for that spray tower due to flooding. In this case the spray tower does have a throughput advantage over the sieve-tray column as reputed. ${ }^{4}$

In the mixture tests, the throughput capacity of the sieve-tray column was reduced considerably. As the concentration of the minor component in the mixture increased, the maximum throughput for the column decreased. The differences in properties in the liquid-liquid preheating section of the column do not account for the differences in flow that were found; thus, although the hydraulics of the preheating trays were thought to impose a throughput or flooding limit in the baseline tests, the hydraulic limit in the mixture tests is thought to be imposed by the section of the column doing the boiling. Since the throughput of the column appears to vary inversely with the number of preheating trays in which boiling occurs, they are suspected of impacting the hydraulic limit on the column. These trays are not designed for handling large quantities of vapor flow. They are closely spaced and have relatively short downcomers leaving little space for the boiling to occur. The entrainment of liquid geofluid in the vapor, weeping of geofluid through the plate perforations, and the venting of working fluid up the downcomer are suspected of contributing to, if not causing, the breakdown of the column hydraulics when boiling occurs in the preheating trays.

The excellent thermal performance of the unit in the baseline tests (isobutane) presented an operational problem in that a significant quantity of working fluid in the column was near the saturation temperature. A drop in column pressure due to the opening of a control valve or change in flows could start the boiling of this fluid. Once started, the control system tended to perpetuate the phenomenon until flooding was produced. Generally, manual control of liquid levels corrected or reduced the problem. The control problems resulting from the boiling in the preheating trays were even more pronounced in the mixtures testing where preheating trays were required to handle the boiling of the fluid. As the concentration of the minor component increased in the mixture, boiling occurred in more of the preheating trays, resulting in increased difficulty in controlling the column. In general, while it was possible to automatically control the column pressure, the level control for the column had to be maintained manually.

At this point, a considerable amount has been learned about the design and operation of a sievetray direct-contact heat exchanger. The column tested was an excellent device for heat transfer producing small pinch points and liquid-liquid preheating tray efficiencies at the design values. While the hydraulics of the column is not totally understood, enough has been learned to design a sieve-tray unit that would be expected to produce higher throughput capacities, particularly when pure fluids are used. Although the hydraulics of the preheating trays where boiling occurs is still largely unknown, it should be noted that these trays were not designed to handle vapor flow. The major questions yet to be resolved are the impact of the hydraulic design on the thermal performance and mass transfer in the section of the column where preheating occurs, and the design changes necessary to improve the hydraulic and thermal performance of trays designed for boiling of working fluid mixtures. With the data generated in the baseline and mixture performance tests, the next sequence of tests can be designed and modifications made to the column internals that would generate the data for the design of a sieve-tray column that could operate near the optimum thermal and hydraulic design limits. 


\section{REFERENCES}

1. R. E. Treybal, Liquid Extraction, 2nd edition, New York: McGraw Hill Book Company Inc., 1973.

2. I. Sheinbaum, "Direct-Contact Heat Exchangers in Geothermal Power Production," AIChE-ASME Heat Transfer Conference, San Francisco, California, August 11-13, 1975.

3. A. H. P. Skelland and R. Johnson, "Jet Breakup in Liquid-Liquid Systems," The Canadian Journal of Chemical Engineering, 52, 1974, pp. 732-738.

4. H. R. Jacobs and R. F. Boehm, "Direct-Contact Binary Cycles," Sourcebook on the Production of Electricity from Geothermal Energy, Brown University, DOE/RA/4051-1, 1980, pp. 413-471.

5. A. H. P. Skelland and Y. F. Huang, "Continuous Phase Mass Transfer During Formation of Drops from Jets," AIChE Journal, 25, 1979, pp. 80-87.

6. A. J. Klee and R. E. Treybal, "Rate of Rise or Fall of Liquid Drops," AIChE Journal, 2, 1956, pp. 444-447.

7. R. H. Perry and C. H. Chilton, Chemical Engineers' Handbook, 5th edition, New York: McGraw Hill Book Company Inc., 1973.

8. M. W. Urbanek, "Experimental Testing of a Direct-Contact Heat Exchanger for Geothermal Brine," ORNL/Sub-79/13564/1 and ORNL/Sub-79/45736/1 DSS-079, December 1979.

9. A. Hlinak et al., " $500 \mathrm{~kW}$ DCHX Pilot Plant Evaluation Testing," Lawrence Berkeley Laboratory, Report LBL-13339, October 1981.

10. R. E. Treybal, Liquid Extraction, 1st edition, New York: McGraw Hill Book Company Inc., 1951.

11. R. S. Deeds, THERPP, A Thermodynamics Properties Program, TREE-1781, May 1977.

12. E. F. Wahl and F. B. Boucher, Theory and Practice of Near Critical Pressure Direct-Contact Heat Exchange, SAN/1076-1, October 1977. 


\section{APPENDIX A \\ DESIGN CONSIDERATIONS FOR A SIEVE-TRAY DIRECT-CONTACT HEAT EXCHANGER}





\section{APPENDIX A}

\section{DESIGN CONSIDERATIONS FOR A SIEVE-TRAY DIRECT-CONTACT HEAT EXCHANGER}

\section{Hydraulic Behavior}

Introduction. The sieve-tray, or perforated plate, tower has been used in industrial liquid-liquid applications for some time as mass transfer equipment. Its principal advantages in mass transfer applications are (a) the mixing of the two fluids is controlled and confined to the region between plates and (b) the dispersed phase drops coalesce and reform at each tray minimizing the concentration gradients within the drop as the dispersed phase is moved through the column. These same characteristics are also desirable in heat transfer applications; the trays provide an ordered countercurrent flow with little back-mixing and the repeated coalescence and formation of the drops minimize temperature gradients within the drops. By continually reforming the drops, the bulk temperature (average temperature) of the dispersed fluid can be brought up to the desired temperature with minimum contact time between the two fluids. Although the two fluids considered for the baseline tests (geothermal fluid and isobutane) are relatively insoluble and mass transfer occurs at a slower rate than heat transfer, some mass transfer will occur between the fluids. Since the loss of working fluid in the effluent geothermal fluid stream represents a parasitic loss to the plant in terms of the cost to recover or replace the fluid, it is desirable to minimize the amount of time the two fluids are in contact.

A general description of the direct-contact heat exchanger (DCHX) column is given in Section 2 of the main report. As indicated, the driving mechanism(s) for moving the two fluids through the tower is the force of gravity and the difference in density between the two fluids; the geothermal fluid flowing down the column due to the force of gravity and the lighter working fluid rising because of the density difference. The trays and downcomers provide for the ordered repeated mixing and separation of the fluids as they move through the column. Each plate contains a number of perforations through which the working fluid is dispersed as rising droplets through the continuous geothermal fluid flowing over the top surface of each plate. These droplets coalesce in the region under the next higher plate formed by the plate and downcomer and the process is repeated. This is illustrated schematically in Figure 4 of the main text.

Flooding. A general characteristic of a countercurrent flow direct-contact device is that for a given velocity or throughput of one fluid, there is a maximum possible velocity for the second fluid. If an attempt is made to exceed this maximum velocity for the second fluid, the column will reject one of the fluids and the unit is said to be flooded. The mechanics of the column hydraulics leading to this flooded condition is complex and dependent upon a number of variables. The usual procedure for attempting to define the operating limits of a column for a given set of conditions is to define maximum continuous, or geothermal, fluid velocity allowable as that equal to the terminal rise velocity of working fluid drop of an arbitrarily selected size. In a sieve-tray column the maximum velocity of the continuous fluid usually occurs in the regions bounded by the downcomers and the vessel wall (downcomer area). Droplets will be carried through the downcomer area to the next plate if their terminal rise velocity does not exceed the geothermal fluid velocity in the downcomer area. If the geothermal fluid velocity is increased, more (as well as larger) drops are swept downward. If the drops do not reach a quiet region where the geothermal fluid velocity is lower than the drop terminal velocity, they will be carried out of the column in the cooled geothermal fluid stream. This mechanical entrainment of the working fluid drops in the geothermal fluid leaving the column is referred to as carryunder. When the geothermal fluid velocity reaches a level where a significant number of working fluid drops are rejected from the column, the condition is called flooding. A flooding condition may occur locally when drops are swept down one or two trays before they resume rising, however, this term is generally used to describe the condition where the carryunder is high enough that the column operation becomes unstable and the working fluid losses from the column would make operation uneconomical even if it were stable. This flooding point represents the practical operating limit for the column and may or may not agree with the maximum 
geothermal fluid flow rate defined by the terminal droplet velocity, depending upon the droplet size selected. Establishing the operating limits of the direct-contact column, therefore, requires some knowledge of the drop formation mechanism and the resulting distribution of drop sizes.

Formation of Working Fluid Droplets. If the plate surface from which the drops discharge is preferentially wetted by the continuous geothermal fluid, the drop formation can be controlled and has been characterized up to certain orifice velocities. At the lower working fluid velocities through the orifice or perforation, the drops will form with a uniform size and breakoff at regular intervals. At the lower orifice velocities the final drop volume can be estimated (from Perry, Reference A-1) as

$$
\begin{aligned}
\frac{\pi \mathrm{d}_{\mathrm{p}}^{3}}{6}= & \frac{\mathrm{F}}{100}\left[\frac{0.02155 \sigma \mathrm{d}_{\mathrm{o}}}{\Delta \rho}+\frac{1.356 \mu_{\mathrm{c}} \mathrm{V}_{\mathrm{o}} \mathrm{d}_{\mathrm{o}}^{3}}{\mathrm{~d}_{\mathrm{p}}{ }^{2} \Delta \rho}\right. \\
& \left.-\frac{3.26 \rho_{\mathrm{d}_{\mathrm{o}} \mathrm{d}_{\mathrm{o}}^{2} \mathrm{v}^{2}}}{\Delta \rho}+4.80 \mathrm{~d}_{\mathrm{o}}^{2}\left(\frac{\mathrm{v}_{\mathrm{o}}^{2} \rho_{\mathrm{d}} \sigma}{\Delta \rho}\right)\right]^{1 / 3}
\end{aligned}
$$

where

$$
\begin{aligned}
& \mathrm{F}=\text { Harkins-Brown correction factor } \\
& \sigma=\text { interfacial tension (dyne/cm) } \\
& \mathrm{d}_{\mathrm{p}}=\text { drop diameter }(\mathrm{ft}) \\
& \mathrm{d}_{\mathrm{O}}=\text { orifice diameter }(\mathrm{ft}) \\
& \mathrm{v}_{\mathrm{o}}=\text { velocity through orifice }(\mathrm{ft} / \mathrm{s}) \\
& \mu_{\mathrm{c}}=\text { viscosity of continuous fluid }(\mathrm{lbm} / \mathrm{ft}-\mathrm{h}) \\
& \rho_{\mathrm{d}}=\text { density of dispersed fluid }\left(\mathrm{lbm} / \mathrm{ft}^{3}\right) \\
& \Delta \rho=\text { density difference }\left(\mathrm{lbm} / \mathrm{ft}^{3}\right) .
\end{aligned}
$$

(The original paper should be consulted for the range of conditions for which the equation is applicable and for the definition of the factor $F$.)

As the velocity through the orifice is increased, a point is reached where the mechanism for drop formation changes. A short jet of dispersed fluid extends from the nozzle and drops form by a necking-in at the top of the jet. Scheele and Meister ${ }^{A-2}$ present two correlations for the orifice velocity at which this jet will form. The first correlation gives the orifice velocity where the liquid leaving the orifice maintains itself in the form of a cylinder whose length is increasing in preference to making the drop diameter larger. This can be written as

$v_{o j}=0.081\left[\frac{\sigma}{\rho_{d_{0}}}\left(1-\frac{d_{0}}{d_{p j}}\right)\right]^{1 / 2}$

where

$$
\begin{aligned}
& d_{p j}=\text { drop diameter if jet did not form (ft) } \\
& v_{o j}=\begin{array}{l}
\text { orifice velocity at which jet forms } \\
(f t / s) .
\end{array}
\end{aligned}
$$

The second correlation predicts the velocity where the drops do not rise over one drop diameter before the next drop forms; the drops merge to form a continuous jet. The correlation is written as

$v_{o j}=\frac{2 d_{p j}^{2} v_{t}}{3 d_{o}^{2}}$

where

$$
v_{t}=\text { terminal velocity of drop } d_{p j}(f t / s) \text {. }
$$

The mechanism (correlation) giving the lower jet velocity is the controlling one and defines the minimum velocity through the orifice at which a jet will form.

\section{Column Conditions for Maximum Interfacial} Area. Although the mechanism of drop formation changes as the orifice velocity increases (to drops formed by jet breakup), investigators have noted that the resulting drops are uniform in size up to a certain velocity. Hayworth and Treybal (Reference A-3) investigated drop formation from jet breakup and present a graphical solution of their correlation for the average drop size (if a graphical solution is not used, a trial and error solution would be required). Skelland and Johnson (Reference A-4) also performed a study 
of jet breakup for two immiscible liquids that defines the drop diameter based on the jet breakup at the maximum interfacial area conditions (minimum drop size). In their derivation of drop size, a dimensionless parameter, $K$, is used to obtain the jet diameter, $\mathrm{d}_{\mathrm{jm}}$, at the maximum area condition (minimum average drop size) as

$K=\frac{d_{o}}{\left(\frac{\sigma}{g \Delta \rho}\right)^{0.5}}$

If $K<0.785$,

then

$\mathrm{d}_{\mathrm{jm}}=\frac{\mathrm{d}_{\mathrm{o}}}{\left(0.485 \mathrm{~K}^{2}+1\right)}$

or if $\mathrm{K}>0.785$

then

$\mathrm{d}_{\mathrm{jm}}=\frac{\mathrm{d}_{\mathrm{o}}}{(1.51 \mathrm{~K}+0.12)}$

where

$$
\begin{aligned}
& d_{0}=\text { nozzle or orifice diameter }(\mathrm{cm}) \\
& d_{j m}=\text { jet diameter at maximum area condi- } \\
& \text { tions }(\mathrm{cm}) \\
& \sigma=\text { interfacial surface tension }(\text { dyne } / \mathrm{cm}) \\
& \Delta \rho=\text { density difference }\left(\mathrm{g} / \mathrm{cm}^{3}\right) .
\end{aligned}
$$

The velocity of the dispersed phase through the orifice giving the maximum interfacial area condition is defined by

$$
\begin{aligned}
v_{o m}= & 2.69\left(\frac{d_{j m}}{d_{0}}\right)^{2} \\
& {\left[\frac{\sigma}{d_{j m}\left(0.5137 \rho_{d}+0.4719 \rho_{c}\right)}\right]^{0.5} }
\end{aligned}
$$

where

$$
\begin{aligned}
& v_{\mathrm{om}}=\begin{array}{l}
\text { orifice velocity at maximum area } \\
\text { condition }(\mathrm{cm} / \mathrm{s})
\end{array} \\
& \rho_{\mathrm{d}}=\text { dispersed fluid density }\left(\mathrm{g} / \mathrm{cm}^{3}\right) \\
& \rho_{\mathrm{c}}=\text { continuous fluid density }\left(\mathrm{g} / \mathrm{cm}^{3}\right)
\end{aligned}
$$

A graphical solution is presented by Skelland and Johnson (Reference A-4) for a drop diameter at an orifice velocity using this velocity at maximum area conditions. In a later investigation by Skelland and Huang (Reference A-5), the jet diameter and orifice velocity at maximum area conditions are used to define the drop diameter as

$$
\begin{gathered}
d_{p}=d_{j m}\left[2.727-0.2028\left(\frac{v_{o}}{v_{o m}}\right)\right. \\
\left.+0.0731\left(\frac{v_{o}}{v_{o m}}\right)^{2}\right]
\end{gathered}
$$

where

$$
\begin{aligned}
& v_{0}=\begin{array}{l}
\text { orifice velocity at operating condition } \\
(\mathrm{cm} / \mathrm{s})
\end{array} \\
& d_{p}=\text { drop diameter at } v_{0}(\mathrm{~cm})
\end{aligned}
$$

Formation of Nonuniform Size Droplets. As the orifice velocity is increased, a point is reached where the drops formed by jet breakup start to become less uniform in size and smaller. In the fluid systems investigated by Hayworth and Treybal (Reference A-3), this transition occurred at a velocity of $\sim 0.33 \mathrm{ft} / \mathrm{s} \cdot(10 \mathrm{~cm} / \mathrm{s})$. Investigators noted that this transition where drops became less uniform generally occurred at or near the point where the jet reached its maximum length. Continued increase in the orifice velocity results in a decreasing jet length and a more random breakup, which produce less and less uniform sized drops, including drops with very small diameters. Eventually, the velocity will reach a point where the jet will disappear and the working fluid stream leaving the orifice will be atomized producing a cloud of small droplets. Perry (Reference A-6) defines the transition to atomization for a liquid jet or droplet in air as 
jet: $\frac{d_{j} V \rho_{d}}{\mu_{d}}>2.8 \times 10^{2}\left[\frac{\mu_{d}}{\left(\sigma \rho_{d_{j}} g_{c}\right)^{1 / 2}}\right]^{-0.82}$

drop: $N_{w e}=\frac{v^{2} \rho_{c} d_{\text {max }}}{\sigma g_{c}}>Z$

where

$$
\begin{aligned}
& \mathrm{V}=\text { relative velocity between drop and } \\
& \text { continuous fluid. }
\end{aligned}
$$

The critical Weber number, or $Z$, at which atomization occurs depends on a number of factors including contact time. Perry (Reference A-1) indicates that value may vary from 4 to 20 while Wallis (Reference A-6) gives a critical Weber number of 12 .

The small droplets formed during the different regimes of drop formation are those entrained in the continuous geothermal fluid. In operating or designing a direct-contact column those conditions for which a large number of small drops are produced represent the operating limits of the column, as the entrainment of these drops will likely result in flooding. The testing with the prototype plant DCHX was not intended to be used for investigating the different mechanisms of drop formation, however these mechanisms were considered in interpreting the operating limits encountered.

\section{Hydraulic Design}

Background. The physical dimensions of a tray and column cross section are defined primarily by the hydraulic design of the column. The number of trays, or length of the column, is defined by the thermal design. The number of trays in the column should not affect the column hydraulics aside from increased contact time and resulting mass transfer between the two fluids.

An initial step in sizing a direct-contact counterflow column is to use the following relationship

$U_{c}^{1 / 2}+U_{d}^{1 / 2}=$ constant where $U_{c}$ is the volume flux or superficial velocity of the continuous fluid and $U_{d}$ is the volume flux of the dispersed fluid. (Volume flux or superficial velocity is defined as the volumetric flow rate divided by the column cross-sectional area.) Once the process conditions have been defined the column can be sized (cross section defined) provided that the constant term is known. Unfortunately, the constant varies with the type of column and process. The relationship is useful in the initial sizing of the columns and provides a means of comparing the hydraulic performance of the different types of columns provided some data exists for the different columns.

Little previous experience exists in the actual hydraulic design and operation of sieve-tray columns for heat transfer application. Most of the information that does exist relates to mass transfer applications. The prototype plant DCHX has an internal configuration like that used in mass transfer units, however, the fluid combination used for the baseline testing, isobutane and geothermal fluid, is not one typically encountered and little if any property data exists for this combination. The remainder of this appendix will review some of the different parameters that will be considered in the hydraulic design of a sieve-tray column.

Plate Perforations. The hole size and spacing selected for an application is generally based on the previous experience of the designer or others. The perforations may be drilled, although punched holes are preferred as the ridge formed in perforating the plate (continuous fluid flow over the ridge) helps eliminate wetting of the plate by the dispersed fluid that interferes with uniform drop formation. Treybal and Perry (References A-3 and A-5) suggest perforations with a $1 / 8$ to $1 / 4$-in. diameter located with centers spaced (triangle or square) at $1 / 2$ to 3/4-in. intervals. The plates in the prototype DCHX have 1/8-in. diameter drilled holes with 7/32-in. staggered centers (rows are separated by 0.1894 -in. centers). The hole diameter and spacing used were based on the previous experience of the designer, the Wahl Company. The hole spacing suggested by Treybal (Reference A-3) appears to be a conservative value that would allow for drop formation from a particular orifice with minimal interference from adjacent perforations. This spacing however does require more plate area for a given working fluid (or dispersed fluid) flow rate, which results in a larger diameter column and higher costs. The smaller hole size is recommended in heat transfer 
applications (unless the interfacial surface tension is low) since conduction dominates the heat transfer process.

Orifice Velocity. The velocity of the working fluid through the plate perforations selected for an application should be kept lower than the velocity that results in the formation of a significant number of small droplets, which could be mechanically entrained in the continuous geothermal fluid. Treybal (Reference A-4) suggests an orifice velocity of 0.5 to $1.0 \mathrm{ft} / \mathrm{s}$ although Hayworth and Treybal (Reference A-3) noted less uniformity in drop size and smaller drops for orifice velocities above $0.33 \mathrm{ft} / \mathrm{s}$. It is recommended in References A-3 and A-4 that Equation (A-9) be used for the maximum orifice velocity

$$
\begin{aligned}
v_{0} & =2.69\left(\frac{d_{j}}{d_{o}}\right) \\
& {\left[\frac{\sigma}{d_{j}\left(0.5137 \rho_{d}+0.4719 \rho_{c}\right)}\right]^{0.5} }
\end{aligned}
$$

where the jet diameter is calculated from either

$$
\begin{gathered}
\frac{d_{0}}{d_{j}}=0.485\left[\frac{d_{0}}{(\sigma / g \Delta \rho)^{0.5}}\right]^{2}+1, \\
\text { if }\left[\frac{d_{0}}{(\sigma / g \Delta \rho)^{0.5}}\right]<0.785
\end{gathered}
$$

$$
\begin{aligned}
& \frac{d_{0}}{d_{j}}=1.51\left[\frac{d_{0}}{(\sigma / g \Delta \rho)}\right]+0.5 \\
& \text { if }\left[\frac{d_{0}}{(\sigma / g \Delta \rho)^{0.5}}\right]>0.785
\end{aligned}
$$

This velocity occurs when the interfacial area is a maximum, or at the minimum drop size. With the orifice velocity determined and the process working fluid flow rate, the perforation area is defined. Using the hole size and spacing selected, the plate area can be found.
Downcomer Velocity. The maximum velocity of the continuous geothermal fluid in the column is established by the terminal rise velocity of an arbitrarily sized droplet, usually $1 / 32$ to $1 / 16$-in. in diameter. The maximum velocity of the geothermal fluid will generally occur in the downcomer region, thus the terminal rise velocity of the drop and the design geothermal fluid flow rate will define the cross-sectional area of this downcomer region. There are a number of sources defining the terminal velocity for a drop that have the form

$V_{t}=\left(\frac{4}{3} \frac{g d_{p} \Delta \rho}{\rho C}\right)^{1 / 2}$

where the drag coefficient, $\mathrm{C}$, is a function of the Reynolds number if the drop is assumed to be a solid smooth sphere.

Investigations (References A-8 and A-9) indicate that the assumption that the drop will behave as a solid smooth sphere is valid only up to a certain drop size, after which the terminal velocity no longer increases with increasing drop diameter and may in some instances decrease. The deviation from the solid sphere assumption is apparently the result of the development of drop oscillation and distortion that produce a higher drag coefficient. $\mathrm{Hu}$ and Kinter provide a graphical correlation for defining the drop terminal velocity. Klee and Treybal define two regions, one where terminal velocity increases with drop diameter and the second where the terminal velocity is independent of the drop size, written as

$$
\begin{aligned}
& \mathrm{V}_{\mathrm{t}_{1}}=38.3 \rho_{\mathrm{c}}^{-0.45} \Delta \rho^{0.58} \mu_{\mathrm{c}}^{-0.11} \mathrm{~d}_{\mathrm{p}}^{0.70} \\
& \mathrm{~V}_{\mathrm{t}_{2}}=17.6 \rho_{\mathrm{c}}^{-0.55} \Delta \rho^{0.28}{ }_{\mu_{\mathrm{c}}}^{0.10}{ }_{\sigma}^{0.18}
\end{aligned}
$$

where

$$
\mathrm{dc}=0.33 \rho_{\mathrm{c}} \mathrm{c}^{-0.14} \Delta \rho^{-0.43} \mu_{\mathrm{c}} 0.30 \sigma^{0.24}
$$

defines the critical drop diameter where the transition takes place. The units for these equations are 


$$
\begin{aligned}
& v_{t}=\text { terminal velocity }(\mathrm{cm} / \mathrm{s}) \\
& \rho_{c}=\text { continuous fluid density }\left(\mathrm{g} / \mathrm{cm}^{3}\right) \\
& \Delta \rho=\text { density difference }\left(\mathrm{g} / \mathrm{cm}^{3}\right) \\
& \mu_{c}=\text { continuous fluid viscosity, poise } \\
& d_{p}=\text { drop diameter }(\mathrm{cm}) \\
& \sigma=\text { interfacial tension }(\text { dyne } / \mathrm{cm})
\end{aligned}
$$

The drop diameter selected for the terminal velocity calculation should be checked to see if the drop can be expected to behave as a solid sphere. If so, the terminal velocity calculation can be made using one of the correlations for a solid sphere or Equation (A-13), and the minimum downcomer area found.

Column Diameter. In sieve-tray column applications it is recommended practice that the area on the plate below the downcomer be free of perforations. The minimum column cross section is then the sum of twice the downcomer area (defined by the terminal drop velocity calculation) and the plate area required for the selected orifice velocity, hole size, and spacing. Generally some small allowance is provided for space required for fabrication, supports, etc. The DCHX discussed here has an internal diameter of $12 \mathrm{in.}$

Downcomer Length. The downcomer length should be sufficiently long to contain the dispersed working fluid that coalesces under the plate at maximum flow conditions. Treybal ${ }^{\mathrm{A}-4}$ gives the following definitions for the layer thickness

$h=h_{c}+h_{d}$

where

$$
h_{c}=\frac{4.5 \mathrm{~V}_{\mathrm{d}}^{2} \rho_{\mathrm{c}}}{2 \mathrm{~g}_{\mathrm{c}} \Delta \rho}
$$

and

$$
\begin{aligned}
& h_{d}=h_{\sigma}+h_{o} . \\
& h_{0}=\frac{\left(v_{0}^{2}-v_{n}^{2}\right) \rho_{d}}{2 g_{c}(0.67)^{2} \Delta \rho}
\end{aligned}
$$

and

$$
\begin{aligned}
& h_{\sigma}=\frac{6 \sigma}{\left(d_{p, 0.1}\right)^{\Delta \rho}} . \\
& \mathrm{h}=\text { total thickness } \\
& h_{c}=\text { head required for continuous fluid } \\
& \text { flow } \\
& h_{d} \quad=\text { head required for dispersed fluid } \\
& \text { flow } \\
& h_{\sigma}=\text { head required to overcome inter- } \\
& \text { facial tension effects at the } \\
& \text { perforation } \\
& \mathrm{h}_{\mathrm{O}}=\begin{array}{l}
\text { head required for flow through the } \\
\text { perforation }
\end{array} \\
& \mathrm{v}_{\mathrm{d}}=\text { velocity in downcomer area } \\
& \rho_{\mathrm{c}} \quad=\text { density of continuous fluid } \\
& \rho_{\mathrm{d}} \quad=\text { density of dispersed fluid } \\
& \Delta \rho \quad=\text { density difference } \\
& \mathrm{g}_{\mathrm{c}} \quad=\text { conversion factor } \\
& \mathrm{V}_{\mathrm{o}}=\text { velocity through orifice } \\
& \mathrm{V}_{\mathbf{n}}=\text { velocity of dispersed fluid based on } \\
& \text { net tower cross section area (col- } \\
& \text { umn area less downcomer area) } \\
& \sigma \quad=\text { interfacial tension } \\
& \begin{aligned}
\mathrm{d}_{\mathrm{p}, 0.1}= & \text { drop diameter at an orifice velocity } \\
& \text { of } 0.1 \mathrm{ft} / \mathrm{s} .
\end{aligned}
\end{aligned}
$$

The downcomer length in the prototype DCHX is 3 in. except as noted in Table 1 of the main text.

Tray Spacing. The typical spacing for the trays is from 6 to $24 \mathrm{in}$. with a spacing of 16 to $18 \mathrm{in.} \mathrm{sug-}$ gested in Reference A-8 for large diameter columns. The prototype DCHX has a tray spacing of 6 in. The use of a smaller tray spacing should increase the heat transfer rate as thermal gradients within the drops would not be as great and the bulk working fluid temperatures could be increased faster with more frequent droplet formation and coalescence. Mass throughputs however would likely decrease with smaller tray 
spacing as the continuous geothermal fluid velocity over the top of the tray would increase tending to sweep more droplets along with it.

This discussion of hydraulics and the design of a direct-contact sieve-tray column -has emphasized the preheating or liquid-liquid contacting section of the column. The hydraulics of the section of the column where boiling occurs is not understood as well as the preheating section. This region of the column requires more area or space in a single tray for heat transfer to occur because of the large change in working fluid density that occurs during boiling. Ideally for pure fluids, only one tray would be required for boiling as it occurs at a constant temperature (assuming no superheating). In reality these trays are not $100 \%$ thermally efficient, and one or more additional trays are required. The DCHX tested had two trays designed for boiling duty for pure fluids. As discussed in the main report, up to 12 trays were required for boiling of some of the mixtures.

\section{References}

A-1. R. H. Perry and C. H. Chilton, Chemical Engineers' Handbook, 5th edition, New York: McGraw Hill Book Company Inc., 1973.

A-2. G. F. Scheele and B. J. Meister, "Drop Formation at Low Velocities in Liquid-Liquid Systems," AIChE Journal, 14, 1968, pp. 15-19.

A-3, C. B. Hayworth and R. E. Treybal, "Drop Formation in Two-Liquid-Phase Systems," Industrial and Engineering Chemistry, 42, 1950, pp. 1174-1181.

A-4. R. E. Treybal, Liquid Extraction, 2nd edition, New York: McGraw Hill Book Company Inc., 1973.

A-5. A. H. P. Skelland and Y. F. Huang, "Continuous Phase Mass Transfer During Formation of Drops from Jets," AIChE Journal, 25, 1979, pp. 80-87.

A-6. G. B. Wallis, One-Dimensional Two-Phase Flow, New York: McGraw-Hill Book Company Inc., 1969.

A-7. H. R. Jacobs and R. F. Boehm, "Direct-Contact Binary Cycles," Sourcebook on the Production of Electricity from Geothermal Energy, Brown University, DOE/RA/4051-1, 1980, pp. 413-471.

A-8. S. Hu and R. C. Kinter, "Fall of Single Liquid Drops Through Water," AIChE Journal, 1, 1955, pp. $42-48$.

A-9. A. J. Klee and R. E. Treybal, "Rate of Rise or Fall of Liquid Drops," AIChE Journal, 2, 1956, pp. 444-447. 